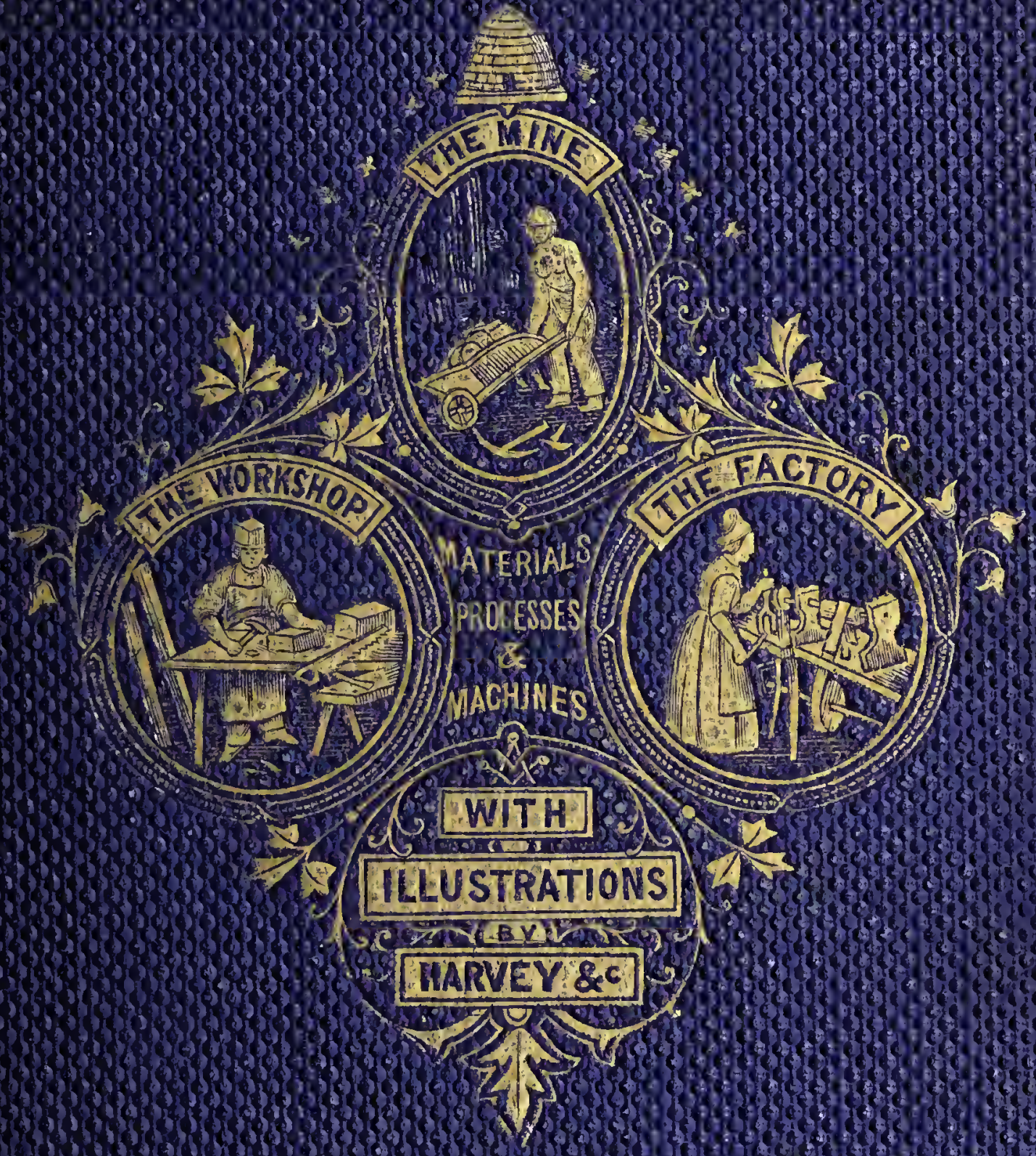




\section{R8262646}

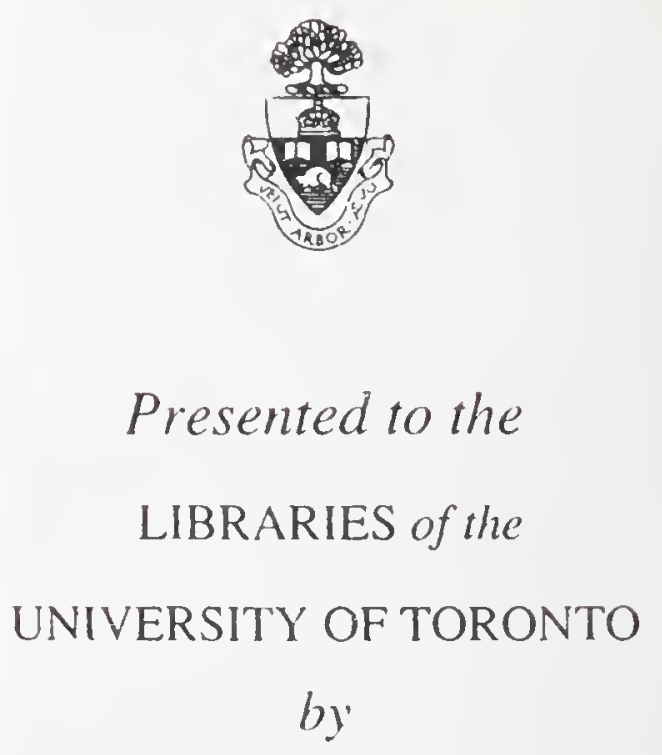

Norman Ball 


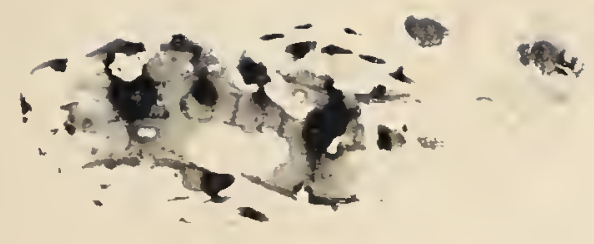





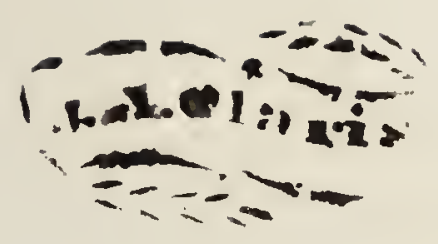

\section{THE BUSY IIVES AROUND US.}

WITIII IIIUUSTRATIONS IFI W. ITATVPEI, IFTC. 



\section{Digitized by the Internet Archive in 2018 with funding from University of Toronto}




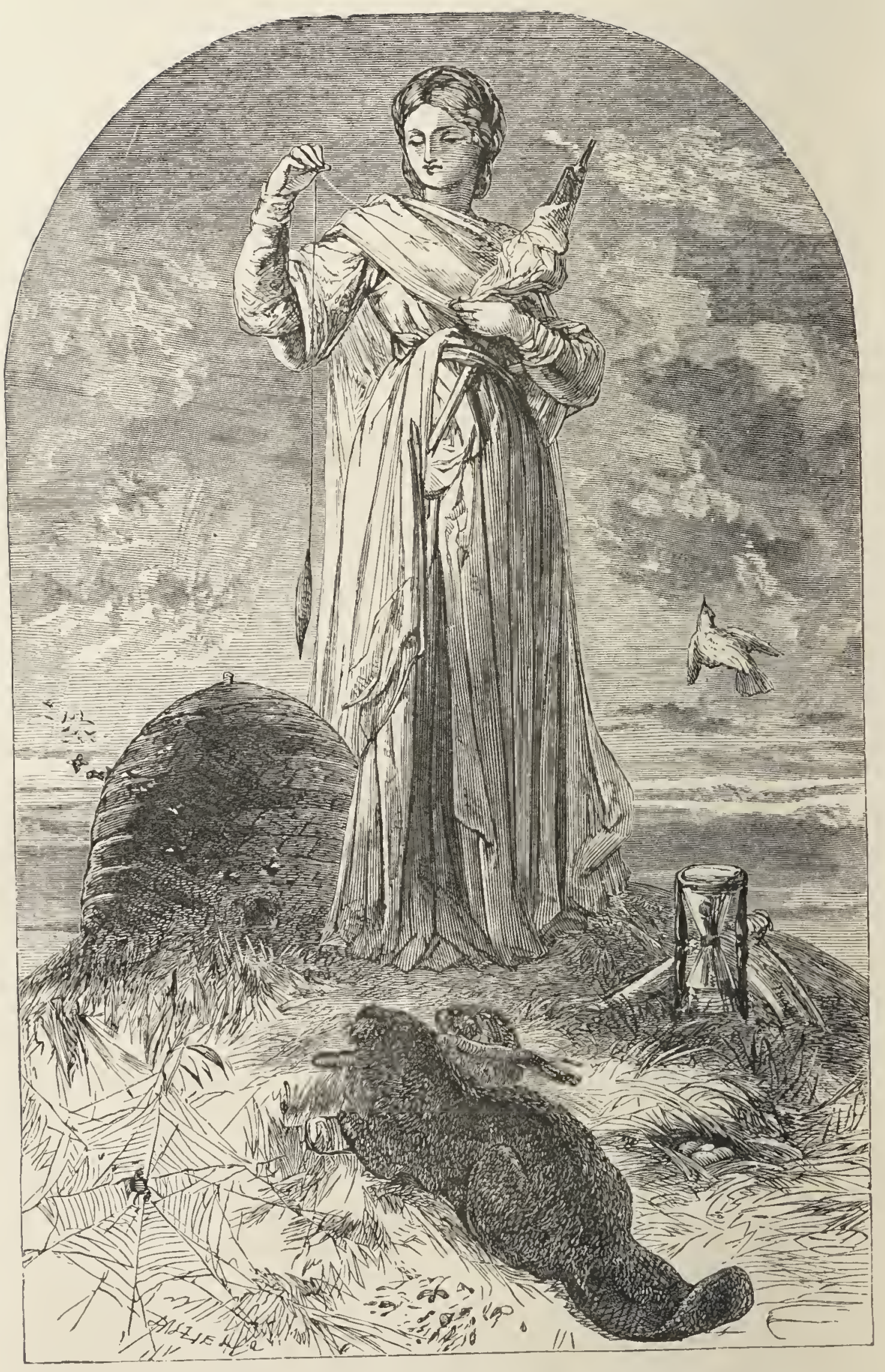

Front.

"IN EVERY RANK, OR GREAT OR SMALL,

"TIS INDUSRTY SUPPORTS US ALL."-Gay. 


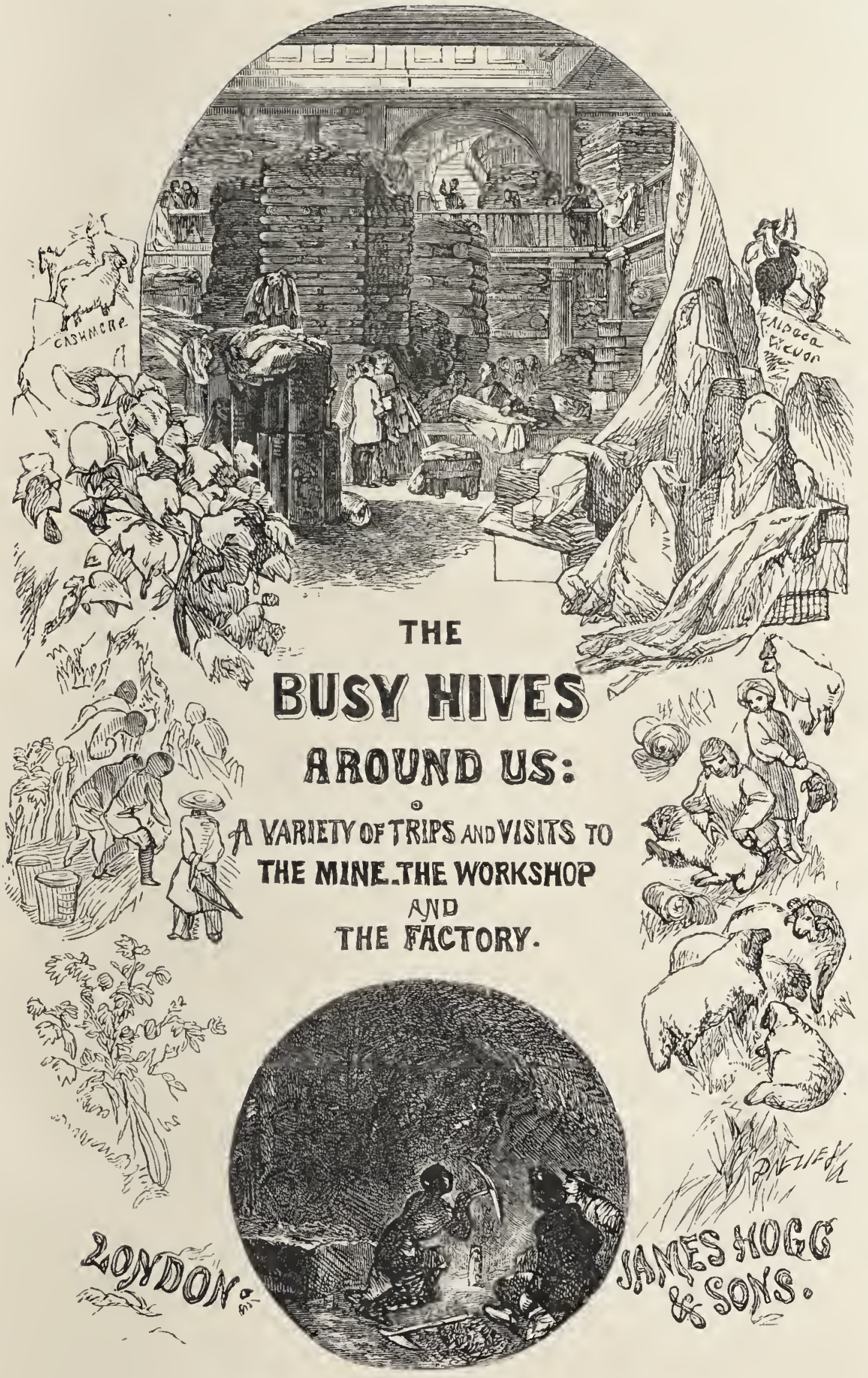





\section{CONTENTS.}

P.LK

MERCHANT PRINCES. A WALK THROUGI A LONDON WARE-

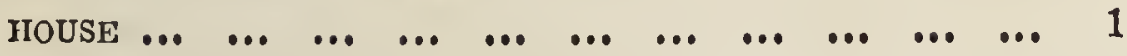

INDIA MILLS. HEATON YORRIS, COTTON LORDS $\ldots . . . . \quad \ldots \quad 19$ MY LORDS OF COAL

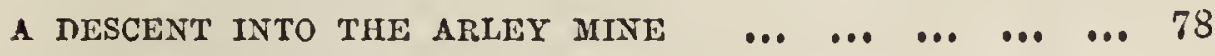

'A SUPerfine ARticle:' A GLANCE at Tite West of ENG-

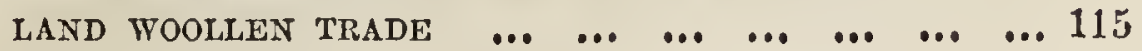

HER MAJESTY'S PRINTERS A

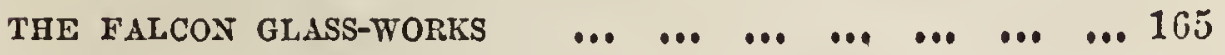

RAILWAY COLONIES-LOCOVILLE _.

GLIMPSES OF LIFE AMONG THE SPITALFIELDS WEAVERS-

PART I.—SPITALFIELDS, ANCIENT AND MODERN _.. $\quad \ldots 219$

PART II.-HISTORY OF TIIE SPITALFIELDS SILK-WEAVING 229

HISTORY OF THE CIEAP PRESS: 'THE DAILY TFLEGRAPII' 239 


\section{SUBJECTS OF THE ILIUSTRATIONS.}

INDUSTRY AND:HER EMBLEMS-Frontispiece.

INTERIOR OF A LONDON WARLHOUSE-Illustrated title-page.

A BIRD'S-EYE VIEW OF THE GREA'I COAL-FIELDS OF THE WORLD, DOWN THE ARLEY MINE-RECKLESS CÚTTING.

ANGLO-VENETIAN, GILT, AND FROSTFD GLASS.

PLAN AND ELEVATION OF A GLASS-FURNACE.

DRAWING OF THE TEN-FEEDER 'HOE' PRINTING MACHINE, USED

IN 'THE 'OFFICE' OF THE 'DAILY TELEGRAPH.'

FRIDAY EVENING AT THE GENERAL POST-OFFICE-THE CLOCE BTRITING SIX. 


\section{THE BUSY HIVES AROUND US.}

\section{MERCHANT PRINCES.}

A WALK THROUGH A LONDON WAREHOUSE.

Ir a Papuan, or a Bosjesman, or an Ojiberwayan, or any one not a smoke-dried townsman, stand by the Statue in Cheapside, and look up that busy mart, the turmoil would indicate to his mind business run mad.

All the world knows of the enormity of London trade, yet few are prepared to appreciate the magnificence of its details. In the narrow byways, where the walls rear themselves so high, that, looking up, one might reasonably expect the stars to appear, as it is said they do when viewed from a deep well, many a house contains a community sufficient to make a German state. The ruler enumerates his subjects by hundreds, and maintains a complete machinery of government. Well may it have become trite to speak of merchant princes. It is traditional that some houses 'turn over' a million, 
a million and a half, or two millions a year; and their territories correspond with their revenues.

It is so customary to associate cramped space with town, that visitors are not at all prepared to wander over acres in one of these establishments. Like the agriculturist, the princes of London trade tell their ground by acres; only the one metes his rent by the same rate, the other by the foot.

If the highly interesting personages with whom we began, are interested enough to seek one of these houses as a type, they will suffer their thoughts to send them forward, till on the left hand of Cheapside there is met with a lonely relic of living wood, still called, from veneration for age, a tree. It is the verdant decoration, for three weeks in the year, of Wood Street. Let our adventurous friends wonder, as they turn down, whether it gave the street its name. Again to the right, with Morley's great hosiery house on one side, and Pickford's mighty waggon-yards on the other; Swan with two Necks passed; Aldermanbury is reached; and, in it, a high, new-fronted edifice will furnish every requisite for a picture of a London house, and at the same time be an exponent of the staple manufacture of the age. Of course we mean cotton. It needs a visit to Manchester to see the loom, and a visit to Manchester or Glasgow to see it printed. How it is disposed of eventually we can learn here.

A coup d'oeil takes in an infinity of 'bales' and 'piles' of every description-an intermingled array 
of bright goods open upon the counters, made brighter by the beams that come through the skylight. A host of gentlemanly-looking individuals, youths, and other folk, bustle about, full of animation and business. Talk of the Maze at Hampton Court, or of the Bower at Woodstock, we aver that Eleanor evinced no greater dexterity in winding Fair Rosamond's Labyrinth, than we on the more peaceful mission of finding a friend to act as our cicerone. By the aid of one or two scouts, we discover him in distant nether realms, piling up innumerable packages in forms that would exhaust the devices of solid geometry. To the walls of an extensive area are fixed wooden hutches, in which goods are comfortably housed to the depth of about ten feet; and here they remain till wanted. In the adjoining and upper departments, we shall learn what these parcels contain.

Leaping through an open trap-door, to test our agility, we proceed, under guidance, on a circumstantial tour. First of all, attention is claimed by the architecture of the interior. Very considerable skill has been exercised by the architect. Where each inch of room has appreciable value, it required. a thorough knowledge of 'space economy' to make the best use of what space there was. Abundance of light, too, was a desideratum, and this in a house locked in on every side by others. A disposition of parts was also requisite, so as to allow of a general view of every department. Each floor forms a 
spacious rectangular gallery, rather than a room, for the central part is wanting. Elegant iron balustrades are fixed round these openings, and give the appearance, when viewed from the loftiest flight, of the staircase of some noble hall, but of yet more magnificent dimensions. The basement floor has its corresponding central part covered with glass, through which a glimpse may be got of the packers and the supervisors of the linen department beneath. At the further end of this fine area, is a double staircase, communicating with the various galleries. Everything on this side conforms to its like on that. The pair of stairs in their zigzag upward course exactly correspond. Everything is clean and bright; everything is beautiful. On giving audible vent to our admiration, we are acquainted how extensive have been the alterations and embellislıments. A few years ago, one house served for the business. Another has of late been added, and the two made into one. The wall between was demolished; an inclined plane skylight given a companion, which, together, form a ridge roof; the old fronts replaced by a handsome and substantial new one, and additional space gained in every imaginable way. The eye will pierce a vista so far retiring as to produce, where not interfered with by the illimitable mountain ranges, hills, and hillocks of goods, all the pretty effect of the vanishing lines of perspective.

The whole place is divider into distinct compart- 
ments, occupying one or two sides or more of each of the floors, according to the magnitude of the transactions in the particular class of goods with which it has to do. Each department is under the sole responsibility of a confidential person, who undertakes purchases and sales to any amount, without reference to the other branches. At 'balancing day," every six months, it is the aim of the 'buyer,' as he is called, to present a good 'balance sheet.' If the account bear favourable comparison with its antecedents, a step in advance is taken by him who has managed so well; if there be exhibited decrease, which change of fashion or fluctuations in trade will often occasion, he must be prepared with a satisfactory explanation. A 'buyer's' office is one that demands, sine quâ non, trustworthiness, diligence, tact. It is the ultimatum of a youth's ambition, and the incentive to unremitting perseverance during the years of his novitiate. The pride with which the clerks identify themselves with the interests of their House, is pleasing and commendable. Ability quickly displays itself with so great opportunity for its development. How services are valued by a good firm, may be judged by the fact that the buyers in the sixteen departments of this establishment receive salaries ranging between 300z. and 1000z. a year. Indeed, there is much to excite interest and pride. Some of the departments think a balance-sheet showing 'returns' of $80,000 \mathrm{l}$. for' the half-year, a good one: we think so too. 
More anon. We shall find amongst the first things to catch the eye, manifold 'cotton prints,' of every imaginable colour, and, as far as we individually are concerned, of every unimaginable as well as imaginable design. They are the product chiefly of the Manchester loom. Cotton edifices reach from the ground to the floor above, and, in shape like the huge, massive pillars of coal left here and there to prevent a pit falling in, impress us with an edifying sense of their magnitude. By a sight of the piles of manufactured cotton, we alone can get the least apprehension of what is meant when the statistics of cotton wool imports point to a thousand mitlions of pounds avoirdupois! More than a thousand tons of raw cotton are worked up in England every day! Pause a moment, and try to think what that means.

A mark upon some of the goods shows us that they have come from the famous print-works of 'Hoyle.' Ask your sister, or your wife, or your mother, sir, 'Who is he?' You'll find the name 'familiar in their mouths as household words.' Truly there is something in a name, for 'Hoyle' is a talisman that will beguile an extra price per yard from the most thrifty student of housewifery. The peculiar excellence of these goods is that the colours are fast-that iș, so we cunningly opine, fixed fast, and won't wash out. A metropolitan schoolboy would call ins 'too fast' for daring to explain so obrious a thing. 
Journeying onwards, we reach a neighbourhood that lets us into a good many of the secrets of a lady's clothing. Without publishing all we learn, may it suffice that we do get extraordinary additions to our knowledge on that delicate subject. Corded slips and petticoats are seen in astounding numbers, and a variety of other things are disposed of by thousands at a time. The Scotch department, close at hand, exposes coloured handkerchiefs in numbers that would cause our interest to fag before we endect computing them. Then, again, we lose ourselves amongst fine fabrics, mousselines-de-laines, and goods that require a lady's vocabulary to recapitulate.

Cotton goods form the bulk of the valuable stock of a house of this kind, yet very extensive business is carried on in other textile fabrics, both of home and foreign make. One long counter is hidden under the heavy heaps of shawls it bears, while, round about, a few are spread out with a most careful negligence, so as to show their graceful folds and beautiful India borders. It is a sight to repay the reigning belle the exertion of dispelling May Fair lassitude, and the fatigue of an 'overland route' from Piccadilly to Aldermanbury. But it is forbidden ground. Wholesale dealers alone are to be enticed by the blandishments of colour and pattern. We dare not pronounce our private opinion upon their excellences, for the terror of the School of Design tri-censorship is as a frontlet between our 
eyes; nor have we the temerity to hazard anything against the 'correct principles of taste.' Despite us, when we reach a spot chequered with sillis of the richest hues and most varied designs, our satisfaction cannot but find an ejaculatory vent. English silks do not stand comparison with French. Bright our own colours are, but they pale beside the produce of our neighbours. Harmony of colour, suitability of design (a bloominess, as the School of Art hath it), and a certain decisiveness in both pattern and colour, give French silks a richness and a glow which please the savant in these things as well as the illiterate, and contrast very strikingly with the inelegance of English goods. Not alone in silks is this seen. The cashmeres of English make are stiff, and have the colours running one into another. The French, on the contrary, retain the siliky softriess of the Cashmere goat, and the brightness of colour characteristic of their silks.

Another portion of their premises is a maison de deuil, the locality of crapes, and kindred vestments of woe; styles and textures varied, to denote every phase of grief.

While making these rather irregular memoranda, we have reached as near as is possible the roof that separates us from the sky, not from daylight. To attain so great an elevation, we have perambulated ground enough to make us tired. When, therefore, our pioneer points to two recesses in the wall, and says we can reach the world again by either of those 
roads, without an effort, we only wait for an assurance of safety to feel thankful. Such assurance is quite requisite; for, peeping into them, we find them to be perpendicular shafts, extending to the ground, and which we should as soon think of trusting ourselves down headlong, as we should over the parapet wall. However much perplexed, thanks to our cultivated prudence, neither of theso ideas tempted us.

The two shafts are used for the ascent and descent of goods. Their utility will be seen soon. Our friend turns a handle, and immediately a commotion is made amongst a number of ropes which are observed in the opening, and a noise as of some great body struggling to ascend. It proves to be a table, or rather an open box, into which we get, and by dexterous control descend to the bottom. A lad is engaged at frequent intervals with one or other of these machines. He controls the apparatus, unassisted; rises, makes a stoppage at each floor to collect the parcels sold in the departments, and descends with them to the 'Packers;' to whose tenderness we have also consigned ourselves. The scheme is just after the fashion of conveying a dinner at the Reform Club to the top of the building, where all the appurtenances of a tête-à-tête banquet are brought up at once. Practice makes the lad in charge expert. If inexpert or forgetful, a sudden, not very gentle bump upon reaching the bottom will restore him to consciousness, and teach him care for the rest of the day. 
We find ourselves precipitated amongst a species of strong and cheap goods, with the euphonious name 'Derries.' They are of Scotch manufacture, and seem to be in great favour. This one house, in the busy season, disposes of the enormous quantity of $1000 \%$. worth a day. It is made up into morning dresses, a piece for which purpose costs about 3s. or 3s. 6 . But here it is only sold in parcels contain. ing many pieces. A small order for a retail customer would be refused, partly from a sense of injustice to the trade, and partly because of the trouble it would give. Many small wholesale houses do a retail trade, but it is always under a silent protest from the regular retailers, and what one of the princely houses would regard as infro dig., and unbusiness-like.

One of the partners is the 'buyer' for the Derry department, a man of the class unmatched elsewhere than in London for business energy and tact. All the members of the firm, indeed, seem to revel and delight in business. Generally, before the rising race are out of their snug beds, these hearty gentlemen have reached their place of business, and are in full activity. Throughout the day, with scaircely an intermission, they are engaged in the duty of supervision, and of receiving their customers. Such attention is the talisman of success. The house has taken strides apace with the cotton trade. Its early history was that of a respectable small house; now it has but few peers. One of the merchant partners 
rose from the ranks, and traces his present influential position entirely to worth and pre-eminent ability.

Leaving the Derries, on our route we pass through a space appropriated to the 'packers' - a band of thirty or forty men, who are hard at work, 'from morn to dewy eve,' packing, in canvas or wooden cases, the goods as they come down the shafts. All articles sold are cleared out before the day closes. Packing is quite an art; and excellence often shows itself in one workman, which another dare hardly emulate. Projecting from a tolerably lengthy wall are many low benches, at each of which are two packers, making cubes and parallelopipedons of all dimensions, from the varied stores around. The geniality and considerateness of the employers extend to the hrumblest of their subjects. Length of service, as well as ability, is acknowledged by increased pay. The patriarch of the 'packers' has been packing for the space of nearly thirty years.

When wo entered the premises, the tout ensemble was so striking, that a number of fancy wares, well deserving a memorandum, escaped special attention. Let us pay our devoirs to them. If we evoke a word of reprehension, may it fall upon the right shoulders. We are glad to be irresponsible for even a gentle rub upon the 'gentle race.' While rapt in admiration of really beautiful cartoons that adorn the boxes of cambric handkerchiefs, and other fancy articles that have to perform the. double duty of 
utility and decoration, the 'salesman' most maliciously insinuates, that they are designed to catch the eyes of ladies, who buy not the dozen handkerchiefs, but the pretty picture outside.

At the back of the building, retired from the commotion of buying and selling, we may peep in, and see a designer or two at work. He it is who devises the countless patterns that captivate a purchaser, be his taste however fastidious or fickle. If a dealer have an idea of a new pattern, he seeks to communicate with the designer, who, by his skill, draws it out, and suggests alterations and improvements. A 'proof copy' is then struck off; if approved, a revise is sent back, and the order executed; if not, the design is destroyed.

The printing of cotton, of course, does not go on here. A small quantity is printed in the neighbourhood of London, but the bulk in Manchester and Glasgow. Most people are aware, that it is done by means of 'blocks,' like to the method of staining paper;-rather was done, for though a large quantity, considered in itself, is even now thus printed, yet it is a very small decimal of the length printed by revolving cylinders.

Were we accompanied by a lady, we are sure the sight that next presents itself would excite and justify her ire. A man has a number of beautiful muslins lying by him, which he seizes one by one, and remorselessly shears into strips. A few feet further off, we get an explication of this wanton 
waste. A little mountain of envelopes, addressed to some hundreds or even thousands of customers, will soon be despatched by post, each containing a variety of these small pieces, as samples for an approaching 'season.' These seasons are, in themselves, worthy of remark. They naturally occur in spring and autumn, when 'linsey-woolseys' are courted, or unungratefully cast aside ; when 'gossamer' is doffed or donned. During the rush of business, extending from March to the beginning of May, and again at the fall of the leaf, little breathing time is allowed in a 'general house.' Every one, from the master to the errand-boy, is indefatigably catering for the comfort of his fellow-citizens of the world. It is an established rule, and one that alone could save inextricablo confusion, that the business of a day is to be a complete thing in itself. Each department is made square before the head of it leaves. The 'entering' clerks' are still more hard worked. Whatever be the time those who have to do with the buying and selling may finish their allotted tasks, the entering clerks must of necessity be after them.

A stock so valuable and extensive as that by which we are environed, demands every care to insure its safety from fire. A few years ago, the place was burned down. In its re-erection, every part was made fireproof. If fire did occur, the catastrophe could never again be very calamitous. The various portions of the house are securely divided from each 
other by double iron doors. The doors roll back on wheels, and are concealed throughout the day. When moved forward into their places at night (a feat easily accomplished, despite their weight), there is a space of eighteen inches, or two feet, between them; so that, if one were red hot, the heat could not extend to any injurious degree to the next compartment. The walls also are very thick, being, in fact, the same as the space between the doors; for, when the doors are closed, they appear but as the continuation, on either side, of the wall.

We have portrayed the daily routine of a hundred houses of business, while sketching the routine of one. The same devotion to work, the same indefatigability, the same preciseness and system, may bo recognized in any great London house. A type has been presented of a class-a class engaging many thousands; but it is only one phase of city occupation. To complete a knowledge of business life, we should have to explore the recesses of a thousand. hidden acres. London is great in manufactures; it rules the monetary world; it abounds with government offices, all of which would give a 'type' of business. Leaving these things, we conclude with the rest of what we have to say.

A goodly number of the employed dwell in the house. Most houses accommodate a fair proportion of their young men; some, the whole of them. The arrangements for their comfort are as pleasing as any feature in the place. An adjoining housse is 
given up to kitchens, dining-hall, reading-room, and dormitories. The kitchen has a side occupied almost entirely by a huge fire, large as the one before which Sinbad's companions were day by day spitted, or 'large enough,' as the glossy personification of what a real English cook ought to be arouches, 'to scorch a woman's eyes out.' From the fire, a good part of a bullock, done to a turn, has just been removed. The buxom cuisinière removes the lid from a mighty saucepan, and reveals a companion piece being cooked by steam. 'She isn't so sure that steam is best; for her part, she likes the old way. They are going to cook with gas soon, and then, at any rate, the fire won't scorch so much.' Pardon us, good dame, for culling the flower's of your eloquence!

Above-stairs are arranged tables for dinner. Parties of thirty or forty take in turn their quantum. Every one employed boards in the house, although only the youngest members reside there altogether. It is the hospitable custom to entertain at dinner what customers happen to be in the house at the time. If a great assortment of wine and stout bottles, all empty, could, they would probably whisper that the banquet is a genial one.

An adjoining room contains a stock of books, for the mental improvement of the young men. When the continued activity of the day and the unlimited hours are thought of, that must seem a littlo bit of a joke. We have heard of quite an original 
method in vogue at a neighbouring house, of getting knowledge from the books into the head. In fact, it is by 'chucking' them at one another's heads, when a curator is not by. It is not surprising, for a day of thorough business is enough to cause complete physical prostration-a state not at all disposable to mental exertion. The cry of 'mental improvement of the young men of business,' has been, and is, a prominent rallying point of the progressionists. Very much good has resulted from their efforts. 'Early closing' has become fashionable. Were early closing always synonymous with early leaving-off work, there is little doubt that innumerable 'mental improvement classes' would spring up of natural growth, and need no philanthropic forcing upon a hotbed of subscriptions.

The dormitories up-stairs contain each five beds, and a space to squeeze between them. They would be better ventilated if there were fewer beds, or if the rooms were larger. Still they are clean, and comfortable as circumstances will admit. A young clerk resides in the house for three years. That ordeal passed, he becomes identified with his occupation, and allowed to live out of the house. Around the rooms are hung decorations of various kinds, exemplifying the peculiar tastes of the embryo merchants. Over one bed a pair of fencing foils, over another a small home-manufactured set of bookshelves, and an assortment of books. In one or two of the rooms, a placard, on which is printed a 
series of characteristics of the man of business, very edifying to 'read, mark, learn, and inwardly digest.'

Before the windows at the back, Guildhall rears its walls, from which the sounds of revelry, presided over by the supreme magnate of the city, oftentimes steal. How many Dick Whittingtons have had, at such hours, premonitions of the chief City dignity, we know not. However many they be, we take our leave with a cordial wish, that every one of them will realise his aspirations. 



\section{INDIA MILLS. HEATON NORRIS.}

\section{COTTON LORDS.}

IN every craft there is ample room for a young man to work himself up to intelligence. Any one truly master of his art must be a learned man. There is no art, no science, no profession, no trade, no working man, a pure $E g o$ in the network of creation.

What an expanse of knowledge opens up in the simple word cotton! Its growth in three quarters of the globe; its natural history; its influence upon mankind; its chained and scourged cultivators, in the freest nation upon earth, a nation whose ears are stuffed with cotton wool, or they would hear the screech of their 'horrible and heartrending' social institution-whose eyes are blinded so that they should not see, or a dense thundercloud would spread. before them over the States, like a mighty black coalfield on a geological map; the laws of competition, and the chances of India and our other possessions outstepping America; the great future of Africa, of which we catch a glimpse through Livingstone's labour; the staple of our country; its effect upon 
our habits, our opinions, our population; its commercial bearings; the enormity and laws of our manufacture ; of our export, and import; of the hindreds of millions of pounds coming to our shores every year. Then of cotton printing; the arts and sciences, the lnnowledge, the acute brains, bound up in this branch. Chemistry is but one art, but it, in turn, radiates as a star. There are the metallic mordants, the madder and other dyes, there are all the elements the chemist controls, to be studied in succession ; their growth, collection, preparation, use, results. The engraver's art leads us to reflect, not only upon his artistic skill, but upon the tools he uses, and the copper cylinder he practises upon. Bleach-grounds, in like manner, are the nucleus of indefinite knowledge. What are we to stop for yet! Is there not warehousing, and our system of mercantile credit; factory and warehouse architecture, and chimneys, of which Lancashire is justly proud ; means of preservation from fire and lightning; the smoke which Lancashire so dearly loves? From smoke to coal and its nuptial tie to cotton; from coal to the steam-engine, to the machinery it drives, the wealth sunk in looms and spinning-frames, their perfection, bearty, magnitude, and sensibility, onwards to the history of the manufacture; of the great names identified with all its branches; wonderful machinists and engineers; of factory labour; of the habits and feelings of the myriad workers; of the relations between employers and employed; of the great cotton- 
lord statesmen; of legislation against capital, and power, and tyranny, and the effect upon jaded humankind of merciful enactments. Indeed, there is no end to the suggestions, but the artificial one of stopping short.

The truth of these remarks will be in a great degree manifest, if you wait upon our steps at the Manchester terminus, and spend an afternoon in a short drive and long examination of about the finest factory England can boast. Here we are, almost before we begin to talk about it. The guard cries, 'Heaton Norris !' or as much of the two words as he can cram into one syllable, and we step out. Screech goes the fiery steed, as in internal agony, and we are left to enjoy a real Lancashire prospect, ten to one, on a real Lancashire day. Drizzle and mist try to outdo the smoke in density, and, between them, do manage to beat it down below its hundred belching craters on to the town beneath. Stockport, low under the railway viaduct, lies at our feet, clothed in a respectable black soot; it muffles itself so warmly and cosily, that, from our elevation, its presence is scarcely discerned. The tapered tops of the chimney forest do ever and anon nod at us, as a gust of wind blows their wreaths aside, and allows them a chance of a 'how d'ye do?' They pique themselves upon their knowledge of the town, for they have been its wardens ever so long; and their blackened coping says, as plainly as Bow Bells spake to Whittington, 'We and smoke are old friends; 'tis not the first 
time he has yielded his aspirations skyward, and favoured us with a whiff.' Dense as are the elements that usually combine to favour the spectacle trade of Stockport, yet so mighty are one chimney and one mansion near the station, that they stand massive in the gloom, as the Halls of Eblis. It is the factory we seek; a mass of brick, grand as the Pyramids, and its chimney more astonishing, as a work of art, than the monument of London.

Pattered down an infinity of slippy steps, we have but a few steps more and arrive at the gateway. Buildings, chequered with scores of windows, are too numerous in Lancashire to excite any great awe, yet here we fain give a glance orer a frontage of eight tiers, and a quarter of a hundred windows in a tier ; 200 windows on one side, as it were, of a cubic chess-board. It is a marvel amongst marvels, and, as if to overwhelm us at once, we see iron binders project from one end of the mill, pointing a finger to another big space yet vacant, and in plain English publishing the banns of marriage between the Adam there and the Eve yet to come. In Kershaw, Leese, \& Co's factory every device of forethought secures easy, and rapid, and vast extension of the works. The grandeur of the cotton trade comes with strange force at the sight of these growing mills. Huger and huger every year, and still encroaching, they dash down whole neighbourhoods in their expanse, and still expand as does a balloon. Cotton is but in its seed, or, at the most, 
but in the shoot, as far as its development in manufacture.

Cerberus in the watch-box satisfied (he is as great a man in a cotton mill as a beadle in a church), we twine round short bricky lanes, made by the outbuildings, here avoiding a horse, and there a bale, no sooner making a sudden bend than another is before us. We pass the chimney, magnificently starting direct from the ground apart from the pile, and get greeted, just as wo think we are all right, with such unfriendly hissing, and fierce, glaring, Cyclopean eyes, that, half affrighted, we hesitate. It is but the way these mills have of welcoming strangers, and a moment reassures us. A row of big boilers, with one-eyed fires underneath, are busy for ever boiling the water, not in small kettles, to supply the greed of near two thousand people. Stone steps, as many as the railway descent, and a few more twists in and out, land us at the office of Mr. Turton, whose son most obligingly becomes our patient caterer.

It would pose us, in the bewildering succession of wonders which his open-sesame displayed to our sight, to tell now in what part of the kingdom (we cannot call it a building) we first arrived. High up the country, doubtless, for there was the crane for hoisting cotton bales from the waggons without, and there were shafts for packing it off below. Comparatively lofty, this room is packed with cotton, almost as it were a bale itself. There is, however, space left open for passage and for some amount of work. The 
foreman over two machines and a boy is a smart, active, sensible fellow, who, with more readiness than we ever met with in à workman before, stops his work, sets it going, pulls it to pieces, lectures all the time in such a simple, straightforward way, that we must have been dull indeed not to have understood. He calls his engines 'blowers,' and well he might, for they blow with the deafening roar of a blast furnace.

'You feel how hard this piece is,' he says, taking a large flake of cotton out of the stores, as one would take a handful of hay out of a farmer's rick. Truly it is hard; full of little lumps, and bits of stick and dirt, and matted like an Indian's hair. One of the machines nibbles at it, and it is gone. The man runs away, and returns with some fleecy gossamer or swandown, that flies off from him as he carries it, a whole armful.

- What are you going to show us now ?'

'Nothing, sir; this is only the cotton you saw me put in.'

Truly it is curious. One blowing has puffed out all the seeds, and it seems to us cleaned the cotton thoroughly. Our teacher thinks otherwise, and will prove it. To please him, it must be many times fleecier and cleaner. We leave the stacks of cotton wool in their raw state, just as they were unskinned. from their American bandages, and reach an under room. Here we find more blowers humming with a sound compounded of a dozen machines. Cotton 
wool comes tumbling through square shafts from the roof above, and now lighter than at first, it goes through further processes of blowing. Engines about the size of a lengthened-out printing-press, or more like the self-acting paper-making machines, receive the cotton wool from a feeding-boy. The snowy aliment travels with its moving bed, like a broad frothy stream of milk, till it meets a pair of rollers, furrowed and ridged from end to end in straight lines and grooves. They nibble the cotton as cows' lips do grass, and never are satisfied. All day long the boy provides them food, and they bite it till one would think their very ratchet teeth must ache. Inside the apparatus, digestion goes on with difficulty, to judge from the tremendous uproar. One is apt to think the food unsuitable to the noisy creature. Its keeper skilfully anatomises the structure. Unlocking first, and then uplifting an iron cover, like the curved lid of a piano keyboard, we trace the interior processes. Before the cotton travels half an inch inwards, it is met with a most unceremonious rap, which dashes it apart into filaments, and sends it flying on. Something whirring, and yet only like a thin mist to the eye, is under the lid, and is evidently the uncourteous welcomer of the cotton. Whirring and mist are both caused, as we find, when the engine bands are put off gear, by the rapid revolution of a skeleton parallelogram of steel, which turns on an axis many times in a second, and thrashes the cotton as it enters. Dirt and cotton- 
seed are separated and fall through chinks into a receptacle at the bottom. As the endless traversing bed is made of separate strips of iron, like to the pieces of a Venetian blind, dust easily works through. Meanwhile, the fleecy wool has flown onwards, not from the current raised by the beater, but by a fan underneath, which winnows the loosened threads. Just the opposite is the result to our common notions of winnowing, for here the corn is useless, and the light covering puffed off by the wind is the valued commodity. The man calls it willowing, which, perhaps, is the Lancashire for ' winnow.' Now the man sets the beater and blower at work again, and in half a minute there is a snow-storm rising from the aperture, and filling the air. Flakes fall as big as the palm of the hand, so fleecy, and pure, and white, that we fail to notice, in admiration of their beauty, that we have gone into Chinese mourning, as well as the machine. Well might the beater be enclosed, if this be the consequence of leaving it open. It is enclosed and padlocked not for this alone, but to prevent careless men and thoughtless boys having their limbs torn off, and beaten into equally thin filaments. More than once this has happened, and our exhibitor shows the utmost care in locking up every door and cover before he opens another. Proud almost to enthusiasm with his trophy, and with his mastery over it, and withal as civil a fellow as you would wish to meet with in any workman, he leads us on. We catch up to the cotton a step further in advance, 
where two large rolling ' cages' have caught it up, and are delivering it to the other side, in a sheet of what ladies call wadding. We are only allowed a peep ; the padlock is affixed and forward is the word. Here the shape of the machine resembles the bulky end, and reasonably, for it is a duplicate of the rollers, and beater, and fan, and cages. But there is another protuberance, and another, and a fifth, and still another. Camel-like, the creature chews the cud, and has no less than six stomachs; it has also, more strangely, the whole appurtenances of digestion, from mastication onwards, six times repeated. Compound in its anatomy, it is one of those polypes that you could cut up, and leave each part a perfect whole.

At every stage the wool is whiter and softer, till, after its seventh thrashing and fanning, it bubbles out at the extreme end, silently and beautifully, in a broad, soft stream of liquid cotton wool. Its duty for the time being is almost ended, and it so cosily snugs itself round like a roll of carpet, that it really is conscious of deserving a rest. Compared with the matted handful we began with, it is another substance altogether. These rollers are called laps; and it is in laps that the foreman 'tells his tale.' They lie about the room telling their own tales, for' they say, as plainly as cotton can speak, that idleness is not the prominent fault of our room. We have not done with the blowing engine yet, for down by each fan is a little door, which the man unlocks, and 
draws thence a handful of siftings. Seeds and dirt by wholesale in the first; less of both in the second; pretty clean in the third; and so on till the last, where a little fine dust, and wool attenuated like a cloud of steam, could alone be swept out. An engine corresponding with this was working side by side on cotton waste, collected in all parts of the factory, to be worked up again. Waste is a misnomer, where nothing is wasted.

Ladies would rejoice at the present of one of these laps. It would so snugly pad a winter's silk, that frost would lose three quarters of its rigour. The laps will not be so applied. They hurry off to a still more spacious room, which we find packed with other machines as close as though the machines themselves were bales of cotton. Our communicative tutor yields us up to a co-patriot, who claims this department, and presently we get immersed in the mysteries of carding and combing.

Carding engines are not small objects, nevertheless eighty stand straight as soldiers and corpulent as aldermen in this area, and seventy more beyond. All of them are doing the same species of work, so that, except for the beauty of much movement, the examination of one engine will suffice. Covered up as it is, we can only see the lap unwinding, and, seized by the grooved rollers, enter into the greedy maw. Fed at this rate, it might well become corpulent. Uncovered, we can see its economy. A large cylinder rolls round in the centre, and round it a 
number of smaller ones play a game of give-andtake. Steel wires cover the faces of these rollers, finer and closer set, and shorter than the hair of a clothes-brush. No sooner does the cotton render itself, than one of the 'cards' politely receives it at full length on a forest of prickles, and is proceeding to roll round, when the middle card meets it. To this dignitary, the centre and dependence of the family, the cotton is yielded without demur, for the teeth of the card incline and revolve the opposite way, and work among the first teeth. This has been the rule so long that it now is law. Paterfamilias proceeds quietly for a while. It is a turbulent family, for he has not stepped forward two inches or so, before one of the smallest members (such is the inflence of example) has robbed him of all he possessed. A never-ending struggle goes on throughout, in which the chief alternates as victor with every card in succession. From card to card the cotton is allowed no respite. Each dresses it more smoothly and seemly, till, when it leaves their care under a final combing, every filament lies straight and even, and in one direction, like pins in a paper, or the hair of our head. Cotton fibres, though thinner than cobweb singly, are yet tubes, growing out of the cotton seeds, and receiving moisture as any other vessel. In their growth they become slightly twisted or spiral, and this peculiarity, small though it be, is the chief assistance in carding. Just as corkscrew wires would point one way after a good shake, so do 
the cotton filaments congregate for the use of the spinner. Sufficiently carded by the time it has been taken off in succession by all the rollers, we see it spun into a cobweb on the middle drum, completing the circuit. Here a tooth comb of "steel plays upon the card and cleans it continually. Teeth work into the wire-cards, as we would comb hair out of a brush. Up and down, rapidly but gently, it sends off a thin, filmy cloud of cotton, more like snowy smoke, floating in the air, till it has gathered into one curling, endless sliver, about as substantial as the wreaths that wind so beautifully from the fragrant weed. Scarcely touchable from its attenuation, it moves gracefully onward through a funnel, bends over and down into a trough, and still travelling, receives, as it passes other machines, fellow-slivers to the number of sixteen. They flow on, a pure milky course, for some time, and, in the end, wind into a flat snaky coil upon a metal reel. Joined into a band as broad and thick as the leather straps that bite the various wheels, it is strange to see it pursuing its way as though sensible of its destiny. A lad has charge of the coil, and when it is grown to the dimensions of a fireman's hosse, he removes it from the metal disks between which it winds.

Down to such a trifling thing as this coil, the cotton lords carry out their great principles of time and labour saving. The spindle round which the band winds is of wood, and is removed with each coil. Two others are placed between the metal 
plates, which keep the plates their proper width, and in their turn tumble down to the centre, becoming: spindles.

The whole 150 carders are doing precisely the same work. We are impressed with admiration at every stage; from the fleecy snowstorm let loose upon us in the blowing-room, through the more complicated, or rather compound, operations of the scutchers, to the surpassingly beautiful cotton cloud from the carders, and the pure, white, endless, impalpable, candle-like sliver.

Before proceeding further, we slip aside into an ante-room, where we find one of the cylindrical brushes or cards grinding against a rough roller, so as to make the points even and straight. The wires are fixed like bristles in thick, tough buff leather, and will last for six or seven years. Technically doubled into sixteen, the cotton next goes through another process of straightening out the fibres. Just as we fancy everything so perfect because of its beauty, we learn that it has undergone but the first of half a dozen or more operations. As in the blowing or willowing (that is, cleansing), where six beatings and fannings followed our assurance of the cotton's purity, so, after this carding, the cotton is not anything like fine, or straight, or strong enough to suit its fastidious lords. To them we must give way. Clearly, the comb is likely to bend a fibre pretty often, and this would produce inequalities of thread. To harmonice them, the same plan is used as with 
the piano keyboard: the inequalities are distributed. Sixteen slivers together are not likely to have all their imperfections come in, the same place; one will counteract another. This system is carried out to an extent that carries us beyond astonishment, if our patient pioneer is not putting a joke upon us.

One-half of the floor we pace is filled with drawing-machines. Packed as if space were charged for by the inch, a multitude is collected, and fed by the product of the carders. Upon the drawing depends the value of the future fabric, for without much care the slivers would not be uniform, and would not, in consequence, make good thread. Two bands of sixteen join in the drawing-frame into one sliver, which passes between a succession of rollers not larger than cotton reels. Each pair from the first moves at increasing rate, and necessarily draws out the thread. The resulting sliver is, if anything, rather smaller than the first, though containing thirty-two of them, and it comes trailing down into a deep tin can, and coils round and round, like the screw of a still, till it fills the measure. Sometimes the can itself has a revolving motion, but most of them not. Sinking down and rising at gentle intervals, much like our old playmate, Jack-in-theBox, are heavy, polished, iron dollies, which press down double the quantity of cotton that formerly went in tho cans. It seems all quite right and natural that they should move up and down, for everylhing is moving, wheels, and spindles, and 
cotton, and cans, and their attendants. We our. selves move; for, charmed with what is before us, we peep into a hundred cans, and find them all alike; we go to the cans which feed the machine, and the cans which are filling from it; we peep inside, and under, and all around; we examine cogwheels, four in one place working into each other, and then, like Sir Isaac Newton, after reading the 'Twelve Books' of Euclid for the first time, we remark, with a nod of approval, 'Yes, well, yes, it is quite right.' Each piece of machinery is a wonder of the world; but wonders count by thousands here; we cannot 'fash' about the units. It would only surprise us to see something not moving. No agent is seen, and the evidence of our eyes impresses our brain that this is all in the course of nature, just the same as the other revolutions, such as stars, and worlds, and those things. Every now and then a whole apparatus stops. 'Ah, there's a sliver broken,' says Mr. Turton. True, there is ; for, glancing along the candley line, we detect one deficient. The minder is beforehand with us though. She has caught up the end in the can, brought back the runaway portion, and, with the gentlest pressure, as a chiding for their misbehaviour, she sets them at one again, and they go on rejoicing. But she has brought something else out of the cana thick little iron disk, as large as a bolt-head on the steam-boiler. She allows it to sink, resting on the sliver, and just over the can's mouth. If the 
sliver breaks down, the dump falls. So beautifully is the apparatus adjusted, that this falling releases a weight at a distance, which kept the gear in place. Now thrown out, the machine is stopped. Now, too, we perceive that every sliver supports a piece of iron similar. Drawing and doubling are repeated to an almost indefinite extent. The finer the thread, the greater the number of 'card-ends' doubled into one. Our good friend the manager remarks, casually, that they are spinning nothing very fine; the utmost just now only amounts to 4608 doublings. Walking sideways between the machines-for there are but eight floors, each a little acre, and room therefore cannot be spared-we watch for any different process.

Here, then, we find it. The slivers come off more compact, and not larger than a candle wick. 'They are not slivers,' says our guide. This is the roving-machine. The little rollers still go at different rates; the cotton wool is doubled and drawn out more and more; the cans continue to feed the machine; but the roving is now strong enough to wind on to a reel.

Reels of lamp wick they would do for. Well, reels of lamp wick are not so very much to wind. That is just because you know nothing about it. There are as many ' movements,' as the man calls them, in the roving-frame as is in the earth itself. It is evident that the roving would, as Sleaveboard says, get in a 'snarl,' if the motion of the reel was a 
'constant.' The cotton would be delivered faster than the reel could wind it, while the spindle was bare, or barely covered; and it would be pulled and broken as the reel grew bulky. This would be a poser to you, but there are no posers for cotton lords. They get over all of them. It is but a wheel here, and a crank there, and set the thing agoing; it does all the rest without telling or grumbling, without fee or reward. What was wanted in the roving was, that the motive strap should move along a conical spindle in lieu of one cylindrical. This it does, and you see that the rate of motion is regulated exactly. No, pray, don't. You were going to ask us why the strap should move along, and why it should know so exactly the proper rate to move. There, there, really — You would become more learned than your teacher. Before you find us out, we are off up another flight, and descanting on another theme.

Suffer us to be silent for a few minutes; we cannot descant more eloquently upon the bewildering vastness and beauty of the throstle-room. Throstles are singing to 18,000 different notes! That is the number of spindles and bobbins whirling round in a giddy waltz. Throstle-frames are ranged in parallels the whole length of the room, with not an inch to spare of promenade. Seated on the long bar that surmounts each frame, are a line of large reels or rovings from the room below, resembling the white breasts of an army of penguins on the shores of the Southern Sea. So white, regular 
myriad-fold they appear, that we, who have been over other mills, are as overwhelmed as any stranger. Bolbbins twirling underneath are miniatures of the reels above, in lines much more close and numerous. There is, where the clock would be in another such grand room, the gear of a steam-engine. A heary iron shaft, rising through the floor and piercing through the ceiling, turns, just before its exit upwards, but one cogged wheel, and this quickens to life 18,000 bobbins, as the last and least of its effects. A bright iron shaft traverses the middle of the ceiling, like a girder to support the roof, till it diminishes in the distance almost to the vanishing point. Tackle is attached to this shaft in the vicinity of each frame, by which in turn they are set to work. All looks new and nice. The atmosphere is warm, but far from that faint, oily sickliness which makes many mills pest-houses for workers and forbidding to visitors. Windowis all round throw in their light, which, multiplied by so many inlets, makes us forget that we are in Lancashire. Walls lime-washed and clean make the place comfortable, and the ceiling of arched brick and iron girders gives such substantiality to the whole, that we fain exclaim, 'It is the model of an English factory!'

'You may be proud, indeed, of such a room; it is beautiful!' we repeat, enthusiastically.

'Yes, it is a nice room,' Mr. Turton replies, with more limited enthusiasm, but with real pride. 'All our visitors,' he adds, 'admire this room, and 
foreigners who come lift their hands and shrug their shoulders in utter amazement.'

We have now got to the spinning. The samo system of doubling and drawing the cotton, but for the last time. Reels at the top unwind and give up their roving; bobbins below wind up a strong thread, as fine as sewing cotton, whose fineness is certainly not the evidence we go upon in asserting it to contain beyond 4000 of the cloudy card-ends whose history we have thus far traced. Strange as it sounds, the finer the thread, the greater the number in it of the primary slivers. For fine lace, as many as 60,000 or more are doubled in one. As they can be drawn indefinitely, this does not affect the gauge of the thread, other than reducing to a vanishing fraction its inequalities.

There are 'movements' again in these machines which do not catch the eye, yet, when pointed out by the overlooker, are impressive of perfection. Fast, without haste, go round the bobbins and rovings; but the bobbins are filled regularly, not in a bunch. From end to end and back again, to and fro, till full, the thread travels the day throughout. The thread is now twisted likewise, but this is done with a small steel guard round the bobbin, whose presence we acknowledged after a rap that felt inclined to take off the tip of our finger; its revolution is, we were told-but why need we say how many thousand times a minute? you won't recollect -just so fast that the eye takes no account of its 
existence. And it is the rising and falling of something that sends the thread straight. Of course that is the way to do it. So easy and natural a thing ought to have been tried at first. What foolish people we are! Here are contrivances, one within another, the very thing wanted, and so simple, and yet brains that we count wise, puzzled over those very things for years, and years, and years, and tried a thousand experiments, before they hit upon them.

An hour on these two or three floors is out of proportion where there are so many, and outbuildings sufficient to make another mill. Ascend a story higher. A like spacious apartment; alike clean, strong-roofed, full of machinery, and lighter. A lamp-man has lately made his rounds with a guarded candle, and illuminated the place. Four rows of double burners throw out their jets, and add a beauty to so much that is admirable. There is our old friend the iron shaft once more, in just the same place. We really believe he lances through the rooms from the foundation to the roof. There is the same length of engine tackle down the centre of the room; and from the windows on one side we look out upon an immense quadrangle of factories, the whole lit up and brilliant from a thousand eyelet holes. It is a grand sight.

Spinning here also; but not with throstles, with mules. Changing birds for quadrupeds, without much resembling either, unless, by thinking very 
hard, we detect a thrush's note in the twirling of the bobbins, and a mule's hoofs in the wheels upon which carriages in this room run. Two mule frames stretch the breadth of the room, and they are in pairs thus throughout the length. Each frame consists of a part fixed and a travelling carriage of spindles in front. Except at the ends, they are put back to back, so that the carriages advance towards and retire from each other pair and pair. Three persons-the spinner, a man it may be, and two boys - take charge of four frames in opposite pairs. They pace between them, the man having the superintendence, and the children looking sharp to mend a broken thread. Look sharp, indeed, they must, with, to our eyes, an innumerable host of spindles to care for. They have no play-time, no time for gossip or profound meditation. The thread breaks and is mended in a twinkle, but another has gone twenty yards off, and before young Cottonwool has reached that, he is again wanted behind. Though the work in itself is not hard, yet the frame is a taskmaster. Not an instant does it wait to rest; the attendant must not wink, or his dilemma - would become inextricable. The room is kept at a high temperature, to prevent breakage, but the thread, at best, is but as strong as the ravelling of new calico. In some conditions of the air, it is almost impossible to spin a high number from the continual breakage. So easily mended, however, is it, that we try our own hand, and get discomfited; fail we do as wofully 
as once with the broken sliver. A touch mends the last, and a twist, unconsciously trifling, the first. The touch and the twist were equal failures with us; the sliver and the thread would provoke us, though we did it righter than the work-people. Indeed, Mr. Turton restores our wounded honour (vanity), by owning that it took him many lessons to learn.

The mule-room does not seem so crowded as the others, because a space must be left for the carriages to travel. : More in the way by our efforts to keep out, we quickly learn how little space there is to spare. The carriages roll forward four or five feet, and draw with them the rovings mounted on the stationary part of the mule. Then receding, it is the turn of the little spindles to dance, which they do inconceivably rapidly, and wind up, twisted in its course, the finally elongated thread. The spinners regulate the motion with practised dexterity, and while we look, a thousand cobs are made, and a thousand others are starting. Cobs are the bundles of thread that spin round each bobbin. They are wound beautifully even, and of the shape, with the spindle remored, of an artist's stump or a boy's kite string, tapering both ends, and bulky in the middle.

Noise, noise, noise; strong walls reverberate with the noise; every place is deafening.

'Where,' we ask our conductor, 'are your quiet parts?'

'You have been in them already,' he replies, wittily. 'We have no others so quiet.' 
Our poor ears comforted thus, we ascend yet higher. Another mule-room, the counterpart of below. Gas by hundreds of jets; still the same swirl of mazy spindles; the same brilliancy seen through the windows; the same great shaft coming up and going higher. Resistless must be its power; we look at the cogs it works into, and we look at the wheels and shafts in motion down to a dim distance in heavy iron, and we wonder the cogs, thick though they be, are not torn off bodily.

Again we ascend, and the picture is renewed. Story after story, we have but throstles and mules, gas-jets, and cranks; ever that mighty shaft rising giantly in force and in aspect. Near it the floor trembles, and strong as the mill is, we a moment tremble for the mill. Work goes forward without a word. It is a dead life. So grand is the area, that pain oppresses us for the want of the sight of humankind. These eloquently dumb machines do the work of multitudes, and better than any in a multitude could. Almost ready are we to cry that machinery must be the artisan's enemy. Not twenty workpeople are present. If these be all you have in your spinning, where are the 1800 hands your factory boasts? Mentally this is said ; but 1800, nor 18,000, we believe, would represent the manual amount of work of this one mill. Thoughts crowd oppressively upon us. Here we are surrounded by the symbols of England's manufacturing greatness. We see life without soul. Excellence of mechanism, in its very 
perfection, wants the relief of human presence. Automata working as with an idea, but without feeling; invoked the incongruous form of sentiment. Types of the hard, and real, and practical, call up the mystical and ideal, and, unlike Glendower's ghosts, they come at the call. A mood comes over us to believe anything about cotton. Thousands of millions of pounds! ay, tens of thousands in a year, it is equally credible. Cotton, cotton, in all shapes-bales, flakes, laps, slivers, rovings, twist-identifies us with itself. Cotton in unbelievable quantity makes us feel that cotton is our great concern. For the time our life hangs upon a thread. Our world is a great ball of cotton. This is but one of the many mills of the North, and that thought helps to impress us with the enormity of our staple trade-the staple of the world. Jets burn in a single room that would make it economy to manufacture the gas; but every room is respleident. The manager himself cannot tell how many thousand jets there are. Such a mill must be a lavish customer to the town company. Gas, as an item of expenditure, must be heavy even for an hour; but it is thought well to incur it during the winter.

Operations at the bon $\hat{a}$ fide spinning-mills end at this point. Kershaw and other large owners carry the cotton through all its stages, from the raw state to fine cloth.

A series of processes, almost as numerous as what we have traced, have to be borne yet before the thread reaches the loom. We pass along; and the 
oppressiveness of speechless motion begins to be removed. Here we enter a comfortable family room, with girls and women, and one or two men, so close and snug, that we feel to have reached the habitable world again. Tables are before them, covered with the bobbins from the throstles. Each work-girl has three or four feet of frame, just enough to keep hands, and feet, and eyes, and all the body moving. There are thirty or forty at similar work. They are unwinding the small bobbins, to reel them upon much larger. Hardly should we say they unwind, for all they do is to piece the ends, fix the bobbins, and trust them to do their own work. They skim and dance merrily round, for that ubiquitous steam, which we have not yet seen, is paramount here, as everywhere. They lead the poor minders a terrible life, for their greatest delight is in breaking and in running out. One smart active girl we address, but she can only catch at an answer- 'Yes, sir' (break); 'we haven't' (a run-out) 'time' (break) 'to talk' (another break). These breaks are not more than commas in her reply, for her quick eye and nimble fingers always come in 'neck-and-neck.' Bobbins not larger than a reel of crochet are thus transferred to reels as large as a publican's pewter quart. Baskets of empty reels tempt us to examine them. They are made of hard wood, the centre holes of box. Composed of several pieces nicely turned and joined, we venture upon sixpence as their market value. 'They cost us halfpenny apiece,' we are told. 'Ye poor authors, hold 
your tongues,' we inwardly rejoin. Factory owners sometimes make their own, but find it generally cheaper to buy: and so we should think. No cobs from the mule are here. Do not they get wound off? Yes; some of the cobs, the largest we saw, are 'twist cobs,' but the greater number, the small, are 'weft cobs,' and go into the shuttle unaltered.

Generally, but by no means invariably, twist to form the warp is throstle spun, and the weft, or breadth thread thrown by shuttle, is spun by the mule.

Latitude and longitude are by this time lost. On the huge spinning-floors we had some notion where we were, though the solid causeway made us oft waver whether we were six stories high or on the solid ground. Faith in our cicerone is no longer a virtue.

Wherever it was, east, west, north, south, top, or bottom, or middle floor, the next sight was most interesting and beautiful-women, in a room larger than the last, preparing the warp. A hundred, or any number, of the last-filled bobbins are arranged on the bars of a horse, not unlike what a laundress uses, only far larger. From all of these bobbins the ends are drawn out, converging towards a roller, the breadth of the cloth required, and passing on their way through two slip gauges, to keep them their exact distance apart. Round the roller they wind, a broad sheet of calico, without the cross threads. Many warping-frames are doing this duty, and the 
straight lines of white thread remind us of our youthful pastime, 'scratch cradle,' here raised to sublimity. Much depends upon the warp, and a careful eye has to keep on the look-out for a thread breaking. More difficult this in myriad-fold threads from all direetions to one point, than in the straight length lines in the mule-spinning.

Weft and warp complete, now for the loom. Ay, . hurry, but the warp stops twice more on the road. Perforce we must wait before the final tableau. Hot, moist, and puddingy smells an out-of-the-way room, loftier than the rest. These are the dressers, says the young manager, with polite readiness.

'And what is in these troughs?' we inquire, curiously smelling under the cover of one, into which the warp dips and passes out the opposite side.

'It is merely flour and water,' he replies. 'The thread is strengthened by this bath, just as an old lady strengthens hers with bees-wax.'

On one side of the bath the sheet of thread unwinds, takes a dive through the paste, and comes forth on the other, wet, but still strained. It meets a series of heated metal cylinders, about which, under and over, it travels, sending up an unsavoury steam, and leaves them dry and stiff. What little moisture might by possibility be left, is dissipated by the action of a revolving fan under the sheet. Stronger than before, and quite dry again, the warp winds on another roller, and looks very little altered.

Dressing the warp, though not so pleasing to the 
beholder as most of the other processes, is one that requires great skill. The men are the best paid in the factory; they know their value, and combine to keep up prices, prohibiting any one from learning their mysteries except through the initiative of apprenticeship, and keeping themselves a close fraternity. Carried to an extreme, these corporations defeat themselves in the long run. Labour-saving machinery has ever received its chief impetus from the combinations of workmen against an altered tariff. Dressers earn from $30 s$. to $2 l$. a week-high wages in a cotton mill; but their craft is threatened with simpler modes of dressing, to which any one can attend with the apprenticeship of an hour. Moist steam and vapour of paste lose their charms by this time, and 'forward' is the order given.

Once more we light upon busy groups in an outof-the-way corner. Boys and men, women and girls, are 'arranging the preliminaries' for the power-loom. The action of the loom upon the warp is, as every one knows, that of lifting every alternate thread, and depressing the others, each in turn, and making them cross close and regularly up to the part already woven. This we shall witness in good time. The difficulty is, how to fix and yet not to fix the threads, so that they rise and fall without one mistaken thread, and at the same time travel on towards the shuttle. Every thread of the warp, it is clear, must be seen to separately. It appears about the most trying, and dry, and tedious work we have yet 
looked upon, and it is done in the room we have got to. Description gets tiring; but solace yourself, oh reader! that the penalty is less than the work described. Here is one group : a boy and a girl sit on benches, face to face, with a roll of warp between them, its ends unwound. To stop the chance of unseemly mirth in such a serious work, a veil of string hangs down to intercept their smiles and speech. This screen is formed of two horizontal slips of wood, six inches or so apart, and joined with close slips of string, the same in number as the threads of the warp. A line of eyelet holes runs across the middle. Every string has a hole, and through these the warp is threaded. It is the girl's duty to pull the threads through on a kind of crochet-hook. This girl was clever at it, and worked with two hooks in one handle! Let my lady look to it. The boy feeds her hooks as they pierce to his side.

Other groups are at like operations; while groups of one in some places save the trouble of piecing the remnants of an old warp. Before a warp is quite used up, the remnant is cut off, and remains in the eyelets. It is easier and quicker to piece these, with the peculiar twist, on to a new warp, than thread again with a hook. This is supposing the eyelets not 'quite used up' likewise. They last but a short time, and give constant employment to a number of hands. Piece, piece, piece, thread after thread, thousands and thousands of millions; so this old man, who has been at it more than forty years, 
still goes on, and will go on, till his fingers grow damp and cold, and stiff-a unit in a kingdom of thirty millions, and the smallest, yet deserving a place on the civil list for untiring devotion for the comfort of others, and a warmer share about him of the cloth he helps to make.

Quit sentiment; 'by the heart of man' (the favourite adjuration of Lancashire), it should find no place in a cotton mill. Grateful, cool air of the stone passages enjoyed for a few moments, we lift a latch, and view the final grand scene of the cotton manufacture. Led through a succession of beauties and wonders, we fancied their consummation in each successive room. Dazzled, bewildered, overwhelmed, scarce do we know to what point to turn. The vast room, made doubly vast by opening upon a second, built out from the main building, produces the sensation of boundlessness. Countless jets shed light that hides the distant walls. Covering the floor are the looms, clashing with the clash of multitudinous machinery, and deafening us so, that we absorb the scene without a word. Side by side again in pairs, each the magnitude of a steam printing-press, they intimate felony in the sacrifice of a morsel of ground. Dare we utter, with the prospect of belief, how many looms are in this room-not 'room'-in this great, covered gaslit field! Trust us, there are 1345! Each is lighted by its own jet; each pair is watched by a woman or girl; and the whole is made to deafen us, by that same omnipotent steam. There 
is our friend, the big bright shaft, who has been eager to receive us in every room, and there are the shafts and wheels dependent upon him for life, multiplied manifold. The giant Vaporifer moves 1345 looms, and a few incidental spindles-18,000, to wit, in the throstle-room, and corresponding work on half a dozen floors. Would it be dutiful to depart without homage to his greatness? An audience anon. Looms and ' hands' present claims in advance.

Weaving is chiefly, as indeed is most of the work of the mill, in the hands of women and girls. It is their best paying work. One young, pleasant, wifely-looking woman had had a reckoning of 26 s. for six weeks in succession, and was going on still at that rate. Her roll of woven cloth keeps increasing as the shuttle flies to and fro, with the relentless rap it gets at either side. Neither end will have it; it is evidently no favourite. Self-acting arms fling it backwards and forwards, as in spite, nor do they cease till the cob is wound out. At each throw of the weft cob, the cloth is batted and fixed with a stroke from the loom; the eyelet string frames also draw the half warps across each other's thread, and make a new road for the shuttle. The self-acting arms are a modern improvement, where all is modern, and relieve the weaver of the labour of throwing the shuttle. Skilful as he once was, he would look awkward now, sitting at the same work.

Here, as elsewhere, wo are lost in admiration 
of the cleanliness and freshness surrounding us. Young girls, rosy-faced and healthful, some of whom would take no low standing amongst farfamed Lancashire witches, work light-heartedly. Our impression is pleasurable. Messrs. Kershaw keep no eleemosynary schools, churches, and reading-rooms, but they preserve their workers' health, and leave them with the more confidence to choose their own means of improvement. They take no 'half-timers' amongst school children, and therefore need no school. In this we think them right. However large the offering of many good men, in the shape of churches and schools, to their factory hands, and we have never been backward in giving them praise, the balance is heavy against them when they live upon the health of their people. Masters should whitewash their walls instead of their consciences. Wo leave the Hall of a Thousand Lights, emblems each of the young soul they shine mpon, and make our obeisance to the Father of all the noise. Alone in all his grandeur we find him, like an Eastern potentate, hid from vulgar ken, with but his grand vizier, the engineer-in-chief, to whom he deigns speech. They know each other well, and one regulates the other. The monarch has but to make the slightest intimation, and his minister is prostrate to learn the royal need. Devotion such as this is rewarded by the willing readiness of the master to listen to the servant. He is ever open to persuasion; let his attendant touch but one of his springs of action, 
and he will in a moment alter his course, reverso his judgment, or give himself up to stillness and reflection.

Ponderous and imposing is the giant with two heads, for it is double. It dwells in solitude, but its influence radiates over a whole region. Its presence-chamber is finished off as brightly and smoothly as any room in a Lancashire lord's mansion. Gas branches come out from the wall in elegant castings. The equipments are all elegant, ornamental, polished, and light. Ay, light. Those mighty beams that see-saw in lofty emulation; that tackle attached to each beam, in themselves like small steam-engines; that massive iron fly-wheel, twenty-four feet across, on a spindle of solid iron, a yard in diameter, all move so quìckly, with such knowledge, that even they look light. The powers of 250 horses are represented, and strong horses they must be. The source of power is from above; as a man's mind directs him from the head downwards, so the steam enters the cylinders, and starts them from a tube on high. Up two flights of iron staircase we mount, examining with gratified eyes this stupendous engine, before we are at the elevation of the beams. From the roof above, weighty iron loops hang in profusion; used when required to fix any part of the engine in its place. We descend, beholding the easy hard work. The motion of those enormous cranks and fly-wheel approaches sublimity. How they were placed there and set to work is be- 
yond our poor comprehension. We are obliged to break silence.

'It would be a misfortune were that spindle to break,' we observe to Mr. Turton, whose goodness is even yet not worn out.

'Yet it did break only last year,' he answers, to our astonishment, for we meant it as a joke.

It broke last year, and the wheel sank down, and many folks said it would never be raised, but that was a mistake, for it is raised, and at work to-day. What is more, it took' but half a dozen men to do it. There is an iron chest with a shört handle projecting. It served us for a temporary seat, we being quite unconscious that we thus dishonoured an instrument mighty enough to wage war with the engine itself. A simple square box, whose apparatus within is principally cold water, lifted, and would lift, that terrific weight into its proper place. Cold water can make steam shrink into nothing. The small box was an hydraulic press, and was procured purposely last year to replace the wheel and a new shaft. A new shaft! how' glibly said, and yet how teeming as a text! - Scarce an incident of our visit but we could expand into an essay. Several weeks, right and day, were the steam-hammers and sledges battering it into shape and consistency. Good evidence is it of the mutial dependence of all crafts. Without Nasmyth's hammer, 'such a trophy could never have been forged, such an engine could never have been reared. The engineer is proud of it; as he says, 
'It is something to have the tending of a fine engine.'

As we pass through bales of cloth ready for the warehouse, the girls are going to tea; the Irish hooded with their shawls, the Stockport belles, less weirdly and less comfortable, in bonnets. Factory girls have their notions of what is becoming, and are as skilful in the arts of fascination as their higherborn sisters. Necklaces and ear-rings are very common among thern, with which they play off wiles upon many a poor spinner, and wind round his heart like his own bobbins.

'Reckoning-day' is once a fortnight in the cotton mills; too long an interval, we think, for improvident people, as most poor people are. By the countinghouse there stands, barred windowed and strong, a room, at times filled with tempting heaps of silver. Hungry eyes in a thousand heads would be urged beyond bounds by the display of treasure, but, alas! the iron bars. In turn it is doled out through an aperture only the size of a man's hand, and distributed, according to their meed, among the expectant throng.

Just in time to catch the train, we have from the railway a parting view of the monstrous pile. Not less than a thousand windows stream forth their light. It is a grand sight. The evening and morning illuminations, while they last, redeem the sludge, and rain, and smoke of Lancashire. Manchester is illuminated. Round the infirmary her warehouses shine from every window magnificently. 
Kershaw, Leese, \& Co. : amongst factories theirs is the finest; amongst warehouses theirs bears away the palm. Loftiest and grandest of any in Manchester, it is the chief feature round the infirmary, and the pride of the parvenu city. Wofully has Manchester wanted an example in decoration. She has of late years begun to dress herself up.

There is a moral to our sketch: Mr. Kershaw, owner of a splendid warehouse, two factories, cotton lord, merchant prince, and senator of the realm, was once a poor warehouse boy, and is not an old man now. As he set Manchester an example of good taste and wise magnificence, so he stands an ensample to all young men of what untiring diligence may achieve. He rose in his house of business because he learned his business well. He waited not for fortune from without, but worked out his own fortune from within. He became one of the many illustrious men which Lancashire points to as her pride ; indispensable to his 'house,' receiving a share, rising to its highest offices, and at length enjoying well-earned and dignified" repose. 



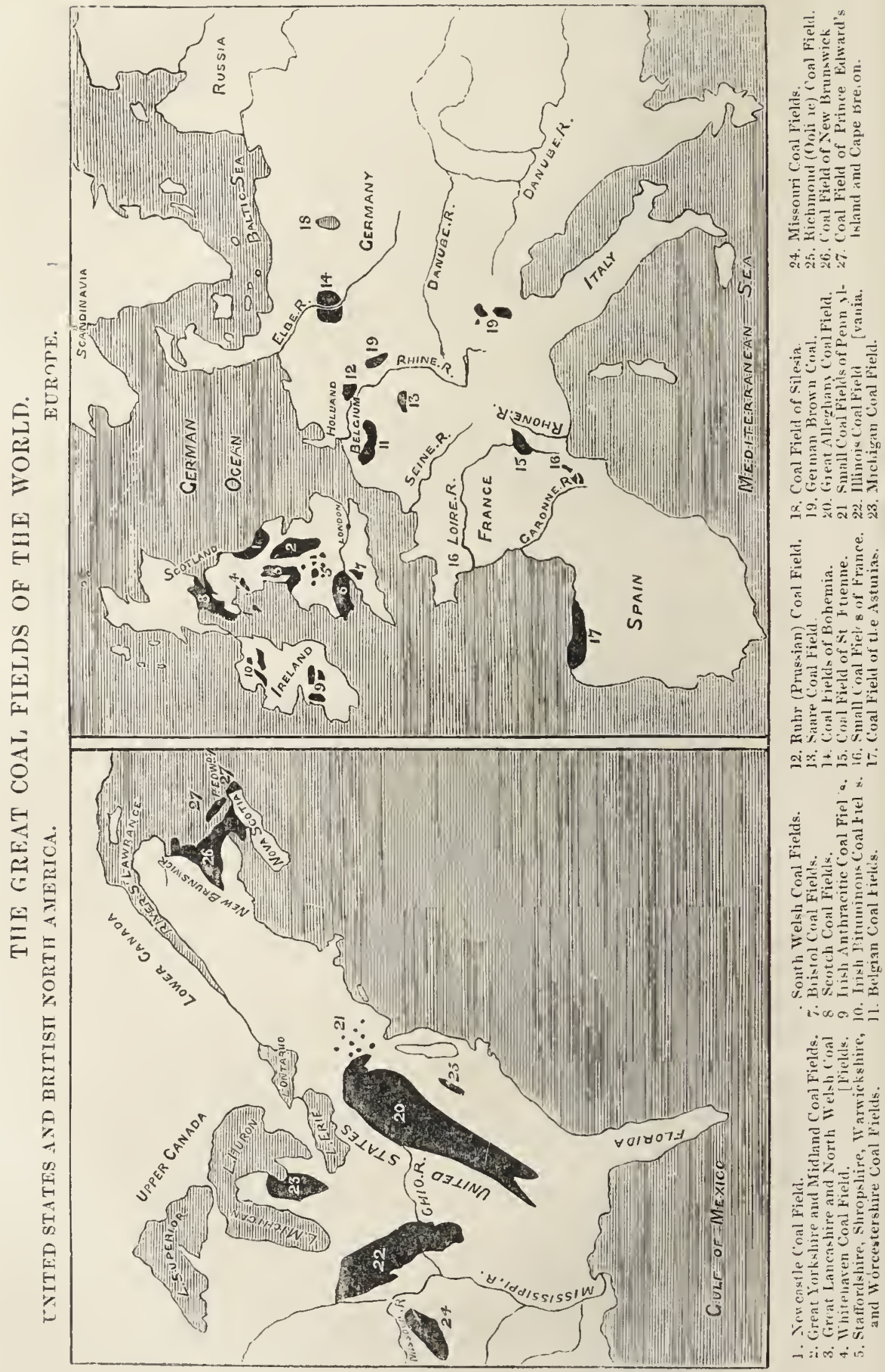




\section{5}

\section{MIY LORDS OF COAL.}

First Native. 'Do'st know 'im, Bill?'

Second Native. 'Noo; he be a stranger.

First Native. ' 'Eave arf a brick at 'm.'

Many readers must remember the graphic cartoon in 'Punch,' which gave this striking illustration of mining hospitality.

Southern eyes fancy the great black skeleton arms that outstretch over the mouths of the coal-pits of South Lancashire odder-looking than the mountains of brickwork, chimney pinnacles, smoke, drizzle, mud, rain, rags, or any other essential of this illused spot of our beautiful earth. Coal districts are rarely very romantic. Where coal abounds, the verdure, foliage, cattle, houses, people, are its scions, and inherit its lively hue. Stunted hedge-rows, and sparse herbage, and waters almost as misty, thick, and black as the skies they reflect, blend to cheer the landscape.

The South Lancashire coal-field, not the largest or richest in England, has more shafts sunk than any other. The craving maw of the steam-engine demands every day more tons of food by far than the 
whole army set to work by its means. Wherever coal can be got, there do we see rising continually the mighty square mansions of My Lords of Cotton. Without coal, many of these same patricians would be in the lower strata whence they sprang; the most distinctive, if not the most cheerful, corner of our country would be raising fat cattle for the shambles, instead of lean hands in the cotton-mill, and old Bogies underground; Manchester would still be nowhere, and Liverpool, 'convenient as a trading port' (so saith ancient chroniclers), would not yet have outstripped London in her yearly import tonnage; the grandfather which Sir Robert 'never had' would have had a grandson never heard of.

Railways 'sloped' in amongst the collieries, and made revolution there as everywhere. Northern coal-trucks are no rare sights at the London stations. Sea-coal has encountered an invading foe in midland supplies. In Lancashire, coal-trucks are thick as blackberries. Coal-coal-coal meets the eye wherever the eye peeps-blazing away at the pit's mouth, half a ton at a time, say a ton, while we are at it; and in-doors blazing all the year through-dog-days and Candlemas, as much from habit as necessity (though we won't allow that), at a rate limited alone by stoves and chimneys, which have scarce a limit at all. Ye thrifty London wives, let your mute uplifted hands denounce the wanton waste! Young housekeepers, proud of your keys, how would your 
eyes glisten at coals 5s. a ton! Well may you heave a matronly sigh at the recollection of $50 \mathrm{~s}$. paid not long since.

In Lancashire the railway system is perfect; there it had its birth, and has grown to manhood. Instinctively from its cradle its arms have stretched out wherever they could seize anything; and so, wherever there is a colliery, there be sure of an arm, finger, toe, joint, or limb of some kind, of the iron tramway. To the pit's very mouth a siding is thrown out, so that the coal may be thrown on the truck, and not kicked down till its travels are complete. New shafts are sunk as near the line as possible, to save length of transit. Trucks, with the owner's or agent's name upon them, run orer the rails by contract-the colliers finding their own trucks.

Of a surety, you see many of the features of the coal scenery as you bound along from Manchester. Here a long line of laden trucks trails out of a tunnel, while our snorter follows a side trail in ; as though about to pierce right in amongst the costly deposits by, at once, a passage of the coal-mine and a thoroughfare for steam traffic. Issuing into daylight, we change tunnel for embankment, and that of extraordinary height. From the brow there is sunk a pit, protected with great skeleton arms again, and with the same great rolling, black pulley above the hole, ever peeping down to see that all goes right below. Now, we muse, for the moment-but 
what a pity express speed gives us no time for musing, and you have lost a beautiful thought-to this effect: Why should they have bored a deep pit, when they might have gouged a short passage from the base of the hill into the bed itself? Had they been cheesemongers, or had we been consulted, we could have saved the engineer from absurdity. But a shrewd fellow-passenger points out to us, that it is easier to bring up the coal direct to the railway, than it would be to bring them to the roadway, and then drag it up the declivity. So much for common sense.

Not so outrageous, after all, is this idea of tunnelling out the coal. Our complacency need not be piqued. In more than one part, it is reached by a tunnel, and brought up a long incline, or jig, in its introduction to daylight. Nay more, so well disposed is Nature towards us now and then, that the coal crops out, or comes to the surface, merely asking for a 'pick' and a basket, and yielding itself' up to be burned. What a variety of adventure may we expect to meet in tracking a bed down from the surface a sweep of 300 fathoms or more! This surface fuel is but poor stuff, and ranks with deep coal much about the same as the Chinese Brick tea does with Hyson.

Grim look the scaffolds that diversify the country, as windmills do on corn lands. Wherever tho workings are extensive, there are two shafts to a mine-the 'upcast' and the 'downcast'-some 50 
to 100 yards apart. Naked framework, and wheel, and rope are over each. Midway between them is an engine-house, containing the motive-power for the gear of both. A wheel within revolves, and lowers a rope towards one shaft, as it winds up one at the other. Slung over the pulley, high above the abyss, each rope makes an acute angle to the engine-house, forming with it, as it were, a gigantic capital M. The pittees are the bases of the letter, as the pulleys are its summits, while the engine keeps all terse and tense, like the chains of a suspensionbridge held by the pier. Two shafts facilitate ventilation. If there be only one, the ascending and descending currents of air knock against each other -a far more dangerous risk than even the frequent knocking of the baskets against one another, and against the sides of the pit.

Lancashire pits are evidence of the strides the Palatinate has taken in half a century. Less than that time ago, nearly all the coal was lying snug in bed. But the shrill whistle of stokers and pokers was its cock-crow, and woke it out of a nap longer than that of the Sleeping Beauty. Exhaustless sources of wealth were held. unconsciously by unenterprising men, who let them go for a peppercorn. One field we know of, with an output of thousands of tons daily, pays annual surface rent for stores and offices near 1000l. a year, where coal and surface together were held once on a perpetual lease of 507 . Roads mended with engine-ashes are black as the 
coal; and skies privileged with more than a due share of Lancashire moisture are shut out as zealously by heary frequent rain-clouds as by the rolling 'milky ways' of dense dark smoke and emulative marsh mists.

Just, however, as eels learn to like skinning, so do the natives learn to love the soil they grow upon. From the lack of decent houses, and the magical abundance of dirty red ruins, you might fancy a secret sweetness in colliery work, which, like virtue, is its own reward. Other labour is lightened, cheered, and varied by domestic comforts; colliers can do without them. Wretched hovels are their portion, for the best part, and the habits of the inmates seldom turn the cot into a palace. A sense of dilapidation, misery, and dirt steals over and shocks the beholder. No green thing, type of freshness and refinement, is to be seen at one window. Sludge covers the roadway of every narrow low lane, and before a score or two of doors there are great heaps of the coal, just as tumbled out of the cart. No one guards the heaps ; coal is not a temptation to the prowling furtive beggar. The rule is pretty general, to deduct the consumption of coal from the fortnight's 'reckoning.' Thrift is nevertheless but little thought of. Lumps lie about in the dirty streets, enough, for the gathering, to keep a continual carouse. Proprietors on other fields, we hear, allow their men a load of coal a monthtwenty to thirty cwts., to wit. O Paterfamilias, old 
or young, presiding over southern hearths, and declaiming so vivaciously against shameful prices, how would your eyes open and hands start up at the sight of a ton or more of coals toppling into your cellars every month! E'en be a collier, and you get them.

How much habits and homes act and react, it is not our present mission to develop. A principle is embodied in a picture. Were it possible to put a few charms in home, we think that the beerhouses would not be innumerable, and the men so riotous. Ignorant and imbruted as thousands of the colliers are, there is yet a human heart within then. Sad as their condition. still is, it promisingly contrasts with days of yore. It is a difficult thing to define where morality demands the interference of the ruling powers; but when, as in times happily past, women, even more than men, and infants of four years, were doomed to toil, certain contamination, untold and untelling vice, and deeds of double darkness in the black pits, it was time for humanity to rescue them. Women might by now have turned the men out of their work completely, and have sold themselves slaves to Legrees abroad, and brutal sots whom they would have kept for husbarlds. Enlightened legislation has done much for themin simply opening out a chance of domestic life. A whole generation must pass away before the effects of the sin of a money-getting selfishness will be obliterated, and more than a faint struggle for im- 
provement be discernible. Here and there we come across a small hut, tidied up with the pride of a busy clean mistress; and the sight is hopeful in its unusualness. No longer fated to the pits and to profligacy, she has a chance to let her womanly modest instincts, which aforetime had 'died out,' expand again, and develop the blessed arrangements of a home.

In the midst of their wretchedness, colliers earn wages that would enable a thrifty mechanic to retire from labour before he was old; but colliers are very reckless. Relics of ingrained guilt, indifference to employers, the imminent perils of the mine, blend to make them callous. How awful to think, that out of the miners this very day working for us underground, so many are to meet inevitable, untimely death! Not a mere surmise is this, but an experience from the returns of late years of accidents, mostly preventible!

'Reckinin' Saturday' comes 'once't' a fortnight. A man and his boy together will sometimes take 10l. or more. Supremely wasteful is then the feast. Butter and unctuous things (for they like it rich) make an ocean for cakes and meats and good things to bathe in. Fires, never small, heat their rooms, while the fat streams out of the ovens, and they keep at it cooking away till far into the Sunday morning. Look in upon them, and in two minutes you feel ready for basting, and make quick exit, for fear of being served up with the roast meats. 
Drop in next Saturday, you are in danger of a different basting. ' Jack o' Bill o' Bob,' as he is known from his grandfather downwards, has spent his 10l., and is starving. A goodly family without a shirt among them is no rare circumstance. Joviality is the watchword when money comes to hand, not so replete as to be quarrelsome while the preliminaries are arranging, but in good-tempered mood of expectation. For two or three days they 'play them.' Church is forgotten, and reckoning Monday fills alı the washy beer-houses with these black sons and daughters of coal.

Colliers have not a good name amongst us Southerns. We think them inclined to riots and strikes, and to take exceeding pleasure in making us pay dear for our fuel. The coalies are not much esteemed, however, by their nearest neighbours. Every townsman has an ellwand history of their rough doings. Rioting, indeed, is no dishonour in their ideas. Morality is at a low ebb, or, as one of the Government Inspectors remarked, it 'does not exist.' Curiously appalling, if one questions the miners' children, he would find it, to hear their glib reference to brothers imprisoned, or fathers transported; facts like household words, which carry little discredit, but are rather looked upon as simple incidents of the craft.

A clergyman who ministered in one of the districts for nearly ten years, has given us striking testimony of mining virtue. Page after page of 
his baptismal register was of children who had 'no fathers.' A legitimate child was an unusual exception. It has, he thinks, improved of late. We hope the belief is not the complacent thought of a good man. He related to us, also, a house-to-house visitation in search of a Bible, when once he had been called into a sick bed, and had, in hurry, forgotten his own. A full hour's search in the neighbourhood resulted in the discovery of only half a dozen torn, old, odd leaves, so ill chosen, that he fain trusted to a well-stored memory. 'Relaxation of labour,' the fine phrase of turbulent delegates, or 'playing them,' as is their deluded victims' Saxon, is continually threatened. Pit-owners, to aroid the consequences of strikes, keep mighty stores, not only in the vicinity of the mines, but in distant towns; enough to last out a winter without a pick working. In face of these facts, men will play them. Wigan remembers, with a shrug, the lawless riotings of a year or two back. When food is dear-that is, when they are least able to support themselves, if people who never spare can be less able to buy dear things without money than cheap-then is the time they cry out for their rights. Yet we profess to believe, however mutinous to order by nature, that a never-cessant inclination to rebel can arise only from some real wrong in their system of labour. However crude it be to their own minds, and in their own expressions, it is there, and it is felt. Inevitably must the wretched beings suffer by playing them. 
If they succeed, they sink all the time of strike, and if they lose (as certain almost as that they suffer), they render themselves more moody, revengeful, and bitter, while they widen the gulf, already wider than the pits are deep, between themselves and their employers. Emaciated health lays them in ruins complete as their mental ruin before; and as pale ghosts they stalk the town, too pitiful a remembrance for feeling hearts, and the subject of their prayers that it never be enacted anew. Ofttimes this may proceed only to the proprietors' enrichment. Their huge stocks are sold off at great advances, increasing as the reserves dwindle. Trade goes on, and with no outlay for labour the returns are heavier by far. Before the supply is gone, when masters would begin to feel, the men are starved into submission, and at work again, piling Pelion upon Ossa, to frustrate their next strike. Truly, blind ignorance is shown on the part of the pitmen; only the small masters could be made to yield, and they dare not. They cannot compete in the markets with mole-hills of coal, nor can they, in the form of immense reserves, have idle capital, whose interest adds to price. My Lords of Cotton and Coal, who tower above them with republican equality not unlike that 'in another place,' would annihilate them with a frown.

Humanity shudders at the degradation of her brothers and sisters. Are these the beings whom God made in his own image? Talk in under-tone 
of the greatness of Britain, while the myriad debasements of a factory and colliery district swarm rampant. Parties squabble over theories and schemes, and the people perish for lack of knowledge. 'Touch not the equality of labour and capital!' cries Manchester, while the equality they wot of is all on one side. Tell us not of Manchester energy, Manchester munificence: Manchester nor Westminster has done the tenth of a tithe of what God's bond requires. A voice cries from the bottom of the coalpit, like the blood of Abel from the ground. The voice is heard above the din of factories; it is heard wherever vice and ignorance are allowed to prevail. We blame individuals, we blame the community. Brahmins there may be in England, but there should be no Pariahs. Let the community move, and no individual whom Fortune, in a freak, has in one generation raised above his toiling fellows, would dare to say that those of whom he was one 'have no right to think,' or dare to feel that a crucible once scantily filled with base copper is now of finer clay because it holds gold. 'God shall smite thee, thou whited wall!'

Believers in the ultimate perfection of human nature, behold our suffering Fatherland! Be she the foremost of all the nations, when will the world accomplish her grand destiny? If colliery manners be the data from which to trace the ultimatum of England, it is well that 'Heaven from all creatures lides the book of fate.' 
'Give him a wiggin; fettle his mouth with a brick !' is an endearment many miles round the town immortalised. 'Fettle,' that is, ' repair' or 'improve,' in the manner of 'Punch's' ' 'eave arf a brick at 'm,' is the welcome to a stranger. It points, without comment, the character of more than one group of the Queen's leal people. Of a truth, some of the greatest reprobates in the earth beneath are coalpitters. The essence of their fatal philosophy is, 'If we are to be blowed up, we are to be blowed up,' and thus leavened, they become wretched fanatics, or loose livers. We were told by a not very erudite authority, the Creole son of a soldier, that 'he'd see'd a good many countries, but he'd a never see'd a ignoranter nor a more wulgrer lot of people than them he looked arter; though some is religious, and them as is religious is wery religious.' Their religion does not of necessity make them provident, nor allay their love of beer.

Dreary as is the coal scenery by day, night beats it. Journey, then, from town to town, and dub yourself a hero, if, on the dismal endless line, now over the dark canal, now across the tramways, terror infects you not. Wrapped in the vague dread of gloom, silence, solitude, and midnight, a long journey grows longer. Assurance of safety is not enough to inspirit you to believe that it is all right. Houses on the road only urge your heart to faster pit-a-pat. No cheering aspect have they, and their tenants, 
without scandal, are not lambs. Better tackle a 'Rooshian,' than a collier provoked.

Glaring round upon the desolation are tremendous fires at every few hundred yards, showing the vicinity of a pit; or, less frequent, the long, twining, serpent streamers of natural gas, brought to the surface from great depths by tubes, and burning in huge neverdying jets; or the lurid brick furnaces, whose glare, not enclosed as in the kilns of the south, shines fiercely out of a row of openings, making ruddy the landscape for miles before it.

A will-o'-the-wisp dances near. Eyes used to the sight know it to be the light of Dary. Tramptramp-tramp succeeds the glimmer. Voices are heard, louder as they draw near, one of which discovers the precincts of Bill 'o Bob, Jack o' Bill's father. An old chum has pounced upon him where two roads meet, with a loud, "Whaw, Jack, is that thee?'

Jack. 'Oi! Doant it faver mah?'

First Collier. 'An wher' th' coiling it nah, lad?'

Second Collier. 'Doon that ere pit amoong fâve feet.'

First Collier. 'An' how art geettin' amoong it, owd feller?'

Second Collier. 'Whaw, thee kneas as I've been retely pown ever sen' I geet bagg'd fra' my owd shop, an' her' hed a summet to du to geet a bite o' bacca an' a sope o' ail, but I'm comin' rand. I've gettin' 
intil a fizzin' drift nah, lad, an' I doant miss'n makin' it smook. What's te thinking? I drawed summet lâke fâve pounds lạs' reckinin', an' I'm littenin's moore next.'

First Collier. 'Wal, I'll tell the whât, as I'm as fain to hear't as if tha' hed been my ain châlt; but I'd hev' thee to be carefu' what the awt aboot, tha' knowen, or some o' th' awfficers sons 'll be shovin' thee awt.'

Second Collier. 'Oh, thou maun't think I'm as daft as I look'n. I know'n a bit o' summet as well as th' doctor. Doesn't see mun, as I can get owth' coils as is in t' drift this fortn't, an' then they may he' th' place!'

First Collier. 'Gooin' awee? Weel, weel; thee'lt tek' care on theesel'! An' wher' shall I leeght on thee Satarda' neeght?'

Second Collier. 'Whaw, somewher' abeawt Black Horse.'

Meeting Jack, or a relay of his sooty chums, late at night, affects a visitor with the idea of being really amongst coals, beyond any circumstance else. Footfall announcements so long before their ebon visage, their white eyeballs glistening like extra Davy lamps, their picks and other tools faintly discoverable over their shoulders, and then the knowledge that they will be immediately a thousand feet below us, picking away, like gnomes and demons of goblin tale, at the black diamonds of the earth, all combine to convey a strangely transfused impression of the grotesque and 
terrible. Jack gives us, nevertheless, a cordial goodnight, and we pass on reassured.

There are curious anomalies in the right to coal property, which you slumbering over your sea-coal fire haven't yet dreamed of. Coal, to be of extensive utility, is as modern as the steam-engine and factory system, and, with them, has taken a leap into life, rather than been born after the natural order of things. Its gestation, for aeons of time, has startled the world at length with all the suddenness of a premature nativity. What feature of the national character does it exemplify, that both in the colliery and factory system, the irregularities and evils incident to sudden gigantic schemes should pretty well all fall upon the poor crushed toilers, and should aim almost undisguisedly to help their lords ' make haste to grow rich.'

We have gossiped with the proprietor of a pit, whose stores had been in possession of his forefathers for quite a misty time, and they happily unconscious that they ought to have been amongst the gentry of the land. The present owner, like his antecedents, was an unenterprising farmer, cultivating a few acres of scanty pasture, and living from hand to mouth, with often nothing in hand. His habiliments do not bespeak wealth, nor his speech cultivation, but he was the first to venture upon sinking a shaft, and now he is a rich man. Change of profession has not made every feature of an old farmer disappear, for slovenliness and waste, the former essentials of farm work, 
can be carried to perfection equally in a colliery. An old, rotten, damp basket, with good part of the bottom out, let us down his pit. Flaming candles in one hand and safety-lamps in the other, with naked lights stuck on the wall, as a guide lights up a cavern, similar means of illumination in the trucks, and even in the working drifts; though the mine was known to be treacherous, and was made doubly so by wasteful digging, and sacrifice of a third of the coal, as well as by careless disregard of ventilation; this was our first introduction to a coal-pit. Our guide actually remarked, that we had better not go up one drift, because he knew there was some gas. We hope to take our troop of readers down a deeper pit; with more regard for their invaluable lives. Yet such a plan will picture only the few pits, while the first does the many.

Our farmer-collier offers another point distinctive, as evincing the amiable relations between railway companies and pit-owners. His passages run under the railway, and, by consequence, the line is constantly sinking and wanting repair. Negotiations have gone on between them for purchase of the pillar of coal under the rails. Disputes about terms arise, as a matter of course. One is willing to sell, the other to buy. True Lancashire, they look out for a bargain, and cannot agree. The owner looks to the value it would be to the company, in his estimate, and demands four times as much as he would get by digging it out. The buyer reckons only what it would fetch in 
the coal market. The result is, the proprietor digs out his coal, and the company has paid already for a man to watch the road, and for never-ending repairs, more than the sum first asked. This is one of a score of such cases, and, as the man says he ' hasn't done with them yet,' they may anticipate a series of like outlays yet to come."

Much of the coal-field is cut up into small properties too unprofitable to work, from the expense of a shaft. These generally get absorbed into neighbouring collieries, but not always. One piece we remember too small to work, but by some legal tie it could not be sold. A very proper neighbour to this is a tiny coal estate belonging to a man too poor to work it, and unable to sell it, because the grass land above is not his own. Very commonly the mines belong to one owner, and the surface-soil to another. Mayhap some day we shall have a claimant for the rock beneath both. Coal-lords are poor lords, after all, unless their patrimony is large enough to dignify their title. It is the policy of any extensive colliery to wind round these small ownerships, and to isolate them in a close embrace. The bargain making is then all on one side, and no retaliation. Sinking a shaft is verily no puny affair. Many days and weeks elapse before its success is beyond speculation, though heary cost is from the first. The progress of boring is of much interest. We have watched the strata pierced, one bed after another, till, as the dark hole got deeper and deeper still, our interest has wound. 
up into eager anxiety. Not the proprietor himself has hailed the sight of the first piece of coal with more emotion.

'Faults' in the coal bed may sometimes hap just at the point where the shaft is sinking. A sudden step down of several hundred feet is no joke to one who invests all his capital as the calculation for a determinate depth. It necessarily provokes a colliery master to spend double what his neighbour does in a shaft, through an ancient volcanic freak of dame Earth, or what not, and to get no better returns in the end. He can only console himself that others ,are in a worse plight. We have in mind a shaft that has sunk a fortune in a quicksand. After many thousands of pounds were spent, it met with the quicksand, which extends over many acres. The pumping cost double the first expense, without any sensible result. These are the alternativesto keep at the pumps indefinitely, or to casemate the shaft; nay, there is a trio choice-to accept the dead loss, and give up the job. The last is most in favour.

Round the pits of a large concern the ground is flagged with iron for the wheeled tubs to roll upon; whence they rush off on the laid plates, and tilt over at the edge of the great rook or mound. Expedition is the principle of action. A never-ending train of tubs goes off full and returns empty. You are sure, as you look, that the manifold contrivances for safety and speed must have cost indefinable study. 
One of the great grievances of the pitmen is in the system of weighing. If a tub be ever so little shorit, it is forfeited. If it contain any amount of dirt, it is forfeited. Forfeit, forfeit-fine, fine, is the rigorous code, against which there is not one merciful enactment. A man rises after a day's work such that we weaklings would shudder at, and has the galling mortification to find several of his tubs put aside marked. $\mathrm{He}$ is paid by the score, and therefore these become waste labour. 'Not alone here, but in other of their pleadings, we, uninfluenced by local feelings, think the men endure wrong. 'Might' replies, we have the right; the men sign articles, knowing the conditions-poor men, mind you, who have to sign or starve! We are led to ask-To whom does the money value of forfeited labour belong? - to the masters? Have they any claim upon it? Because one man is fined, has the self-elected judge a right to put the fine in his pocket? Yes; a legal rightthe initiative of tyranny-a right legalised by the conditions which the master that is the judge frames for himself. On the simple ground of justice, this legal right looks flagrant. Tubs over-weight are allowed to pass-they are regarded good measure. It is charged to the masters likewise, without much attempt at denial, that tubs forfeited for dirt are yet continually sent off to the trucks, and sold as best coal. Very hard, it seems indeed, that workers in dead gloom, with but the flicker of a tiny wick to let them see the darkness, should have to cut Antonio's 
flesh to the weight of a hair; if in excess to lose considerably; if in default to forfeit all, and this without Shylock's scales. The design appears to make the men send up invariably over measure for safety's sake. This is a special injustice, not universal. Collieries in other parts tempt the miners to send" up good measure, by striking an average for the fortnight from the weight of a few promiscuous tubs. It would never do to weigh all. The browman cries, 'That tub's mine,' or, 'I claim that tub,' and it is weighed. The tally shows to whom it belongs, and the average of two or three during the term decides the weight and payment of all. This seems fair play. The men demand it; but the system here denies it. Could not then the forfeit account go into a general fund, for allowances to the injured and sick? Even were it to pay for a yearly feast, in lieu of increasing dividends, the wrong would cease, the company woulds not suffer, and the men would be better pleased.

The constant plea is, that the system requires it. System anywhere is more easily acquired than broken through. It gives a prescriptive right to any amount of wrong. How does it speak for British naturethat nature boasted the most generous in the world -and therefore of human nature, that system seldom or ever mistakes its side, but chooses the side of selfishness! Quite against the expressed feeling of the age is it that unqualified rigour is a good means of improvement. Granted that the men are reckless and wicked; will care for themselves or sympathy 
for their taskmasters be of spontaneous growth, or ever be, while the lash is the single source of encouragement? These very men we have seen in earnest at their meetings, uttering good sentiments amongst much that was crude, and displaying, in a united and hearty condemnation of one of themselves, who had been imprisoned for tampering with a lamp in the pits, that they were not so sublimely indifferent to danger.

Two rookmen or browmen are engaged-one by the colliers, one by the masters - to look to the tubs. The men's man would let all the tubs pass, but the masters' has of necessity a sharp eye. Were he not to mark and keep the tallies back of a good many tubs, he would soon hear that he didn't pay for his salt. He pounces upon a suspected tub, weighs it, the men's man by; the two, exponents of mutual distrust, representatives as much as Topsy and Eva of distinct races.

Pits are in every direction-coal above, coal below. Valleys between the coal-hills are filled characteristically-a score of vehicles, tumble-down, home-made carts, drawn by dumb donkeys, and more patrician blind and lame ponies, wait their turn for a load, or half a load, according to the horsepowers employed, to be retailed in penn'orths and two-penn'orths to the poor of the town. The tradesfolks are of both sexes, and of all ages under their majority. Scanty shirtage, and display in nether parts of what little they do possess, give presump- 
tive proof of ties of blood between some of them and the pitmen. Great commotion of wheels, and ropes, and steam and people, testifies where the pit is. Tubs or baskets go up and down rapidly. An iron hammer pulled from below, gives a two-tap intimation to the engine-tenter of the slinging of every full basket. Now and then, in the course of the day, three taps are heard, announcing, the overlooker says, the rise of a man. And it requires this certificate from him; for the first time we saw the basket come up after the three taps, we did not believe it held men, but live coal, moving, and big, and queer-shaped, but real coal.

So much for my lords, now for my lady miners. 'Is that a.woman?' said a lady on our arm.- 'No, you silly creature,' we replied, with wise rebuff.'I do believe it is,' said she-it is so hard a thing to convince a lady of folly. Her persistence led her to be conqueror as usual. Yet was there reason in denial. Nothing but a flat sort of thing, which my lady called a bonnet, but as little like one as the fashionable bonnets of the day are, distinguish women from the men; and in one or two cases this was off; perhaps, however, they might be told by being grimier. Tugging hold of the baskets as they rose in quick succession, their brawny arms, and necks bare and dirty, and their legs stretching out like men's, they urged the trucks along. Lusty, fine young women, some of them, better able to use a 'pick' than their spouses. One such woman 
we have seen, now landlord of a public-house, who used to work down the pits, and who, when the law interfered with her rights, bade defiance to it, and, changing her bonnet for her husband's cap, and his place down the pit for her place at top, she would get out double as much coal as he could.

Father, mother, and children will work together at times, and not have a shirt amongst them. Trousers and coat are the same for women and men, and both alike tattered and dirty. Without exception, they look the roughest and rudest beings earth could produce. Molest them, and woe betide; leave them alone, and you escape with a stare, or a sample of Attic. Yet we have learned that they appreciate an unobtrusive word of kindness, and will return an answer intended to be polite. There is hope in the trait.

\section{$\triangle$ DESOENT INTO THE ARLEY MINE.}

Amongst the most celebrated of the collieries, are those of the Ince Hall Coal and Cannel Company. According to an elegant coal-pitter, whom we heard debating at a monster meeting "whether we shall have a strike,' the current topic at the approach of winter, 'Wiggin is th' main 0 ' th' tree from which all th' tother branches, such as them about Hindley, Ince, an' th' tother places, springs.' Whether right in his philosophy or not-and these roughs do get an odd practical knowledge of the earth's crust, defiant perchance of Lyell's Principles--there is round. 
Wigan sufficient to feed, and to spare, the inquisitive taste of any one bent upon testing the Lancashire geological map. The Arley Mine is the deepest of her coal beds, being about 250 fathoms; the shafts passing through other coal strata overlying. It is enviably rich in its deposits, and as unenviably celebrated in the annals of mining catastrophes.

Immense coal mounds, like the tumuli of ancient wars, cover the whole space claimed by the Ince Hall Company. One side the canal, so laden with barges and so black its water at times, we might regard it as liquid coal; the other side, the railway, so supplied with trucks, we might think coal its whole concern. Between the two so many coaly operations above ground as to take up a great deal of room; so many coal pits, coaly mounds, coaly people, coaly donkeys, carts, ponies, and other coaly things, that we can think, feel, see nothing beyond coal. Environed with coal, we seem to absorb its substance; we have nothing to do but with coal, we lose the outside world, and ourselves change to coal. Coaly overlookers tread about with dignity, ordering their black servants to attend to their duties, or scolding them in a louder key for neglect, as if coal were what they were all born for, and they could think of naught beside. The feeling is infectious, for could we believe that any one worker let a fancy stray, we should rebuke him as though the company were comprised in our worthy selves, and we had received the damage. 
Offices distributed over the coaly ground are also coaly. All, all is coaly, but a radiant old gentleman in one of them, whose genial countenance beams, as he makes us free of any part of colliery, atop or bottom. Gathering our wits together on the weighing machine sunk in the ground before his office, and in fact fixed with trams for the trucks; each in its course to the railway indicating its weight on an index inside the office-gathering our wits, we say, for it is so long back we have lost them again, we are troubled how to proceed with decorum, and doubly troubled with such a bathos to a tangled sentence.

Scramble up the loose knobbly mountain, and stand upon its brow. Hie away, or over you go. Here comes a tub of coal, and here another, and here another. Women nor men heed your broadcloth. On at full speed, like mad engines, full dash down upon you, and it is but by a dexterous turn the driver saves you from demolition. Before you have uttered your thanks, you have got in the way of another, and yet another, and the cry is, 'still they come.' You are in danger of losing the few senses left you, when a gentle pull from the manager puts you in a safe place. Numerous people are about, and the women look queerer than ever; every one is so agile and busy, that each might be taken as the personification of the county.

We peep in upon the ponderous engine, and directly a loud, not unpleasant voice is heard, exclaiming, 'Come in, and have a good look.' 
The chief good look inside is that of the jolly 'engine-tenter.' His rosy face is dimpled with goodhumour, while his sparkling eye, looking everywhere at once, tells us we have already gone wrong, for we obstruct his view. He stands high-priest of Eolus, his temple open to the winds, so that he may observe both fore and aft, through the open window, the slightest signal at either pit. It puzzles us, as well it might, how he knows precisely when the rope has reached the bottom, but he points to an index, and says, 'Just you look.' The signal calls, he starts the engine; the rope travels out of one window and comes home through the other, while the index hand moves round with a tick, tick, tick, till it strikes a sonorous spring, and the engine is stopped.

'It isn't at the bottom yet,' we cry- for he hasn't been half a minute.

'It is though,' he answers. 'Look!'

A cage of four tubs has risen at one pit, and the rope is deep down the other. Each tub holds six cwts. Such is the celerity with which the work is done, that when we turned to the tubs again, they have vanished, empty ones having been wheeled into the cage; the signal is caught, the engine reversed, and in precisely the same time a like cage rises at the opposite pit. The index hand touches the little spring something like a thousand times a day, but without it, the engine-minder says he could tell to an inch when the cage was down, so perfect has the practice of years made him. Thus were our 
fears of bumping when we descended quietly allayed.

'That's the great wheel to wind the rope round, is it?'

'Go up-go up and look, sir,' says the same jolly voice; 'only don't tumble in anywhere, because you'd spoil the engine.'

Thanking him for his saving clause, more friendly than complimentary to our prudence or skill, up we mount the steep stairs, to better survey the ropewinding. The gigantic fly-wheel whirs and whirls at a rate to produce a gale. Two deep grooves in its circumference pay out and take home respectively the rope. With a ton and a half to lift from depths compared to which the look-down from St. Paul's golden cross to the Wellington crypt is only a fourth part, you may venture upon guessing that a stout rope is wanted. Moving upwards at the rate of ten miles an hour, tow would get such a tug as to break by mere torsion. Wire rope has come into common use, and this at the Arley Mine has to be platted and bound into a band four inches broad. Well tarred in its whole length, it crackles and uncrackles an accompaniment to the wind music of the wheel. To work the two pits, the engine is of 60 horsepower. 'Good morning, hearty friend; you are a true Cerberus ; but we need not puzzle you with such far-away comparisons.'

Near at hand, a sccond engine pumps water out of the mine. Leviathan boilers, four of them forming 
a phalanx, hiss from their safety-valves and stop-cocks, puffing like the frog in the fable, though more resembling the bull in unwieldiness, in their vain efforts to burst. Another office is the lamp-house, where every man leaves his Davy after work, and returns for it before half-past five in the morning. It is necessary to place strict watch over careless men, and to bind them with rules of the utmost stringency. Every lamp is numbered and locked, the lamplighter keeping the key. He trims the lamp, and lights it, and locks it, ready for the pitman, but none are given out, and no men are allowed to go down the pit, a minute after time. Hundreds of lives depend upon the secure fastening of the lamp. Yet the devices to take off the top, so as to get a better light, or to draw the flame through the gauze to light a pipe, are too ingenious for such a cause, and would bring fame to the American picklock. Heavy fines and prosecution are certain, yet hardly a week passes without a foolhardy delinquent.

A wooden affair on the Brow has so peculiar a look as to excite our curiosity. It is long, and covered with a box-like body, whose interior rumbles as if in pain. Underneath there appears to be a screen, through which coal dust is falling in thundershowers. We jump down to prosecute researches in the pit, when one of the roguish, independent, carefor-naught fellows abashes us with this libellous judgment of our motives-' The young woman's down there; you'll find her t'other' side.' 
But we pursued our aim, and found that the box contained an endless chain, or Jacob's Ladder of small scuttles, such as ballast-heavers use, which in their revolution scoop into the coal and fill, rise to the top, and empty over the screen. That which slides down is the best screened; the produce underneath is small coal or slack for the furnaces. Lucky is the cotton-master who has a pit of his own to supply him with slack for engine food, saving him the cost of coal, and ridding his colliery of waste and valueless dirt.

At last we are looking over into the depth of darkness, and watching the cage descend; weighing the necessity of descending too, much as a schoolboy weighs his jalap; inevitable while we shrink. Going so fast, the cage is quickly lost. It is not long getting a quarter of a mile down, and as the tubs are traversing a thousand passages below, there are ever waiting four tubs at the bottom, ready for ascent. Before we have had time to wonder, the rope moves a moment slowly, then at its proper speed. Tubs are up again and off, empty ones are on, and down they go. Up and down, down and up, continually; multitudes of men and women wheeling off, and returning; all these things assist to explain how coal rocks, so many and huge, were ever formed, not, like their fellows the Pyramids, one brick at a time, but by four tubs. We can better comprehend the aspect of the canal, of the rail, of the colliery as a whole; of a magnificent trade so peculiarly English, both in 
staple and value, amounting to near 70,000,000 tons a year, and to $15,000,000 l$. or $16,000,000 l$. sterling.

Our introduction to Dobison, the underlooker, is laid hold of by a grim blackamoor, whose fingers instantly made our carte-blanche piebald.

'Hast thou seen Dobison on the Broo?' he inquires of a mate.

' $\mathrm{Na}$ ', is the rejoinder of a fellow smut.

'I thinks he be gone doon,' he says, turning to us. 'I'll jist go and look; stop thee 'ere.'

Think but of his 'jist go !' No fear, good fellow, of our leaping after thee; we'll stop here.

The cage hung for a moment quiet, and then suddenly let the adventurer go flop. So strongly did it associate with a more ignoble exhibition, that the sight caused sickly giddiness. Leaning over tho scaffold, we watched him long, long, long, like an arrow shot down. Darkness reached, still down, down, down. Man, cage, Davy twinkle, all were lost; only the speedy rope could be seen piercing at a mighty depth the pitchy black abyss. Not like rope was it, but as a stiff endless lance penetrating the lower world, and resistless as the lance of great Michael. Down it still went. Twice the time had passed of his keeping in sight, time lengthened out as in waiting for the hands of a watch. Deeper, deeper, deeper. Is there no bottom? It stops.

What a breath, almost as deep as the deep pit, while we wondered where the man could be! Giddiness was relieved by the gasp. What a hole for a 
man to dig! Who first thought of going down there to see what he could find? The rope moves once more, then starts up silent, with a swift sweep. In a minute at the top, with two boxes of coal and two live men. Our grim attendant had jist fished up the underlooker.

We loiter on the top, arranging for the final leap. It is but a step, and down we go. There is reason for hesitation. But a short time ago the very iron flags, now our cause way, the platform and apparatus near, were blown uy by an explosion of fire-damp. Through miles of pasiages below raged the devastating blaze, searching out with dire precision the drifts where solitary mien one moment were working in health and vigour, the next were dead. Eightynine mangled bodies were brought up to light. Imagination, says a friend, an eyewitness, could never paint the picture, and remembrance of it will haunt him as a horrid dream for ever. This, too, was a second explosion within twelve months, both equally fearful and fatal. One old woman had three sons down the pit at the time. She was wailing in agony and suspense, for she had lost a son in the first firing. Her three sons were brought up dead. Mutilated bodies, and parts of bodies, scorched and blacked, as to be indistinguishable, lay scattered in every direction. Wives who would not be comforted, sisters and brothers, in one loud wail of woe. Did they then show they had human feeling, outside as they are of social sympathy? Widows and orphans, in 
the lowest depth before, have seen since then a lower still, for misery and want find many lowest extremes before they end in self-oblivion. With this remembrance of these dread events, we step upon the fated plank. Now we dangle between heaven and earth; our men instructing us in the Freemasonry of 'footing,' before they let us down, though really we feel to be on no fair footing for the nonce. Swift the descent, but, swift as it is, it appears a long time to hang at the end of a rope, much longer than to watch others down. Easy gliding and silent, so well is the gear greased, yet at the sudden motion our senses grow giddy and sick, and our throat is rather choked. So gentle is the progress withal, that trepidation soon ranishes, and except some degree of swimming-in-air-like sensation, we feel as bold as a miner. Looking up, there is the mouth of the pit, a speck of light like half a crown; and then that is lost. In total darkness, we feel the motion as it were upwards, and cannot persuade ourselves we are going down.

The glimmer of the Dary deepens the gloom. Down, down the abyss, and still deeper down. Trickling on the moist walls we hear the water, and can even distinguish a pattering like rain-drops on the stones. Consciousness grows that we approach our journey's end, and have reached the top. Thinking thus, we look skyward, and get welcomed with a shower, an initiatory rite, which falls upon our eyes and neck more gritty than pure water ought It makes 
us suspect our personal beauty at a discount since the glass flattered us at shaving. Voices are heard before we land, and a moment after, lights and grim goblins await us, and we are in the Arley Mine. A roof of rock protects us from Lancashire skies, but the cold rush of damp air down the shaft is more pitiless, if possible, than the county climate. Such thickness of impending earth to weigh upon our mind, is more than any one could bear. Fancy digging a hole upward!

'Well, Jem, how art thee getting on ?' says the underlooker to the 'fireman' he meets.

'Weel, weel, I ha' sen' oop fifteen.'

'An' how many more shall tha' send up to-day?'

'I doon noo, they bean't a workin' mooch, an' its reck'nin'.'

'Well, Jem, I have brought thee a gentleman to see thee at work.'

'Hopes the gen'leman will ken this is a dry place.'

'Oh, indeed,' says Dobison; 'you must wait till you earn it.'

'Ask us when we get back safe,' we add, 'and we won't forget you.'

Our lamps have to be trimmed at the underlooker's office, a hermit's cell cut out of the rock, but inside as cosy as Friar Tuck's, when he was alone. A table is there, and so are seats and a fire; a barometer hangs on one side, and the officer has hung his up-stair clothes on the other, 
While various kinds of lamps are getting ready, we listen to a practical lecture on their varied merits. First comes our old friend Sir Humphry, most extensively used even now, almost to the exclusion of patent and improved successors. It is a simple cylinder of gauze, with brass top and wick lamp at bottom, both carefully locked. Though it gives but a feeble light, it is safe. Desiderata of a new lamp are, more light and equal safety. Our guide issues forth with a Davy. He puts into our hand a beautiful lamp of Smellie's, but his caution to be 'very careful' betrays misgiving. Very thick glass surrounds the flame, and the safety gauze is fitted above and under. The light is bright, and all that could be desired; but glass is treacherous. A current of cold air would make it fly, and against this its thickness is the opposite of a safeguard. An unfortunate blow with a pick is less to be feared than the casualties against which caution is of no avail. To make up a trio, another in company lays hold of a third lamp. A large bull's-eye lens sheds a strong light from it, but, unfortunately, several feet farther off from the miner than he wishes, or, if it shine upon his work, he must put it inconveniently far off. Sir Humphry is not yet superseded, and the problem of a better lamp being yet open, our readers may make their fortune by solving it. The officer's lamp is lined with glass, not to give more light, but to prevent pipes being lit by the flame drawn through the meshes. Were it not that you 
are getting peevish at the time we keep you gossiping, we should like to tell you about these meshes, how many can be allowed to an inch, and so on, but the philosophy of it is too lengthy.

Our mine branches north and south. The south workings follow the dip of the coal, descending five inches to the yard, for a distance of half a mile. The north workings are the scene of the awful calamities to which we have alluded. Curiosity tempts us to the site, and we trust to time and inclination for an after view of the deepest parts. The underground map corresponds pretty well to north and south; we shall understand both by fairly examining either.

Odd appointments we. think some, so far out of humanity's reach. The high road for 100 yards is lit with gas, which, as full moon down here is not seen, is always alight. Choking up the gangways are trains of tubs, and, scrambling out of the way of these, we get muddled amongst the ponies that brought them. Ponies? Ay, there they are, and their stables, and the ostlers, all with duties allotted. Clear of these, the way is easy to pay our respects to his mightiness the Furnace. Somewhat out of order, as our route would guide, but the magnate plays so important a part in the economy of the mine, that neglect would be unpolite.

Of the road ask for no record. A coal-mine is not the place to feel quite at home in at once. Doors opened and shut, and we passed through vaults very 
dry and dusty, and heard the air rushing through the passages with the force and noise of torrents of water; and we put our hands in apertures, and felt a hurricane sweep by, the thickness of a frail board off; we found a clock, too, in the corner, to register the wakefulness of the night fireman, who at regular intervals has to point it, and we were ushered through a spacious, warm, brick-built tunnel, and saluted the guardian of the mine. It is a fire! blazing away, without stint of fuel, a lurid intensity of 140 cubic feet or thereabouts. It has an opening nine feet wide, it rises two feet high, and goes eight feet back.

'How is she doing this morning?' the underlooker demands of another Jem.

Jem is a lusty fellow of six feet, and announces in reply, that 'She ha' been dooin vera weel a' the mornin'.'

This is the whole contrivance for ventilating the mine. The fiercer the furnace, the greater the current, and the fresher the whole rnine. Air heated and rarefied at the fire passes rapidly over into the 'upcast,' and seeks the firmament. Cold air to supply its lack comes by way of the downcast, a monstrous stream of 130,000 cubic feet a minute, tested by our conductor's anemometer. Before it reaches the thirsty furnace, it has to travel through ten miles of passages and crannies, going in and out and round about the point, but intent upon it, and coming to it at last. But, upon being devoured, the 
air rushes the faster the nearer it reaches destruction. A mighty bellows it would be to give the mad, pealing tornado that thunders past into the ever lurid jaws of the living thing before us.

As the fuel burns down, it is pushed back, and fresh is built up in front. Smoke mixes with the heated air in the upcast, but passing first over the fire, and then having to ascend so enormous a vent, it becomes mostly consumed, and never reaches the top. The stoker tells us, however, that it had been smoking at top pretty well just now, for he had been piling on coals for 'ever so long.'

There is an old joke about sending coals to Newcastle, but it sounded much richer to hear of coals sent down the coal pit. But the Arley Mine coal, though of the best quality for household use, does not serve so well for the furnace as an inferior sort; so that the rook before the fire, the reserve for its future need, has presented the odd sight of full tubs going down the shaft.

At the time of the 'misfortune,' as the guide always calls it, the furnace was blown quite away. That such a mass of brick-work, firmly buitt in the earth, could be torn out, indicates the exceeding fury of the explosion. This would not occur again. The furnace has becn made to breathe part fresh air direct from the downcast. The half explosive mixture of gases, compounded in a long journey through drifts and openings, is walked up by an air-course over the fire into the upcast. 
Obeisance thus made to the tutelary of the mine, we are free to prowl into its deepest recesses. Groping back to the highway, through currents that ought to blow off the possibility of danger, we make a start in earnest. We linger at the last light, as it were parting with the last of our earthly friends. So evident is the advantage of gas forced down, that we would willingly have its help all the road. But Dobison is inexorable. He bids us say good-bye to daylight. However, signs of an up-stair world are not altogether exhausted. Here is a bench, where, we are told, the 'firemen' examine every lamp before its owner is allowed to pass on to work. Early in the morning three firemen stand under these vestiges of gaslight, and to them each collier gives up his lamp for inspection. Nor is it a mere glance they receive; every minute mesh is scrutinized. Then, for fear any man should slip by (many a one would if he could), another officer awaits them at the first door, to give each lamp a final examination.

All these precautions, instead of helping us to realise the presence of danger, more completely banished the thought. Verily, we would, with the temerity of a pitman, have tried the effect of taking the top off our lamp, the risk adding a zest to the feat. Our habit aforetime had been to condemn the men, but the peculiar reckless feeling that stole over ourselves left room to consider and palliate them. Had we essayed a philosophical experiment, to which 
we were as sore tempted as sometimes at the top of a mountain to one of another kind, you would never have been told of our hairbreadth 'scapes from heights and depths. Be ye duly thankful. Codes of law, of pains and penalties, of Draconic rigour, have been passed at various points, to terrify the miners into carefulness. Foremen over districts are employed, whose sole, and simple, and not easy duty it is to keep a close eye upon the men.

Tunnels, as yet, have been lofty and broad enough for a coach and team. Double lines of railway make it easier for the tubs than for us, and an immensity of brickwork gives a secure aspect to the walls and roof. Tubs of mortar, in some places, are as numerous as the tubs of coal. Brick-work is daily in demand. Such security is little sought in small concerns, but in a mine meant to last many years, the underlooker is sure it pays best in the end.

The last relics of civilised life now disappear. WA reach a wooden door, where our guide's voice acts as open-sesame, and an old man is found behind, bent double with age and rheumatism, whose form, rather than visage, enables us to recognize a wretched cripple we had often seen in the town, hobbling along on crutches. He had been a man-o'-war's man, but was a collier before and after. He was eling out the huge pension granted to a common sailor by the exciting duty of tending this door-a human springbolt. Before daylight till dark at night, he spent his life down the pit, an almost perpetual night, for the 
Sabbath was really his only day. Bent dorible, crippled, rheumatic, friendless, seventy-two years old, existing in a coal pit, seldom breathing a sumbeam, without hope of better things, this old man liked life.

The door has its counterpart, a few paces on, even to the old attendant. Our underlooker employs these ancients in preference to boys or infants. They prefer it before the Union, and he renders his mine securer than it would be with giddy children, who cannot feel the importance of keeping the doors shut. Without these doors, the atmosphere would rush across into the nearest path to the furnace, instead of walking its proper course through all the intricacies of the workings, and the extreme drifts would be deprived of air. Gas would of necessity soon accumulate. Beyond the second door, the current is split into two courses; we take but one.

'How art thee going on?' the underlooker in a constant, kind tone of inquiry, asks of the men he meets. There has been a delay of the gang of tubs at a bend from the main road, or jig bow, as we are taught to term it. An examination in rapid Lancashire, which Tim Bobbin could hardly follow, ends in the acquittal of the men, who prove the break-down an inadvertency beyond their control.

Between the plates of a railway tunnel, we stand a good chance of being run down by a train. Sounds of a locomotive in the distance, and soon after the sight of a lamp, warn ns to step aside. But which side? Are the laws of the road the same in the 
realms of Pluto as in Victoria's? Our leader goes forward, unconcernedly, and not till the last minute tells us to move aside. He hails the coming train. The engine resolves itself into a pony, the bull's-eye into a safety, and the engineer into a tiny urchin, seated as coachman on his box. His arms swing aloft, and his heels kick the tub. Fearless and happy as Murillo's Beggar Boy, he gallops by, and whistles as he goes for want of thought. The burden of his lay changing in view of the officer, 'Ching-a-ringorang-outang ' turns to 'Gee-ho tchick!' at which the pony pricks up.

'Hoy! hoy!' cries Dobison, as he plays a tattoo upon the last tub with his measuring-stick. Some long coaly is stretched out at full length on the top. 'What art doing there? Thou knowest that is not right.'

The voice is one that the man knows too well when he is doing wrong. It is one of the finable offences. As the pony canters away, the man whimpers out that his leg is hurt, but the incredulous 'humph' of the underlooker causes us to suspect that the man has made a mistake. Compunction would not visit every miner, though he did play such a trick.

A little way farther, we encounter another gang. For all we could tell, the boy might be the same, for he was doing the same things, and in all the glory of 'coachee' of the old London stage. This past, we are in danger from behind, but knowing at length the rules of the whip, we can safely choose our side. 
Full half a mile we have to waddle, as well as we can both sides at once, to keep clear of ponies, and full tubs, and empty ones. On each side of this long tunnel we trace the coal, though thick with dust, in a four feet seam, the middle part of the wall. The coal has been got out, and the roof cut away above it, and a warren or roadway under it, to make a passage big enough for ponies. Expensive work, but our leader still assures us it pays in the long run. Men must otherwise have been the only ponies, and their labour would amount to much more in a very few months. Enlightened as four-footed ponies must be that never see light, except when they are taken poorly, and can't enjoy it, yet they cannot be taught to travel with bent knees, as boys (and girls once) were learned to do in a three or four feet, or, miserable beings, as has been known, in less than a two feet seam. Be the pony pace the rule to go by, we should pronounce them as merry as their young drivers. They gallop in the dark as if they were doing nothing uncommon. Were we a pony, we fain think we should prefer being always poorly.

'Why do you call it a jig bow? Bow or bend is easy, but how about jig?'

We are led to ask this at No. 2 Jig.

'Don't you see, sir, the full tubs as they come down the incline $\ddot{j} g$ up the empty ones. There is a pulley at the top of the jig, and the rope goes round it, up and down, on either side.'

This knot undone, we start afresh. Ever and anon 
we pass a spot about which the guide has a little history. That was formerly an air-course, but the last 'misfortune' tore the solid brick down, blew off' the doors, and made ruins of the whole. This was an opening with doors once, but is bricked up, to prevent the current of air being too much split. It makes the journey farther round into the ' return,' but it lessens risk from inattention. Then we arrive at a new air-course, strongly arched masonry, over which traverses, for strength's sake, an inverted arch, the path of return air. Part of the tunnel, with smooth, strong roof of 'blue metal' or hard rock, upholds itself. Elsewhere shaley shivers cover the path, significant of a rotten ceiling. Other parts are supported by timber, great trunks of which are here and there cracked across, like sticks of firewood upon the housemaid's knee. Enormous must be the force upon blocks of wood standing upright, and no more than from four to six feet in height, and thick as a man's body. Nevertheless, it is not the pressure of the roof, we are informed, that performs such startling work, but the rising of the warren, or ground. Well may we imagine the ground to be elastic, relieved from the superincumbent weight of centuries of fathoms and of ages of solid rock.

'It is a long lane that has no turning.' This is a long lane with three turnings, and we have reached the last. Who wants us now must inquire at No. 3 Jig. We "were beginning to wonder when we should get to the men at work, but Dobison gizesses that we 
prefer going to the extremity of the mine, and has brought us to the last jig. A minute, he says, would have taken us amongst the men, up either of the others.

Pony work ends at the jigs, and ours begins. Hard as was stepping into dust ankle deep, over shale, and shivers, and sleepers, clearing ponies, and trains, and tattered coachmen, it is harder to bend double, as we travel quite as bad a road. Pained beyond endurance, we soon complain. About a mile up the jig, though Dobison insists that it is exactly twenty yards, we come to an opening. By the same authority, whom we are in a mood regularly to disbelieve, it is four and a half yards wide, and goes back thirty yards. Wooden posts support the roof as far in as our lamps carry our sight, but ' we won't go up there-that drift has been worked out;' so says Dobison.

'Is there a place to stand upright in there?' we plead on behalf of our poor back.

Discouraging is the rejoinder, and a little querulous, we plagne our guide with, 'How long is this to last ?'

'Oh,' says he, 'this is about the highest part we have to go in ; you'll have to stoop all the time now.'

What a malignant answer, only fit for a coal-pit; but if se can't stand, we may sit, and e'en we do. Black is the seat, but so is it all, atop, afoot, on either side. Coal but lately got out sparkles on the walls. In the main road dust from the ponies rendered it dubious whether coal surrounded us or not. 
There is no doubt, here, except that the shining surface might well be of rarel, richer gems than coal, for their ten thousand lustrous scintillations are worthy the halls of Eblis.

Our resting-place is well chosen, for we tread a dip of the seam, but only of a few yards, and all to be dug out in time. The dip terminates in a fault, and the coal rises at a step to its former level. These faults are numerous; but this is so small a one, that we can trace it out with our Davy.

Another mile, or as Dobison will persist, another twenty yards, we arrive at a second opening. Every like interval brings us to a drift, or working-place, till we are stopped short by the uncomfortable belief that the guide has shot ahead of us, and got lost. We may as well confess that our concern was not wholly for him. Toilsome and slow our steps, and too surely do we learn that more haste is less speed, for a careless swing of the lamp, in the effort to catch up, puts the light out.

Let us off our reflections, in ' darkness that could be felt.' Forgive 'us, too, if we cried out, rather aloud, for our conductor. Coming to our aid, we found it was not distance that hid him, but a tarpaulin, fixed from the roof to the ground, a bar to our further progress. The underlooker's lamp shows that this bodice-cloth extends up a drift, leaving only a narrow alley aside the nearest wall, for the air to walk through.

'Le' us turn in here,' says Dobison, and we turn 
in. The thoroughfare leads us to a scene only to be found beneath the world. No German picture of Gnomes in the depths of the Black Forest, and under the mountain's base, hammering for unholy and ungeological treasures, could be more ludicrously terrible than a north collier, with his wedge and sledge hewing out the coal. Here was a young, heartybuilt chap, naked down to the loins, of the texture and colour of his work, driving in an iron wedge, to separate a luge bulk of coal. His strokes went fast and furious, till the block fell, and he had earned a moment's reprieve. His 'drawer,' a fellow stout and strong, though but an epitome of the master, was still more simply attired. A skin-tight suit of black, which Stultz could never have done in broadcloth, did credit to his own artistic skill. Clogs, and a girdle about his loins, the band without the leggings of a pair of pantaloons, clad him, and finished his getting up.' Nothing could be easier and simpler for wear.

'Is all going well with thee?' demands the same suave voice, which we can hardly admire enough, and which must make the officer a favourite amongst these roughs, despite the power he wields.

'Ay!' Jack replies ; ' all right.'

'How many tubs hast thee filled?'

'We've sen' awee fort'n or fift'n this mornin'.'

'And how many more shalt tha' send?'

'Doon noo, I'm sure, It's reck'nin?'; we shall loose SOCn: 
Dobison's eye has detected something out of order. 'How is this, Tom?' turning to the drawer, and pointing to a safety-lamp hung on the point of a pick. 'Thou know'st this is wrong.'

'On'y put it there the moment afore tha' came.'

'It ought not to be there at all, you know.'

'It hasn't done any harm.'

'No, but thou never know'st when it might. Thou know'st the pick might fall, and make a hole in the ga'ze. Tom, I shall fine thee.'

'I've workit in the pit ever sen' it was open, Mas'r Dobison, an' hev ne'er been fined yet,' poor Tom grizzled out.

'Thou'rt not going the right way to keep from fines now, Tom.'

If it be true what the man says, we almost hope Dobison will let him off.

'Now,' says he, sparing us his attention, 'you can see the use of this cloth. It brings the fresh air to the man working,' and he held his lamp in the current to show the draught, and, 'walks round, carrying off' with it all the gas from the drift.'

'Hast thee seen any gas lately, Jack?'

' $\mathrm{Na}$ !' is Jack's laconism, as he pursues his work.

Dobison tries his lamp in all the chinks, but fails to show us any gas. He lowers the wick to the tiniest flame, when, if there were but a small quantity, it would ignite in a pointed red jet above the wick, but this test fails likewise. He says, we might without danger light the lamp here that has gone out; 
. 


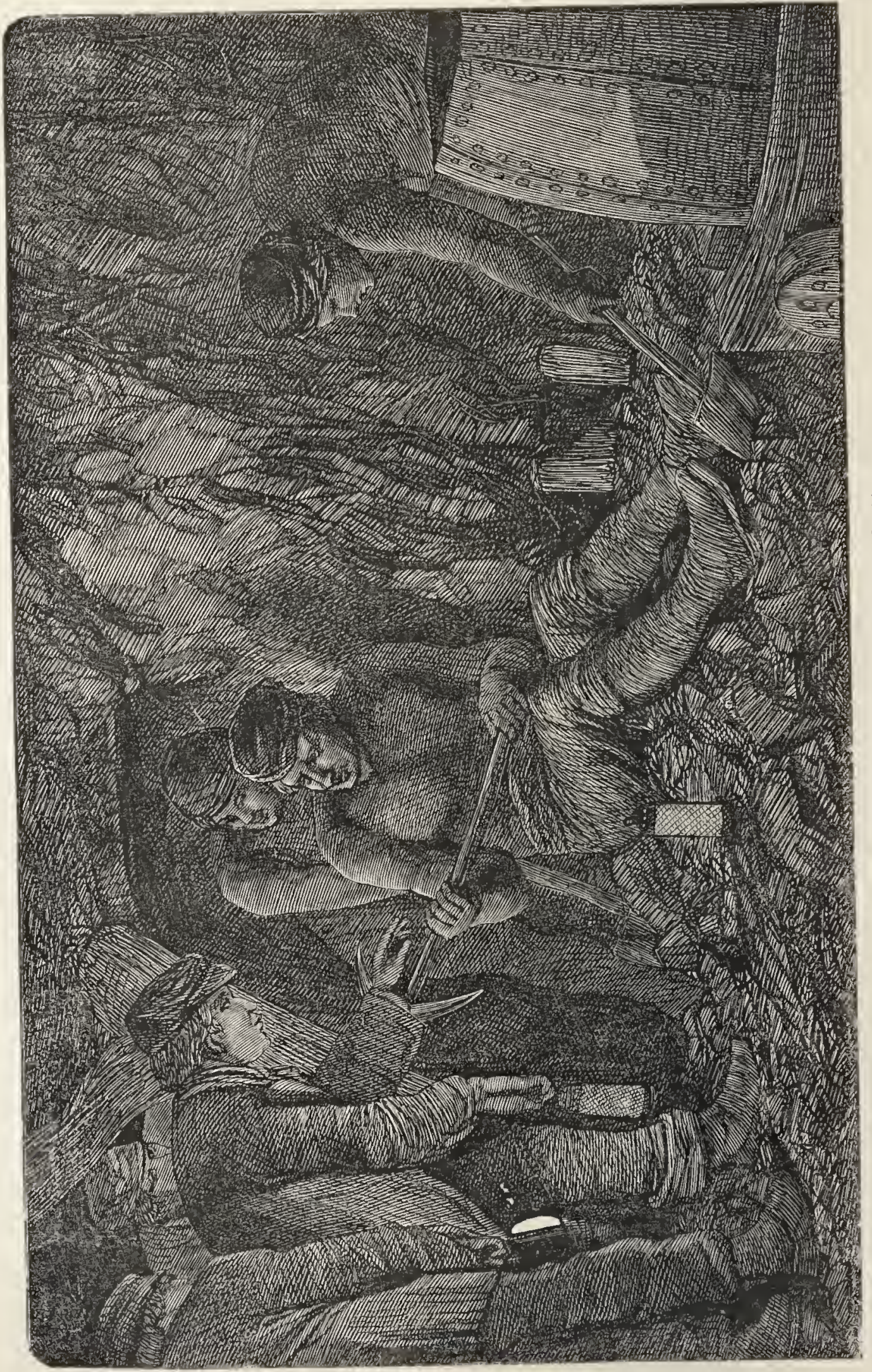

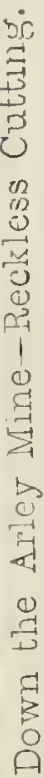


notwithstanding which he won't yield to our request, and do it.

Round the cloth with the return air, we travel back to the jig. On the ascent again, we by-and-by approach another bodice-cloth, and alley, but this time lift it up, and creep under into the easier road. Much the same scene is enacting. Lines of wood uphold the roof its whole depth. Rails are laid down even to the man at work. A tub waits to be shovelled full by the drawer.

'How long must it take them to accomplish such real tough work!' we wonder; and wonder still more, when we learn they can do it in a month-more than a yard deep a day.

A black stalwart man, above half naked, as before, and two sturdy youths in still simpler drapery! So warm has the mine become, that we think the black, close soot, sole privilege of the collier and of the London 'sv-e-e-p!' really is "as comfortable as any costume we could devise. Indeed, as far as is decorous, we essay it. Doffing cravat and throwing open our bosom, add to comfort, at the cost of a future investment in soap.

'All going well with thee to-day?' the watchful and anxious officer asks as usual.

' Ya!' says the man interrogated.

'Thee ote to ha' a prop to that 'ere piece o' coal; tha' know'st a man was kilt th' tother day, through th' same neglect; tha' ne'er can tell when 'twill fall.'

Our leader uses strong Lancashire or English, as 
feeling prompts or occasion requires. His man has undermined a monstrous block, and cut in deep at each side. Rather than lose time, for mere life-sake, he stoops every minute or so, to drive another wedge and another blow. He, like the rest, has excuse ever ready- 'There are no props sent down.'

'That won't do,' says Dobison; 'I saw them a minute ago.'

'Well, then, the drawer told me so,' he pleads, unwilling to be in the wrong.

Dobison knows his customer, and will not let him proceed, till he has made a place to fix a support, and has sent for props.also for the roof, which has extended far beyond its proper limits. Our instinct makes us creep back. The roof looks tottering, as though some heavy lumps would dearly like to tumble, and cracks are heard with every blow of the hammer. We remark to our leader, 'It would give one an ugly knock, were they to tumble upon him.'

'Thee'd ha' thout so, if thee'd seen all that loose stuff come topplin' down th' 'tother day without warnin' us,' says the man, who clearly had taken little warning from it.

Just such as these are the risks that lead to more fatalities than do the awful explosions, that carry off their hundreds at a fell swoop.

Our course for a time is the repetition of these scenes. We wall with the air up Canvas Alley, turn round with it at the end of the drift, try the force of the current, now feeble, though not from the 
bodies and breath of the men, and test for gas. Each drift suppilies us with an incident.

At one place our leader is the first addressed.

'Hast te brote some moor men to work, Mas'r Dobison?"

'I have brought thee a gentleman from London to see thee work,' Dobison tells him.

The fellow turns round, with grinning white eyeballs and teeth, and says, 'Tha' maun tell th' Queen, when tha' go'st back, how we work'n, and sen' her to du some of 't.'

'No, no, man; all to their trade. You would beat the Queen, or Prince Albert, or any Londoner.'

$\mathrm{He}$ is not a bad fellow, take him altogether, for he shows us how the coal 'grows,' and where it is still ' growing.' He has a better notion, however, of using the pick than of the familiar relationship between a Londoner and his Queen. He is a dry son of the dust like the rest, and does not fail to intimate a word about 'beer.' 'Dobison will make that all right,' we assure him.

Drift after drift like this, at last our aching spine feels irremediably bent, and we experience such cricks in the neck, that the thought of it makes them come again. Near three hours have we explored these dark coal cellars, and not got through one district. Stores, indeed, there are for all the engines of Lancashire, and some to boot for benighted London. Mostly we find the men working as if they meant a good reckoning, but in one or two instances 
they were indulging their 'smoking time ;' not that pipes are allowed-it is a criminal offence to light one; but that they rest, and would smoke, and designate the time as they would like it to be, regaling on the bare imagination of a feast.

'How much further have I to goo ?' one of these indulgents wanted to know.

'On'y three or four yards, Sam; but thee'lt ha' th' same a good while, the rate thee'rt workin' jist now.'

The underlooker had measured each drift with a rod as we passed up, and was always ready to encourage the men with their progress.

'Would the gentleman like to dig a bit of coal?' Sam innocently asks.

We know the fellow's move, but, willing to favour him, take the tool, and carry off a trophy, part of the base of the Parish Church, as we were told afterwards, more than a mile and a half from our descent.

'The gentleman knows that apprentices pay footing,' the sly dog now adds.

We submit, asking him, as he pockets the largess, 'Is it proper to pay footing twice?'

'Oh, no!' says he; 'you needn't pay anywhere else.'

'Because we paid down the Cannel Pit a week ago. So give it us back, please.'

Sam actually allows the lawfulness of paying twice; at any rate, his only restitution is a grin. 
'I want to come to-morrow,' is his next remark, as if he didn't mind work in the distance. 'It's no use our playin' us.'

'Well, thee can come and get some coal if thou'st a mind; thee't not obliged to keep't Reckoning Saturday.'

' Yx, I know that. I shall tumble into bed directly I loose to-day.'

'But won't tha' wash thyself, Sam?' we ask him, rather astonished.

' $\mathrm{Na}$ ! not I. If I du that, I shall goo out. What's use washin' to coom down 'ere to-morrow ?'

'Ah, but Sam, how'll thy wife like that?' laughingly asks Dobison.

'If she ben't use to it by noo, she ne'er will be,' he philosophically answers.

May-Fair ladies, are you taken aback? Who will be the collier's wife?

When a man has done his thirty yards, he has to begin an opening at right angles to his drift, to form a communication with the next. Owing to the narrowness of these openings, being only half the width of the drift, it is far more tedious work for the men. They are paid two shillings a yard over what they earn for the coal got out. The work completed, there stands a solid mass of coal, twenty yards by thirty, and four feet high. These are the 'pillars' left standing to support the roof, such as we read of in accounts of coal-pits. If the mine were laid open to view, we should see them placed geometrically 
exact along each jig. It is the surveyor's work to do this, and he maps out the mine as skilfully as an estate above ground. Our guide himself seems as well acquainted with the nature of their plans as the best of them could be. He is never at a loss to tell us precisely what part of the town is direct above our heads, though the passages undermine nearly the whole of it. But so tremendously deep are the workings, that the surface level is never affected. A fall of roof could not shake strata 500 yards thick. Out of proportion altogether are these massive pillars to the passages round about them. It is about the same to a coal bed as the perforations of worms in wood with the dry-rot. When the mine is filled with them (and it is quite a relief to hear that they are not waste), they themselves will be dug out, the men advancing backwards. Far greater danger there will be then to the men, who fill the old passages as they retreat, with the rubbish they can collect, and complete it by letting the roof fall in.

A goblin company are we, making out this map. Join us in fancy, while with weary back we squat upon the loose coal-heap in a drift, and help the man and the guide to make a comical trio.

Jack, of course, is a character, as have been all his mates. He works, while the perspiration steams through his black jacket in a cloud, nor is he going to give over yet a bit; for, when Dobison asks him about reckoning, 'he won't keep it, not he; he's lost quite enough money lately in play. I mean to cheat 
somebody out of five pounds by next reckonin' or two,' he observes to us, half in soliloquy.

'Nobody will trust thee, Jack, depend upon it,' Dobison tells him.

' I'll do it, for a' that,' says Jack.

'Who art tha' going to cheat-not me, for certain?' says Dobison.

"Why, the beer-house; they have had my money, and I'll have theirs.'

'How'll tha' do that, Jack?'

'Why, I don't mean to have any more.'

'That's good,' we interpolate; 'but you should have left it off, not be always meaning to leave it. Cheat the beer-house as much as you like.'

'I ha' left off for a fortneeght, and haven't had a drop.'

'Hast thee signed the pledge, Jack?' says Dobison.

'Ya! I have, and mean to keep to't.'

'Well, we must bid thee good-day, Jack, and hope thee won't break tha' pledge.'

'Hope the gentleman,' Jack responds, 'can spare a shilling to buy a loaf?'

'Surely tha' can't want a loaf, Jack,' says the underlooker, becoming spokesman for us; 'thee must be saving money; and we can't give thee beer, for tha' wouldn't drink.'

Dobison tells us, as we go off, that Jack is a bit of a scapegrace, and will be, without doubt, found next, day at the Black Horse. 
Enough and to spare have re endured of stooping; to satiate the most cringing soul. We beseech our guide to give us the nearest chance of standing erect. He therefore takes us by cuts which we would not venture upon alone, and not long after lands us in the pony tunnel. Fresher breezes chill while they refresh us, and we willingly close up our throat again. Not to go back wholly the same road we came, he turns aside by roads better known to him than to us, beguiling us with most melancholy reminiscences of the great misfortune; how it spread through all the parts we had traversed, and pointing out spots where the poor victims were discovered. Most affecting, too, were some of the incidents. Dobison himself lost a fine boy, and we fancy that it is the recollection that gives a gentler tone to his speech. In a dark passage he takes us to, he says, 'There, upon that spot, we took up a poor little fellow, who came to, but had no knowledge of what had happened. He was asked about his companion, and he pointed out where he waś, as he said, "asleep." But it was the sleep of death.' We cannot leave the mine without viewing the spot where the calamity had its origin. It is at present deserted; no one has worked in it since the fire. To reach it, we have to unbolt doors, whose rusty locks evince their little use, and pass through complete devastation not yet touched or remedied. Without association of any kind, it would shock one, so blasted is its aspect. It is the haunted part of the mine, given up to the 
spirits of the departed. Scorched and blacked, though the fury of the misfortune was over in a few seconds, the marks of its power are visible in sooty floor and ceiling, and in walls, surface burned to cinder. A bodice-cloth lies on the ground, but rather what was a bodice-cloth, for now it is fragments of tinder. 'Here,' says Dobison, 'the man sat waiting for his blast to take effect; he had just fired a shot, and that must have gone off at the moment a gust of gas was passing. He was found blown many yards distant, dreadfully mutilated. Few, comparatively, were killed by the actual firing of the mine. The horrid choke damp that always succeeds a fire was the really fatal enemy of life. This was proved by the places the bodies were found in; for, burned and mangled as they were, it was evident that many had tried to make their way out.

Dreary are the histories at the underlooker's command; they add horror to the place. Yet there is an infatuation about the scene-we persuade our guide to try here also for gas. Ventilation now is so complete in every part of the mine, though the return air is vitiated like the atmosphere of a crowded. room, that neither gas nor damp can be discovered. Particular states of the weather in the world over us influence the generation of these gases. On other days, so Dobison says, we should not find it hard to meet with some gas. Since the last firing, it has been made penal to blast for coal. The men are paid higher rates for wedging and hammering, to 
make up for the loss amount they get. Plenty of them would 'fire a shot' to-day, if allowed, and plenty would be found to fill their places, if they paid the penalty with their lives. Gas is capricious in its appearance, sometimes coming in a sudden whiff, sometimes hanging about a corner for days. The miners are required to cease work when much is seen, but they will occasionally persist, while their lamp is filled with flame, and even till the gauze becomes red hot, and would but little longer be a 'safety.'

Our route is nearly ended. Recovering our feet, we go groping after our leader through a passage so warm as to make us expect the fierce face of the furnace to show up. Nor are we far out. We light upon the top of the hot enclosure, a platform smooth, slippery, and warm. We pass over, and breathe from a yawning gap such sulphureous and tormenting fumes, that but a little spice more of imagination would peopie it with 'horrid shrieks and sights mholy.' It is the smoke of the furnace and the return air mingling to ascend the chimney. Up this chimney we can see but very little. Laugh with us, that Dobison asks if we will ascend it! Hark! Surely the earth is a capital conductor of sound! Why, we hear the noise of the steamengine? Not so, says our conductor ; the engine is itself here. The steam is made above, and comes down this pipe; the warmth of the upcast serves for a wrapper to retain the heat. Attention called to 
the pipe, we feel it too hot to touch long; though it has descended so far. It leads us to a cabin near the upcast, where we find a steam-engine usurping pony work for the south districts. It winds 800 yards of wire rope, and draws a long train of laden tubs at the end.

Dobison's argument that the upcast is warmer to ascend needs no confutation. We accept it, but are more persuaded to try it by his assurance that he likes it best. There is a good deal of under-talk amongst the men as we prepare to go up, some of which would need interpretation.

'Oten't we ha' the ponies 'ere, Jem, and set 'em kicking?' says one.

'I think so,' says Jem; 'the gen'leman oten't to go up without the reck'nin'.'

'Don't be alarmed,' Dobison puts in, coming to the rescue; 'the gentleman has made that all right.'

'Oh, has he?' says Jem. 'Where does his honour put up ?'

'All right,' chimes in another. 'Where are we to goo? the Swan or the George?'

'No, no; the gentleman stays at the Royal,' says Dobison, elevating his visitor to an hotel that has received special proof of the coal riots, because, and only because, it is chief of the district. ,

Our return earthwards is warm. Vapours of carbon and sulphur stream out as we pass the furnace gap. Respiration is not easy, though our journey is. Up, and up, and up, with a surety that 
we are all the while going down. By the time we reaci the bottom, we find ourselves atop; our valuable life preserved to society, and we brought to believe, after all, that Lancashire is a fine place. Glorious is the burst of sunshine that gladdens our eyes, more glorious is the verdure and foliage than ever we yet allowed. Elated with beauty so long hidden from us, we cry the county's pardon for ever decrying her. People we pass reciprocate our delight, for they look at us as though they too were full of enjoyment. Reaching home, even there every one appeared buoyant with mirth. Rather dirty from our tour in the coal cellar, we hasten our ablutions. But the scene our glass reveals! The élégant who stepped so gaily forth this morning has changed condition with a sweep. It was a mistake to dress for the occasion. A bath restores us to comfort, and to our senses. The enjoyment of the people had been at our, cost. The sunshine we admired was but murky daylight beautified by senses irnmured for many hours in the dark. The lovely landscape was Lancashire, and the verdure was more scant of green than of Lancashire rain and smut. 


\section{5}

\section{'A SUPERFINE ARTICLE:'}

A GLANCE AT THE WEST OF ENGLAND WOOLLEN TRADE.

Vistrons to the West of England, as often as "they have whisked along the 'broad-gauge,' have had their sleepy eyes brightened, and their tired frames refreshed, with the scenery between Swindon and Gloucester. From London onwards, the country is pretty enough, but unstriking. Where the South Wales line branches off, it enters new and original scenery. Hilly woodlands take the place of meadows; rocks and trees grow more and more imposing, till the guard cries 'Stroud.' At this point a landscape may be glanced up, fairly vying with the most noted spots of English beauty. A lengthened, irregular vale bursts upon the eye, and transfixes the beholder with admiration. The mountainous sides are clothed with foliage to their very summits, except here and there where the rocks peep out, or where roads have wound themselves, or where many a great, white, square, many-windowed building has chosen a deep ravine over which to rear its hoary head. Huge things are these buildings, but, having the grand and 
sublime all round them, they look but pigmy light chalk rocks, to stud and diversify the scene. The beauty would not be complete without a river, so a river is here too. The Slade, or Stroudwater, twines and wreaths itself along like a silver eel. At every short interval of a mile or more it has a progeny of streamlets. These are always in the neighbourhood of the white buildings; and, what is very curious about them, they are of as many colours as the fish in the Arabian Tales. In one place we see a pool of milk, as white as any in the cheese island of Gulliver. In another place is a stream of indigo blue. To-morrow our eyes would open wider still, by finding the milk changed to red ink, and the indigo to yellow or green wash, fit for a water-colour artist. Where the tall factories are not embellished with these ornamental waters, another kind of decoration is in use. Over the grass grounds, lie bleaching and drying thick layers of snowy wool, making the spot wear quite a wintry aspect. Adjoining fields are crossed with lines, from which hang, what we rashly pronounce, blankets. The colour would lead us to such a thought, but seeing what extensive blankets they must needs be that stretch from one end of the field to the other, we fain call our judgment back, and believe the hangings to be undyed woollen cloth.

This is the secret of the whole: We are in the centre of the woollen trade of the West of England; the former staple, and an ancient branch of England's 
great doings in trade. Though cotton has outrun woollen, yet the value of the last is more than $25,000,000 z$. sterling every year; and it employs more than 300,000 of our people. Stroud, and the adjacent 'Chalford Bottoms,' together with Ebley, and other towns in the immediate vicinity, have long been famous for their broadcloth productions, not only for the texture, but also for the brilliancy of the dyes, a quality which they owe, it has always been thought, to the water of the streams that run by the mills. The Yorkshire market has gallantly combated the superiority of the west in both particulars for a good many years, yet, in the public mind at large, a 'superfine wool-dyed West of England broadcloth' still bears the palm.

Our curiosity had been excited many times over by the sights which our carriage-window had revealed to us. We had often wished to arrest our locomotive, so that we might enter more into their details. The hive-like animation of a busy community we knew to be always interesting. Here, in addition, we could get some of the most romantic scenery in our country, disfigured, as minds akin to the place would say, by ugly invasions of stone and brick. Emblems of the age, they peep into the most secluded spots, with maiden modesty at first, but creep on surely as old Frost himself, till they steal the green banks of the rivers, and split the rocks that stand in their way.

One fine morning we had an opportunity of grati- 
rying our wishes. Behold us, then, stopping at Stonehouse, on the route for Messrs. Marling's mills at Ebley, the most extensive works in the district, if not in the whole western trade. By the gond offices of a friend at court, we had assurance beforehand of a ready admission. One of the managers received. us with courtesy, and supplied us with an antiquated cicerone. From his age, you would think he had grown up with the place; he would have been a capital subject for the Archæological Society to descant upon. Old Peter (if we remember right) told us he had been at his post a long time, and that he knew every stone in the place; and we did not doubt him in the least. He was a little thin fellow, but nimble withal. He proved his knowledge of the 'stones,' and his agility at the same time, by scrambling up the steps leading to the wool-sorters' room. Not to be outdone, and exhilarated by a real autumnal morning, we were at the top as soon as the old man. There is such a plethora of work in the factory, that much of it, without special arrangements, would ooze out at the windows, which are placed, seemingly to aid such an operation, so thickly side by side, that very little room is left for the bricks and mortar. Out-buildings, therefore, like limpets to the rocks, attach to the main building. In the wool-sorters' room, our senses are regaled with the sight of many large baskets, and with the smell of strong greasy wool. The man in charge of the room appears little enough affected, for he is the 
Leartiest specimen of an English workman that wo have seen for a long time. We address him, and he immediately becomes full of explanations and instruction. As he stands before his bench, which is covered with wirework, like a bricklayer's screen, and picks the wool apart into its proper qualities, he tells us that there is a great deal of fat and dirt left in the wool after it is washed at shearing time. To get these impurities out, is the next process to sorting the wool.

'Now, which would you think is the best quality of these two sorts?' asks the man, putting into our hands the sorts named. Having pulled out each sort in turn, like a connoisseur, we very knowingly pronounce for the last; for, as we said, 'there are so many threads in that.' - 'And that's just why it is the worst,' the man answered; 'that's about the coarsest quality we have; and the other, where you can hardly see the threads, because they are so fine, is the best.' Failing so wofully in choosing between the very best and very worst, we gave up the task of discriminating the degrees of quality into which the man was sorting the wool before him. Out of one heap he made seven. Spreading out the wool on the wire bench, the dust passed down into a kind of bin, while the wool was separated as fast as we could have taken up handfuls of it from one of the baskets. The best wool comes from Germany, we are toldstill a great source of our yearly supplies, although we have lately heard so much of Australian wool. 
England produces about 1,000,000 packs of wool annually. We import about 100,000,000 lbs. More than half of this quantity, though not the finest quality, comes from our own colonies. The wool from Silesia has the pre-eminence over all the rest. Even to our unprofessional eyes, the sample shown to us looked beautifully fine, and felt silky soft. That wool, the workman assures us, is worth half a guinea a pound; and it will take two pounds to inake a yard of cloth. Think of that, ye exquisites! The coat on your back, before it has endured one of the inflictions of manufacture, to cost at the rate of one guinea a yard! Our preceptor, interested in the eagerness of his pupil, is next anxious to show us some wool from the Cape, but fails in finding a specimen. We go off, therefore, as the wool itself does after sorting, to the cleansing house, leaving, without more than a passing glance, the stores of full sacks in an under room, where a capacious area holds them as they come from abroad, till the imperative voice of the sorter above calls them out to daylight and to usefulness.

In the cleansing house, a man has under his care an enormous boiler, from which is rising a fragrance most abominable in volumes of steam. A cold-water bath is also one of the appurtenances of the house. Everything that comes under the influence of the vile decoction in the boiler must find the bath a requisite. The man is now at the copper; let us watch his doings. Over the boiler is a board made 
of cross pieces of wood, like an area grating, or the foot-board of a bath-room. He takes out a soft, greenish mass of queer-looking. stuff, which we are still told is wool, and lays it on the board. Having heaped up enough to drain for a few minutes, he goes off to the cold bath. He clearly has not a moment to spare. Wool is in the bath also. In the boiler it rolls over and over, and moves about in all manner of ways, of its own free will, as though it had really determined to get clean. In the water it is knocked about by the labourer's long but narrowpronged pitchfork. He dashes to and fro, without mercy for the wool or for himself. When he has knocked it about enough, he takes it out with his fork, and forms a heap of white, clean washed wool. This, when drained, becomes the fleecy coverlet to the grass plots. The boiling took out all the grease; the rough usage in the bath has made the wool quite clean. The bath emptied, it is replenished again from the board over the boiler. Just as we have seen the complete cycle of operations in the cleansing room, our old friend from the sorters comes running up to us as fast as his rotund geniality admitted of running. He had found some Cape wool, and asks our opinion of it. "Why, it is all matted, and full of hair,' we said; 'it is in our opinion the worst we have seen.' We did honour to our teaching, for we were quite right; a fact that pleased our teacher and elated us. 'Cape wool always has some hair in it,' he continued; 'it is not of good quality, 
though seldom so bad as this sample. It is almost black now,' the good man proceeds, 'but when it is washed, it will be so white you wouldn't know it again.' With that he pulled a handful out of the pile of the washed wool, to show how white he meant. 'The washing does not get the bits of stick, and things of that kind, out,' we remarked.- 'No,' says the man, "they have all to be picked out by hand. Come this way, and you shall see.' With this we go off to another part of the premises, where we find a row of women, seated at benches, hard at work, picking away at the wool, till the baskets at their side are filled with a clean and clear substance, ready for any after operation. Machinery has been tried for this picking, but has not yet superseded hand work; nor does it seem likely soon to do so, for the pieces of dirt are so irregular in size and place, that only the hand yields enough to all the inequalities.

We beg pardon of our venerable guide for leaving him in the back ground, when, as the leader, he ought throughout to have been foremost. He replies to our question as to what is the next, sight to be seen, by leading us along a dark lane, the thoroughfare to a gloomy apartment, where dwells an old woman, and a queer-looking piece of apparatus. The wool picked and cleaned as we have seen it, is brought here. Nothing is going on for a moment, and we wonder why the old woman has her mouth muffled. In a little time she begins to feed the machine with 
wool, and immediately we hear its masticating organs at work. The digestive powers of this great boxlike machine are only limited by the quantity of food given to it. And no wonder; for, while we look, behold, the wool fed in at the back is pouring and puffing out of the front, in large and beautiful snowflakes, which soon lie thick upon the ground. The machine is the same that is used to separate the cotton seeds from the cotton wool, but here it only tears the fibres of wool apart, and by so doing; allows all the remaining small impurities to fall to the bottom, while the now perfectly cleansed fleece is blown out in a snow-storm. If we were to look inside, we should find a drum set with naily spikes, and working in and out other. spikes or teeth set in the box-work round the drum. A most fearful-looking engine it is. We ask our old man what is its name?

'Well, sir,' he says, hesitatingly, 'I don't know what is its proper name, but I hear it called the devil oftener than anything else.'

'That's near enough,' answered we; 'for it is more like Old Scratch than anything we have seen for a long time.'

It was clear now why the place was so dark, since such a notable individual resided there. It was also evident why the old woman had her face muffled. 'Avoid bad company,' was one of our earliest text hands, so we will hasten from his sable highness. 'If' we stay much longer, more wool-flakes will get intc 
our lungs than would do us good, thus proving that we cannot associate with what is evil, without coming to harm.

We have traced the wool up to the point when, if the cloth is to be 'wool-dyed,' it is ready to go off to the dyers. We lose sight of it, therefore, for a time. The dyeing and weaving are not carried on in the same factory. Entering at last the bona fide mills, we find that the dyers have done their duty, and that all the workers are using coloured wool. All the best broadcloths are dyed in the wool; and here they produce, as we promised, 'a superfine article.'

In one long and spacious room we get introduced for the first time to the machinery. Down our path are ranged alternate scribbling and carding engines, which form an avenue, with billies or slubbing machines on the opposite hand.

The 'scribblers' and 'carders' are nearly the same in shape, but the first is much the largest. Scribbling is in fact only a preliminary carding. Both engines consist of a number of rollers, with faces of felt. The felt is covered with close short wire, like the hair of a scrubbing brush. Each roller acts as a card or a comb to another. Supplying, therefore, the 'scribbler' with the soft dyed wool, one roller directly takes it up, but in the course of the first revolution loses it again. A second roller meeting the first, but revolving in an opposite direction, neatly pilfers every filament, by combing it off the first 
roller. A third roller serves the second just as badly, and a fourth serves out the third. By the time the wool reaches the opposite side of the machine, it has been delivered from one to another of a whole series of rollers, till each fibre is brushed and combed, and made to lie evenly with the rest. It falls a broad, thin fleece or lap into a basket ready to receive it. This first carding is similar to the process which cotton undergoes. There is a similarity of flament in the two products which causes a like treatment to be pursued to persuade the fibres to lie all in one direction. To take up a cotton pod, and draw out its contents, or to look into a matted piece of a fleece, would make one despair of ever getting the fibres side by side.

Carding is but the repetition of scribbling with a smaller machine. The last roller which the wool has to pass is, however, not uniformly covered with the wire bristles. The wiry surface is divided into half a dozen parallel strips. The consequence is, that there is not a continuous delivery of the carded wool. Long snaky stivers are given off instead, and roll down into a trough placed before the roller, and of the same length. These slivers remain in the trough a very short time, for a little maiden is feeding one of the slubbing machines as fast as they render themselves. She joins them to the end of the other slivers that went before, with a peculiar twist of her thumb and finger, which we try to excel, but wofully fail in, much to the maiden's diversion, 
and not less to our own. We should fail still more wofully, if we attempt to tell how it is that a row of 200 bobbins wheel up to meet the newly supplied thread, and how they know exactly when to stop, and how the wool spins round the top of the spindle without breaking, and then how the bobbins go back again, stretching out and twisting round, at the same time, the sliver. It came out from the carding operation as thick as one's finger, and is now a slightly twisted, spongy, worsted thread, or roving. So these strange automata will keep on. Backwards and forwards, backwards and forwards, twisting and twirling they go, till the bobbins are all filled with thread. All down the long room these operations are vis-à-vis with the scribbling and carding. In such a vast establishment, the blending of processes is an important consideration. One process follows so immediately upon another, that it is very convenient in some parts of the work to have different machines near together. Our curiosity in this quarter being now pretty well satisfied, we are about to leave, but first ask our ancient, "What the workmen call the machine for filling the bobbins??

' 'They do call that a Warder Billy,' says he.

'A Warder Billy,' we muse; 'what can that mean ?' but our etymology was entirely at fault.

Another large apartment, a story higher, discloses just the same work going on as below-no end of machinery, the same endless noise of wheels, and the 
same whirr every now and then with the 'Warder Billies.'

'Oh, no,' cries our guide, as we mention the last words; "these are "Hand Billies."

'Then why do you call the other's Warder Billies?'

'I suppose it is that they do work by warder,' answered he, in the true Glo'stershire improvement on the Queen's English. 'We have some that do go by hand, and some that do go by warder, but the warder has failed lately, and we are having some to. go by steam.'

Our discovery as to the identity of 'warder' and 'water,' has not yet helped us to the derivation of 'Billy,' as applied to these machines. Perhaps some clever lexicographer can help us out. Even the other name of 'slubber' does not assist.

Now that the woollen thread is ready for weaving, we follow its course into an immense room on the ground-floor. It is a great space, filled with machinery again. We pace from one end to the other, with power-looms on both sides of our path, shuttles flying to and fro to form the weft, and the thousand threads so perfectly arranged in the loom, crossing each flight of the shuttle so as to form the warp. Each loom is so large and complicated, that it would excite surprise, and cause surmises as to its cost. Here we have passed twenty on each hand, in going up only one side aisle. Having reached the end, we stay to take a survcy. One of the most extraordinary sights presents itself to a strange eye. 
The whole space is filled with looms at work. So much movement is at first bewildering. Our wits go a wool-gathering. When they come home again, we are beset with all manner of thoughts at once. The opposite path down to the door has looms as many as the path we came up. Eighty looms on one floor, and not small things either. Each of these has its great length of black or blue cloth weaving. But eighty does not satisfy the greed of business. Twenty smaller looms are placed on each side, in open galleries, which run the whole length of the room, like the side galleries of a church. All the work at the looms is done by women. It adds very much to the curious aspect of the place to see these women. They are dressed in uniform. A blue cotton pinafore, fastened round the neck with the usual string, makes them look like great gawky girls. At first we thought they were only girls, and were not a little struck, on addressing one of them, to see her marriage ring on her blue-dyed hand, and to find that she was quite an elderly woman. Our chief thoughts upon leaving this scene were computations, which we gave up, of the vast capital sunk in a place so chole full of valuable machinery; and economic speculations upon the employment of the labour of women. A very great deal of the work of the factory is done by women; so much, it seemed to us, that we asked our attendant whether any men were employed at all?

'Oh, yes, we shall come to them very soon,' says 
he. 'Yes,' he says again, in reply to a question about the workwomen, "we employ nearly all the women about the town, and a good many have to rork for themselves and their husbands too.'

'But how is that? Can't the husbands get work?'

'Oh, yes, they could easily, if they tried, but while their wives earn any money, they won't work; they only go idling about and drinking.'

So much for the morality of the married men. We hope there is not a large proportion amongst them of the lazy' good-for-nothings.

If you think the cloth is now ready for the tailor, you are under a delusion. It has to go through more numerous ordeals than before it was woven. Broadcloth indeed it is just now, for, fresh from the loom, it would well carpet the Great Western 'broad-gauge' that runs close by. Common baize, rough and coarse, would also exceed it in beauty of texture. How it is to be made into 'a superfine article' puzzles us for some time longer.

Our leader ascends to another floor, where there is again an assemblage of machinery. The unwieldy breadth has to be reduced, and the substance has to be thickened. This is the first step towards making the coarse baize put on a respectable appearance. The fulling mills undertake the task of shrinking the cloth. Enormous tilt-hammers, according to good old fashion, move up and down at a great mechanical disadvantage, by the turning of a bulky toothed wheel, moved in its turn by water- 
power. They are called 'the stocks', and are constructed of wood. By their bulk and cumbersome aspect they get attention, much more than by the elegance of their motion. They are odd-looking, overgrown leviathans, and from their very ugliness claim inspection. Several of them tumble in succerssion side by side upon the cloth exposed to their heavy and frequent falls. But their doom is fixed. Modern craft cannot endure their clumsy style of work. Some of them have already vanished. One by one the others are going. We can safely predict a clearance not long hence. A modern method of 'milling' is gradually usurping the rights of the 'stocks.' By the improved plans, great economy of space is effected, and the apparatus is much more sightly. The cloth in these last is sewn into an endless piece, like a jack-towel, and wends its way upwards, twisting and turning like a boa-constrictor, squeezing between two vertical rollers at top, whence it descends again into a bath, containing a compound of a soapy character. Saturated over and over again with this thick mixture, it is as often relieved of it by a passage between the rollers. Whether in the stocks or in these new mills, the cloth submits to a 'milling' for many hours. Its thickness is increased by the treatment. The length is diminished by a third, and the breadth by a half. We perceive also that it has lost its coarseness. It has become a fine grained cloth. If extra thickness and strength be required, the process is repeated. 
'Double-milled broadcloth,' as the drapers advertiso it, is the result of this second operation.

The milling having been accomplished, it is as necessary to get all the soapy compound out, as it was before to get it in. Onwards we go, following the destination of the cloth, till we arrive at another cleaning-house. All the cloth made in the factory passes through this house. It is a cold, stonepaved room, containing a few troughs and tubs. Why the cleansing rooms should be filled with viler odours than any others, seems at a first venture rather odd. The troughs round about us scent the air far more outrageousily than did the boiler in the wool-cleansing house. In fact, the cleansing liquids consist of unnamable and almost unbelievable abominations.' They are far more odious in their own nature than are the impurities they are used to remove. Strange to say, all the resources of art and science cannot substitute, or have not yet substituted, any substance of a little more delectable nature than excrement, to perform the duty of a cleansing agent in this and kindred branches of industry.

We have seen the cloth woven and shrunk, and now, after a thorough washing in clear water, it is quite clean. Can a fastidious taste require more than this? Yes; you, our readers, who of course are not: the least fastidious, would not be pleased without a fine gloss upon your new coat. It is the zext duty of the manufacturer to put this gloss upon 
the cloth, or to 'dress' it, as he himself would say. Dressing the surface is one of the most curious operations amongst so much that is curious. Teasels, a large kind of thistle, are used for the purpose. The wiry sharp hooks of the thistle head (which we all well know, from schoolboy experience, to possess a 'touch-me-not' character) become an indispensable utility in cloth-dressing. We noticed two boys, when we entered the factory, busy with these teascls, fixing them in frames ready for use. By leaving a little of the stalk, they were able to fix them in rows, and, by a tap with a small mallet, to keep them in their places. The stalks, peeping through the narrow aperture in which they were fixed, were afterwards shaven off close, and the little rack was ready to go into the 'dressing'-room, and do duty there. Teasels are named from their size (so the boys tell us), 'kings, queens, middlings, and small ones.' The kings and queens are large enough to be placed side by side, and fill the frame with a single file. The middlings and small ones are put end to end across, and pressed together, taking two with their points rather overlapping to reach the frames. The teasels, thus fixed, are placed in the 'dressing' machines. The room where these machines are is crowded with them. 'More machinery; more machinery,' we soliloquize, in astonishment, although we had nearly lost our power of astonishment. As for counting the engines and spparatus, we had given that up long before. Here 
they are again all in motion. Thousands upon thousands of teasels revolving, are dressing up the surfice of the cloth exposed to their friction. As the cloth reaches the ground, small jets of water play upon it, which keep a moist surface for the teasels to act upon. Manifold schemes have been devised to do away with the teasel heads, but all have failed.

' You see,' our old pioneer says, 'when we tried wires, the points used to turn back, and then they wouldn't return to their places.'

'And will the teasels?' we ask.

' Yes, we can use them over and over a dozen times.'

The new teasels, as they are wanted, are put in at the top of the apparatus, and gradually get removed lower and lower, till, by the time they have gone round the whole circumference of the wheel, they are pretty well used up. Children pick them clean when filled with the nap from the cloth, and, when they are softened by the moisture, drying restores their elasticity. Even though serving a dozen times nearly, as the man tells us, the consumption of teasels must necessarily be immense. A procession of ten or twelve waggons laden with teasels is not an unfrequent sight in the neighbourhood of the mill gates. The number in daily use is immense. The number in store is this countless quantity many times multiplied. The store is in the open air. We are led out of the factory to a large, open, wooden erection. Ready for use, and already fixed in their frames, they are here kept in vertical racks, 
reaching a good height above the ground, like the receptacles for 'cases' not in use, at a large printing office. Neighbouring counties, more than Glo'stershire, supply the teasels. Somersetshire is one of the chief places of their cultivation. Capricious in their yield, they sometimes double or triple the always heavy item on their account in the balance-sheet of a cloth factory. When the teasel harvest has failed, from blight or other carses, they have gone as high as 4l. a bushel. Their common value is twenty shillings. No wonder, then, that manufacturers have tried hard to find some instrument less whimsical in its supply, and less perishable when obtained, to dress the face of their cloth. The achievement is not, however, an easy one. To blend, in any artificial contrivance, the beartiful elasticity of the teasel hook, which yields to the cloth without injuring it, with the stifiness and strength which render it more durable than one would think, has been, and promises to be yet awhile, unsuccessful.

Looking at the cloth after the teasels have done their office upon it, we see how nicely all the ends of the wool have been hooked out and laid straight, so as to form the nap. There is now a face upon the material. Still, it is not yet 'a superfine article.' The teasels have done their duty like faithful servants; but, though they have pulled out a 'nap' from the substance of the cloth, they could not insure that all the ends should be of equal length. The whole surface has next to be sheared. 'Is 
there really no end at all to these machines?' we mied, half in soliloquy, half to our indefatigable proneer. There was, indeed, reason for the ejaculation. Again, a great apartment astonished us with a sight of a multitude of shearing: machines. Tho first workman we greet is so obliging as to stop his work, to show us how he contrives to take the superfluous floss and long ends from the beaver surface that the toaisels made. Under his tuition, we find that the cuting part of his apparatus consists of a roller, round which wind spiral sharp edges. As the roller revolves, it presents these edges to a fixed horizontal blade. Meeting together, they act as several sharp scissors, cutting clean off anything going near enough, as tho workman satisfactorily proved by an experiment with a sheet of paper. The operative hooks the cloth with about half a dozen hooks across its breadth, and sets the machinery a-going. While the cloth passes under the cutting instruments, he, with a youthful assistant, starts to another machine to do the same things. Wach man takes charge of two machines. It is wonderiful how clcan shaved the face of the cloth is after going under the blade of this unustal barber. Somctimes the cloth is toaselied twice and sherred trice, before we have in good frith ' a superine article.'

We follow it very little further. One more rocm, and we have traced it through most of its stagas. Sevoral bic presses are giving the cloth a good squeeze, which, as if their affection were very strong; 
they will keep up for a whole day. This pressing will take out all the creases, and reduce the bulk, and leave the cloth ready for packing.

In going through one spacious room after another in this gigantic factory, we could not but admire how gradually steam is invading the domain of water-power, and of the hand. The three giants work here pretty harmoniously while they are really at it, but it is plain that hand labour is 'getting smaller by degrees, and beautifully less.' Water power, too, a big brother of hand labour, is destined to annihilation some day, not long hence; for, while it has to give constant battle to its vigorous, hissing, and hot kinsman, steam, the source of its strengththe stream that flows by-has been for some time failing. Such a tremendous place as one of these cloth factories takes as long a time to revolutionise, as Parliament to pass a Reform Bill. Revolution is going on, notwithstanding. Two great steamengines, of 45 -horse power, are clutching hold of one department after another, till some future day will hail them as lords paramount over the whole of the works. Modern improvements, unhappily, too often increase the risk of accident. It is not many years ago that the bursting of a steam-boiler tore down and laid in ruins a large corner of Messrs. Marling's mill. The old guide referred to it as a fearful catastrophe. Yet it is not in these unusual accidents that injury is to be so much apprehended. Where such a huge amount of machinery is accumu- 
lated, occasional accidents, however pitiful, seem to be unaroidable. Printed warnings and rules are put up in every available spot, which, if attended to, would doubtless prevent all accident. But it is more than we shall find or can expect in human nature, that people will be thoughtful at all times. A moment's carelessness at the scribbling or carding engines might fearfully lacerate a poor girl's hand, and the other machines in motion show no mercy towards the thoughtless, and have no pity. The machine whose name we dare not mention to ears polite, would play havoc with a limb, and tear it into sausage-meat very expeditiously. This terrible engine luckily works in a box, and we can only see its effects upon the wool, and hear its internal working.

We are now about to leave this busy hive. We have seen hundreds of 'hands,' men and women, so closely occupied, that they could not afford more than one look up, however long we staid watching their quick movements. Rambling, without question, wherever we pleased, was a privilege, as far as it gave us opportunity to make a most leisurely survey, yet it was a privilege that surprised us somewhat, for it had been whispered to us that the western manufacturers are apt to view with jealousy strangers who wish to see their works.

The picture we have sketched of Messrs. Marling's, except as to the extent of the works, would serve for any of the numerous establishments of the kind in 
Wiltshire, Glo'stershire, and the vicinity. We have been over the largest these counties can boast. There are cloth lords as well as cotton lords. Each of the mills maintains a corps of itinerant ambassadors, who negotiate with the drapers all over the land, and are the medium of communication between the magnates of the mill and the heads of wholesale houses.

As to the healthiness of factory work, we speak with feeling, yet, withal, with great difficence. Great part 'of it is done with the cloth in a moist state. The work-people, on the whole, seem healthy, except the women at the power-looms. We could not decide as to their healthy looks. Hands and faces were dyed as deep as the cloth they were weaving. Many had the 'blue disease,' and the'rest the 'black fever.' It is not possible for the various strong smells through which we passed to be quite innocuous to those who breathe them all day long. Of the effect upon ourselves, we are bound to add, that, unless we were predisposed to fever, that morning's catering for our readers' entertainment cost us sevcral weeks' inaction, too much of which was spent in bed. 


\section{HER MAJESTY'S PRINTEPS.}

THere exists not far from the spot made classic by the footsteps of Dr. Johnson, a great irregular black block of building, reticulated in a mazy network of close meshes, with blacker alleys and narrow lanes, from which issue all day long, and every day, still blacker streams of printer's ink. Like oak timber that has seen service, the spot is eaten with the torredo chambers of age-perforations which riadle it through and through, yet leave the heart of a harder and closer texture than before. For it is a heart indeed : an old centre of civilization. Its narrow, tortuous veins and arteries are the channels of light and life. At every pulsation, wisdom issues her precepts, genius distributes her gifts, intellect sends forth her fire, the comforts of religion flow. Rash people who picture royal roads and rosy paths to the seat of these blessings, learn the delusion they have cherished. If the printing craft be ancient cnough to boast a batelary saint, it is here he holds his court.

By special courtesy, we have been led through every devious way and curious cranny by the resi- 
dent spirit, whose finger sways undisputed over the busy denizens. One moment traversing an openair byway, the next we were diving down in nether darkness amongst steam-engines and workshops. Agrain, aloft, we alighted in large and airy rooms, sacred to compositors, machinists, or pressmen; ' frames,' machines, or presses. Presto, and we grew bewildered amongst a region of little rooms, and closets, and 'prentice boys. Whether photographs of the busy scenes will please our readers as much as the original did us, be it yours to decide. We will, with your gracious leave, take you a tour, and present you with both positive and negative pictures.

Join us in heart-the heart of the square of which Fleet Street and Shoe Lane form two sides, and Fetter Lane a third. It matters not at what house or block of houses you announce yourself, for every one, however far detached, has something or another to do with Her Majesty's Printers. Maybe you know the iron gate, with the royal arms gilt at top, which you pass to reach the office where acts of parliament and proclamations are retailed to liege subjects of the queen.

Contiguous to this office, five hundred craftsmen, aided by the power of steam, are ever engaged in putting into a cheap and portable form the bulky results of the six hundred and fifty at Westminster. Although parliamentary work is distributed amongst several great printers, yet so great a share comes to Messrs. Eyre and Spottiswoode, that they are known, 
par excellence, as Printers to the Queen. Senatorial wisdom, heavy enough when dropped from the lip in debate, feels still heavier when done up in reams, and pressing the shoulders of some young canvas jacket at this establishment.

If we may judge the merit of a constitution by the bulkiness of its records, then assuredly one will be convinced of the excellences of ours, by the mere computation of paper and type consumed every year. It needs the economical working of an enormous business to admit of our laws being obtainable at a cheap rate. This fact removes the appearance of an unfair monopoly of the national work by one or two great firms. Without an assurance of long-continued patronage, no firm could undertake the vast and special arrangements the work requires. Government, of course, takes a large supply of every act, or bill, or blue book. As the Treasury, however, fixes the price at which all papers are sold, we should be apt to think that the largest customer might possibly become the worst. Private demand varies according to the popularity of the subject. Local acts, which interest but few, are charged a somewhat higher price than others. Under any circumstances the sale is barely remunerative.

We will make no critical survey of this department, but pass on to the more general work; that of books and pamphlets. This is the office of Messrs. Spottiswoode \& Co. Having, under the obliging auspices of the proprietor, ascended a wind- 
ing iron staircase, we enter a room where a little hundred of compositors are amusing themselves. To one unaccustomed to see them it is an interesting sight. It is instructive to witness a large number of men working together anywhere. Similarity of movement is pleasing to the eye. So here, dipping into their cases as rapidly as a fowl pecks up corn, or Hullah's classes beat time, or we awhile ago played tit-tat-toe at school, they arrest our interest.

A 'chase' is pointed out to us, filled with pages arranged so as to fall into their proper order when printed. The type is fresh from the foundry in all its silvery brightness. Pieces of metal or wood, which the compositor teaches us to call 'furniture,' are placed round, to fix the matter in its proper position. It has also been 'locked up,' to keep every part tight. The 'form ' is now properly 'imposed,' and ready for the press below.

A short stay in the compositors' room of a great printer has an interest peculiarly its own. We get a glance at the manuscript, or at the 'revise' of some of our greatest men. To tell the truth, many of thein express thoughts far more beautiful than is the handwriting: One compositor heaped wholesale condemnation upon an eminent political writer of the present time, whose patrician scrawl and utter regardlessness of the printer's labour are the abomination to every one into whose hands his 'copy' has ever fallen. No outrageous manuscript was in tine office just then, we were told, unless there might bo 
excepted some French writing, without stops or accents, and just so legible that in English it would be anathematised. Compositors will bear us out, that it is too bad to rob a working man of his time, which is his bread. Those writers who think it plebeian to write so as to be easily read do so. It stands to reason that a compositor, paid by the number of letters he sets, loses money by bad copy; and, 'though,' as our informant at Spottiswoodes' says, 'we do get a little allowance sometimes, it is very seldom, and never anything like what we lose by it.'

Outside the door of this room are the stores of type. Cases of letter ready for use are placed in vertical ' racks,' ranged side by side, reaching from the floor to the ceiling, extending round a spacious area, filling up several unimagined corners. Tons upon tons of type are stowed away, but ready and willing at the call of any of the caterers of the world's enlightenment, to come forth and give wings to thought.

Two or three 'forms' are going off to be stereotyped. It is advantageous to preserve the means of extra impressions of a work likely to have a continuous sale-such, particularly as schoolbooks, which go through many editions without emendations or revision. This purpose is gained by the thin stereo. type metal plates, which may be conveniently packed away after use till wanted again, or multiplied in number, and transmitted any distance. The manager of this section of the works lets us into these secrets, 
while he produces a few of the new shining platesa whole form paged and arranged in one sheet, and waiting its turn in the machine-room. Other pleasant technicalities he also expounds. The racks contain every kind of letter and typographical sign used in printed composition. Less than five minutes makes us learned in the theory of 'spaces,' and ' hair spaces,' and 'leading,'--names given to the metal divisions between words and lines, and a multitude of other terms, for which we now want to look in the manual.

Typo measures his work in true professional style. Instead of inches, it is how many 'pica m's.' His payments, on the other hand, are computed by the number of ' $n$ 's' of the type he may be using that would fill a page.

'Then this is the kind of work you like best,' said we, and pointed to a page or two set up, but having about as many letters as the blank leaves in 'Tristram Shandy.'

'Yes,' he returned; "we call that "fat." It's a sort of make-up for what we have to do at other times. We don't get enough of it, or we should do pretty well.'

If the same rule obtains in the typography of the 'returns' ordered by the House of Commons, the 'bills,' 'acts,' and 'blue books,' there must be a pretty good slice of 'fat.'

' You would like all writers to have plenty of pasagraphs, and all very short ones, eh?' 
'Yes,' the man laughed; 'but we can't get them of our way of thinking.'

Typo says magazine work is very lean.

$\Lambda$ heap of loose type, we are informed, is pie-a species of aliment which makes a juvenile smack his lips, but is the aversion of a compositor. Pie, in typography, is like 'squab' in Devonshire-a mixture of everything in general, and nothing in particular. Printer's pie is composed of the ruins of a 'form;' when perhaps the work was half accomplished, an mulucky accident has upset it, and mingled the letter's, and spaces, and leads. A heap of pie is, on the whole, about as good a test of a printer's temper as any one could desire. If anything could ruffle him, it is that. Well the unfortunate wight knows the weary work he has before him, to separate the pieces one by one. It were hard to say which is most difficult, to compose the sheet again, or to compose himself.

Before the impression is struck off, very careful revision takes place. First, the 'reader' marks all mere 'literal' errors, and has them rectified. A 'proof' is then 'pulled' and sent to the writer, who, if fastidious, as most are, alters, and re-alters, and lets remain as at first, what has cost so much pains in putting together. Authors, if near when their revise is at the 'correcting-stone,' would sometimes hear worse than blessings involied upon them for their fastidity and indecision.

Low, monotonous humming and buzzmg intimate 
that we approach the 'reading-boys.' Begging one to continue his duty, he proceeds to the following effect :-

'Though a variety of opinions exist as to the individual by whom the art of printing was discovered, yet all authorities concur in almitting PETER SCHOEFFER (three taps on the desk) to be the person who invented cast (one tap) metal (tap) types (tap), having learned the art of cutting (one tap) the letters from the Guttembergs. He is also supposed to have been the first who engraved on copper plates.'

This going on in a rapid manner, with no attention to pause, and in the most grave monotony, is very comical, the taps indicating italics, small capitals or large, as the case may be. The only approach, to a rest is the lengthening out of an occasional vowel when an illegible or a hard word is coming, making a long 'the-eh' or a 'to-eh,' instead of 'the' or ' to.' For five minutes he buzzed Greek. Half an hour would have helped us less to interpret the strange sound, than the clandestine peep we took at the paper itself. In particular work, such as the Bible, when the pointing is important, commas and colons, and every other sign, are read off with the text. The introduction of 'com.,' 'col.,' 'quote,' \&c., every half-dozen words, would be very edifying to an audience.

Leaving the 'sanctum' of the reader (who understonds the boy better than we, for his corrections aro 
marked in the margin as fast as the boy can read), we pass a number of rooms ir which embryo typos are learning their craft under the care of experienced men. They are apprenticod, as usual, for seven ycars, and a considerable number of them are not, as in most other offices, 'out-door,' but 'in-door'" apprentices. Kept thus under the constant eye of the master, they grow up steady, intelligent, good men, although at the sacrifice of that liberty youths at times pine for, and which too often, with thin less-cared-for comrades, leads to dissipation and reckless irregularity. Out-door apprentices generally are paid a proportion of their earnings. At the Queen's Printeris, being in-door, they receivo their maintenance, and are encouraged to work well by a small bonus for pocket-money, upon every sovereign their work would amount to. The greater portion of their time they can be intrusted only with common work. Lengthened experience and cultirated tact alone make a good compositor.

The downward joumey has located us at length in the midst of 'feeders,' and 'takers-off', and 'machine-managers.' Presses and machines, all worked by steam power, fill another great room. Moving round from the simplest to the most complicated, we are struck with the wonderful economy of labour, and time, and space, brought about by improved machinery, all so requisite in a vast esta3.ishment like this. Evidences abound, that the progressive spirit of the age has visited this place as 
all others. The simple machines are made to strike off copies of two works, eren of different sizes, at one movement of the press. Gigantic cylinders, placed opposite, are printing both sides of a large sheet at once. No one can see without admiration the ingenious contrivances by means of which the great cylindrical engines are fod with paper, and then perform every other part of their duty in the most perfect manner without aid. Clutching the expanded sheets one after another, as fast as the 'imp ' can supply them, their greed is insatiable. Tapes wind round the paper, carrying it over and under, in and out, up and down, till the white surfaces present themselves to the 'taker-off', both sides covered with printed wisdom. Most intelligently does the mechanism adjust itself, and perform its duty.

Two boys, and a man to look after them, are required at each machine. The boys are true Londoners-rogues only happy when dabbling in dirt. Some of them are as black as the gentleman upon whom they are occasionally affiliated. To muck themselves from head to foot with ink, though quite needless, proves how hard they have been at work. They are all dressed uniformly in linen suits, some of which must provide poor old mothers at the end of the week work more troublesome than profitable. A few boys show a remarkable contrast to the others; as if with an innate sense of neatness, they keep white and clean in work that would make sweeps of their comrades. Erery boy saves a penny 
a week for his jacket, and is supplied with a new one twice a year.

Similar interest attaches to the machine-room as to the work-room of the compositors. At one machine there is a new work on which no profane eye has yet been permitted to look. Then the magazines and reviews for the forthcoming month or quarter are assuming their proper form, and we may in anticipation feast upon the literary repast in store for us. Here a people's edition is promising a treat speedily to many readers. At the next press, parliamentary papers are striking off a far less delectable diet. We recognize as an old friend our diamond edition of the Church Service. Bibles of every variety are at other presses multiplying in countless numbers.

There are two holes in each sheet that excite our notice. We are informed that pins pierce the paper when the first side is printed; these punctures. guide the lad in fixing the paper for the second side. 'True register' is thus secured-a term which our readers will comprehend, by observing how exactly the letters on one page of a volume are placed upon those back to back, on the other side of the leaf. Printing has so greatly improved of late years, that, unless these niceties are attended to, readers will grant a book little indulgence.

One great space is cleared away, and strong woodwork and rafters are being placed to accommodate a larger machine than any yet in the establishment. 
Visitors to any of the great London works are impressed with like sights wherever they go. The tendency of great places is still to grow. Messrs. Srottiswoode take in house after house, and cover with bricks every vacant space they can seize. Still the cry is, 'Room! room!' Vulcan roars and hisses with the force of twelve horses, in some Vesuvian abyss below. His grumblings are to be atcended to immediately; he has been promised a big brother of twice his powers, for society and a helpmate.

Minch of the collateral work is dowe on the premises. Several enginecrs, lathemen, and other artisans, aro employed apart from the printers. Repairs of machines, and even in good part the consbruction of the steam-engines, are under their jurisdiction.

A great coppor is parted of from the steamboilers, but yet sufficiently near to boil at the same fire, to supply the men with water for breakfast and tea. Men, generally speaking, appreciate a little, better than they do great attention in this respect. Where dining-rooms and culinary appurtenances have been prepared, they have been in a measure filitures. Not improbably this arises from the sense of delicacy which prevents men from parading their humble dimners-a similar feeling to that which prevents the poor women from using the new 'wash-houses,' choosing rather their own close room, and waste of fire and laundry needfuls, to half 
cleanse their poor habiliments. For the apprentices, special arrangements are inade, to which we shall have to allude.

Despite the extraordinary encroachments of steampower, it has not yet entirely superseded the handpress. Wood-cuts, where there are many of them, are still best printed by the last. Even the illustrations of our ever-welcome friend, the 'Mlustrated News,' beautiful as they are from their vertical machine, would be far more beautiful taken with the handpress. This could not be accomplished, for the blocks themselves are, we believe, curved now to suit the printing-machine. We bestow only a glance, in passing, upon a dozen of these presses at work in an ante-room. Wonders of the age years ago, they are now immeasurably eclipsed by their leviathan progeny.

Multifold as are tho operations we witness, it would be tiring to describe them all. The sheets are printed wet; it is necessary to dry them afterwards. A room well ventilated, and at the same time heated, is slung with a thousand lines, over which hang the sheets till they are dry enough for 'pressing.' Hydraulic presses are used for this purpose, being so simple in working, yet so powerful in effect. Alternate sheets of mill-board and letterpress are piled up in enormous columns, and submitted to pressure. After some hours they are flattened, and have received a gloss, or cold glaze. The operation is called cold-pressing. 
In preparing the paper for pressing, the samo economy of labour is seen as before. Two things are always done at once. One great column dwindles down as a workman removes the pressed sheets, and passes the boards towards his mate. Meanwhile another column is rising under the hands of the second man, whose duty consists in making literary sandwiches with the same boards, and fresh sheets from the drying-room.

There has been a cry lately of a scarcity of paper. Demand is grown so vastly, that rags cannot be procured to supply it. Those who fear a catastrophe should visit the Queen's Printers'; they would come away with a full belief that paper enough is stored up in the warerooms there to supply the world for ever. White, massive pillars of paper are the supports apparently to the ceiling. As an area for concealment, we would choose the spacious stowageroom; it would have served the 'Bonnie Prince' better than the Royal Oak. Like great vertical shafts in a mine of rock-salt, the white pillars persuade us of their exhaustlessness. Yet it is the supply of only a few months!

Paper is not so good as formerly; really good paper can hardly be obtained. Cotton is used in its manufacture, in the scarcity of linen. As a consequence, the toughness and durability of the old paper is not secured. Machine-made paper is not so good as that made by hand. For writing purposes in governmeat offices, hand-made papei is still used, Paper for 
printing is almost invariably machine-made, as is also the general run of letter paper.

Now that the sheets have been struck off and pressed, they only await a few incidental operations before they are done up into books, stitched and bound, and sent off, some to their publishers, some to the retail office, some back again to illuminate our Legislature. Great heaps successively vanish through a wicket, and are received on the other side by one who counts them off, sixty to our six. We may meet with them again by-and-by, in a small room, where a troop of tiny ' gatherers' are at work. They are gathering, at the time we look in upon them, an edition of the 'Book of Common Prayer.'

Ranged round the sides of a small room are four counters. Upon them are placed, in like-sized heaps, the sheets of the book. Each pile contains sheets distinguished by the letter which is seen at the bottom of the page of a book. Space enough is left in the middle of the room for half a dozen boys to run round one after another in an endless chase. A merry game of 'Catch who can' goes on. To prevent it being quite unprofitable, each boy catches up the sheets in their proper order as he passes rapidly round, and deposits the whole book ready for folding and stitching in a pile with others, at the end of each circuit. Quickly the sheets sink lower and lower under their nimble hands and feet. Thousands upon thousands of volumes they will make ready for the binder in the course of a single day. 
- We ought to be very good people, with so many Bibles printed for us,' we remarked to our obliging conductor.

'We ought,' is the reply; 'but it is grievous to think what becomes of most of them.' Where one does good, there are too many bartered away for frivolities, or even evil purposes. The number that find their way to the pawnshop, especially of those given away in charity, stands in array like a national crime.'

A 'collator' then receives the sheets properly arranged. By constant practice he is able to detect a wrong placement, or a double sheet, in hardly any time, and with a jerk to eject it.

Description conveys but half a picture of Messrs. Spottiswoode's; there is a moral half. Bare enumeration of facts makes one feel that there is work going on here more than surface deep. The photograph on the mind of the visitor is vivid, deep, and pleasing. We have been impressed, throughout our tour, with the quiet demeanour and orderliness, the activity and diligence of every one engaged. They work not with the hurry of eye-service, detecting the approach of an employer, but with a steady attention that persuades us of a habit.

The simple cause of all this is, that the proprietors of the Queen's Printing Office are gentlemen who feel deeply anxious for the welfare of the workers under their care. There are nearly 1000 men in all at work. In the general printing, 350 ; in the 
government department, as we have said; 500; and in an establishment a few miles out of the city, given up entirely to Bibles and Testaments, about 100 . This little community is governed by a constitution of so great a liberality, that it makes the chief appear to have advanced even upon the many laws they print. The stidy of our legislative papers has peradventure enlightened their minds and enlarged their hearts.

Messrs. Spottiswoode may be taken as a type-to speak professionally-of a class of masters quite modern in their regard for employés. They are examples of what was once very rare-eminent mastermen, who believe that their journeymen have thoughts and feelings capable of cultivation, and independent of their craft. Too few in their position are regardful of those they employ beyond working out of them what they can.

Here we may see in one part a little room, set off to contain a case of books for the use of the workmen and boys. A librarian is appointed, and a system of rules is carried out with regularity. The management is in the hands of the men themselves. Some idea may be formed of the extent to which the advantages offered by the library are appreciated, from the fact, that the present average number of books in circulation is considerably above a lrundred. The great favourites are the weelly periodicals of the best clıss. Our arts and manufactures are well represented. History and biography, poetry and travels, 
have illustrations from the pens of the most eminent men. The popularity of the scheme is remarkably great considering that novels are not amongst the books. Not that the managers are squeamish either. A better selection of books it would be hard to find. Every book is unobjectionable, although neither theology nor romance (and very properly) find a place. The peculiar propriety of the mottoes on the catalogue is worth a note. The title-page quotes Seneca very happily, that ' as the soil, however rich it may be, cannot be productive without culture, so the mind, without cultivation, can never produce good fruit.' Over the leaf we are advised, 'to make the same use of a book that a bee does of a flower-steal sweets from it, but not injure it.' Such sentence are books in themselves.

We enter afterwards a room arranged with forms and desks, and various appurtenances that appertain to a schoolroom.

All the boys under the age of fifteen employed in the office of Messrs. Eyre and Spottiswoode, and Spottiswoode \& Co., are required to attend school; 'Reading-boys' from 8 to 9 A.M. every morning except Saturday-Machine and Warehouse boys on two evenings each week from September to Mayfrom 7 to 8.30 P.Mr. The instruction is given by the Chaplain, assisted by teachers out of the establishment. The attendance is compulsory, and a fine of $1 d$. is exacted in case of alssence ; each boy, however, as a kind of incitement to punctuality and 
attention, receives a ticket for each attendance, exchangeable at the rate of four a penny, for books, knives, \&c. \&c., according to his fancy. Prizes are also given for especial proficiency. Examinations take place at stated intervals, which every boy who wishes to be apprenticed must 'pass' before he can be sent up 'to case.'

We learnt also that during the winter months, Mr. W. Spottiswoode, and his brother and sisters, devoted one evening in the week for holding advanced classes for the apprentices and others who wished for further instruction. Nor is music left out of the programme, for there is a choral society which meets once a week, and finds no lack of members to keep it up with considerable spirit.

We are pleased to find that they have in the summer-time, instead of books, a run into the fields to enjoy a game at cricket, or they solace themselves with boating. Clubs for both these recreations are established. A field is rented in the neighbourhood of Highgate for their first method of enjoyment, and many a right hearty and merry match comes off. 'But how can they find time for these things ?' we hear asked, very naturally. It was the inquiry that rose in our own mind. At the moment of asking, we were in the sanctum sanctorum of the proprietor, one of the private offices. Upon the table were heaped bags and towers of silver coin. A reply to the question came in its appropriate place. On observing the cash, our conductor remarked, 'It 
is Friday, to-day, I see; we pay the morr on Friday afternoon.'

'How do you find that answer? I was told by the chief of a firm the other day, that they had been obliged to go back to the old Saturday night's payments?

The evidence of one in the position of the Queen's Printer, and master over so many men is very valuable. It was, 'We find it work admirably.'

'Don't the men take advantage of the Saturday, and make holiday: keeping St. Saturday instead of St. Monday?'

'No,' said Mr. Spottiswoode. 'When the plan was first tried, it was announced that any man who stayed away on Saturday would be discharged; but that has been long ago forgotten; the men come now as an established thing, and don't think of stopping away.'

We have no doubt that such would be the invariable result of a fair trial of the plan. It is easy, by regardlessness of the men, to let it become a greater abuse than a Saturday payment. Wives, we doubt not, have felt the blessing of the new plan. Their partners, who could hardly be trusted with the prospect of a Sunday's leisure, dare not venture to break bounds, with a Saturday's work in view. Homes have been a comfort at the end of the week, which once upon a time were the reverse. All the arrangements for the welfare of the employed must have a powerful, unseen, good infuence. 
Where men are disposed to teach the young by boolss, they will unconsciously be guarded also in example. Where real earnestness for good is evinced by employers, it must in the end be appreciated by their men.

We are told, that during the summer the men are given Saturday aftermoon for their boating and cricket. In winter, when they could not thus employ themselves, they work on till four or five o'clock, instead of leaving off at two. This example is now beginning to be followed by the trade generally.

Winter amusements are more domesticated. Some of the rooms give evidence even now of last Christmas gaities. They are ingeniously hung with garlands of coloured paper, and with rosettes, the work of the young people, who spend a deal of time and labour upon them. Upon their schoolroom they had lavished all their constructive and decorative skill. It was, we are assured, a really beautiful sight.

During these festive timnes, one or two concert's have been got up. Everything was done in good style, we assure you, too. The library of Mir. Spottiswoode's private house, a fine large room, was used for the hall of performance, programmes of words printed off, and everything as it onglit to be. Orchestra and audience, both disposed to please, found-the one, kind critics; the other, performers in their very best.

Since the great Volunteer Novement commenced a corps has been formed, called the 2nd London, of 
which Mr. Greorge Spottiswoode is Captain-command. ant, originally consisting of men employed in the offices, but now thrown open to all young men from other offices whose time and income are limited. We were told that Mr. Young, the secretary of the corps, would give us any information, if we called at Head Quarters, No. 10 Little New Street, E.C. It appeared that several local and financial advantages had already induced persons not in the employ of the Messrs. Spottiswoode to swell its ranks, such as the small cost of the really pretty uniform (accoutrements and all only costing $3 l$.), which could be paid for by instalments, as also the central position of the drill-ground in New Bridge Street, Blackfriars. A drum and fife band. we learnt were very strenuously practising, so that they might be able to accompany the corps when they marched out on Saturdays. But the movement in these offices has by no means ended with the men-for a number of the boys have been formed into a cadet corps, and smart little fellows some of them looked in their neat uniform of gray and green.

We are requested now to glance at the accommo. dation for the apprentices.

'I am not very proud of this part of our establishment, but you had better see all.' So our conductor remarked, as he ushered us through his own private house. Whether he felt proud or not, we thought the youths must be proud of their master. After going through the innumerable rooms of an old 
English mansion, all of which seemed given up to the apprentices, we began to wonder where the private rooms were. We believe that the master has retained very little space for himself. Twentysix apprentices are in the house, and two or three are coming. Their instruction and supervision seem Mr. Spottiswoode's peculiar charge. The dining-hall of his house is arrayed at our entry with the preliminaries of the midday banquet. As the 'prentices are the aristocrats of the business, so also there is an aristocracy amongst themselves. Age as well as acquirements place them in advance of the machine boys. Social position, too, is generally very superior; some of them being from respectable well-to-do families. They do not, therefore, attend school, but, as we have said before, receive all their teaching from their master.

At the top of the house, the rooms are parted off to make a range of dormitories. They are well ventilated, roomy, and clean: so much so as to surprise ns, considering the densely-built neighbourhood. Contiguous to the dormitories, we push aside the hangings of a doorway, and enter a complete little sanctuary. Family worship is conducted here by the Chaplain before business in the morning, and before retiring at night. The tiny church must impress a visitor very strongly. We dare not doubt that real good is effected by the daily meeting of master and apprentices for a holy purpose. The place of assembly is arranged with seats and books, 
the fac-simile of a church. The service is short, but from its very nature is impressive.

Such an example is effecting a great moral change. Printers have been particularly open to the charge of neglecting their employed. Every concession of a master, we have been informed, is registered by the trade, as an extra argument with other masters, to bring about a more general liberal treatment. We regard Messrs. Spottiswoode as partial witnesses with respect to the moral improvement of the craft. Their anxiety that improvement should evince itself, and their indefatigability in bringing it about, would tend sometimes, perhaps, to make them give too great importance to the signs. Yet we do not question that vast improvement has taken place. Printers have not always been models of sobriety. Even the remarkably intelligent body of compositors have not always claimed the character. Owing to the exertions and sympathy of good masters, in a great measure, we believe, working men of any craft are a different class to what they were. The great companies, as well as the great masters, are beginning to feel that capital has duties as well as immunities. Throughout our country the feeling is spreading, that the people ought to be educated. If it be really necessary to take the young to work, it then becomes the duty of the employer to see that they are taught. We hail with pleasure such masters as the Queen's Printers. They are the pioneers of a better state of things. 
There must be, in gentlemen whose position enables them, if they chose, to dwell at ease, a deep under-current of pure philanthropy, when we find them giving up comfort for a feeling of duty. There is no glory in it. All that can be got out of it is real hard work and constant anxiety. When we hear the present proprietor attribute much to the good feeling between his father and the men in his time, and when we find, above all, that accomplished ladies also enlist in the cause, it convinces us that the benevolent spirit is common to all.

We may well conclude by appropriating a motto from the biographical section of the catalogue, which section, in its turn, appropriated it from Plutarch. Altered to make it applicable to all masters, it would run-' We fill our mind with images of good men, by observing their actions and life. If we have contracted any blemish, or followed ill custom, from the company in which we unavoidably engage, we correct and dispel it, by calmly turning our thoughts to these excellent examples.' 



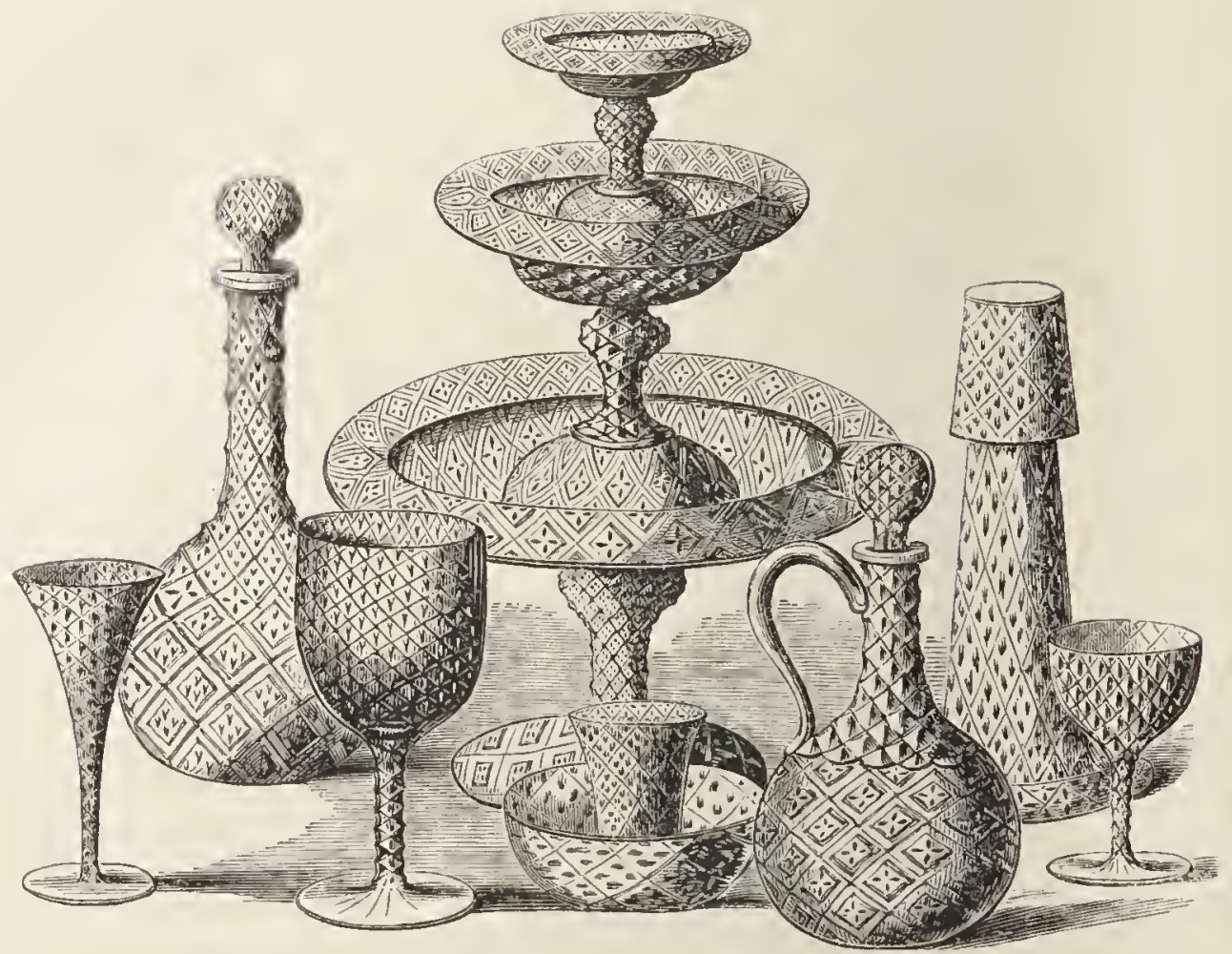

Apsler Pellatt \& Co.'s Anglo-Venetian Gilt and Frosted Giass.

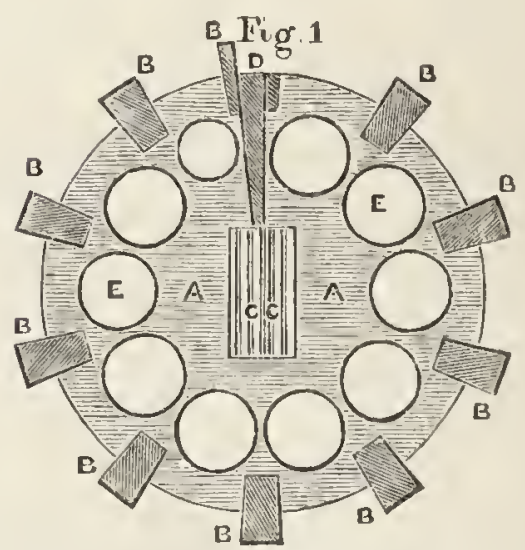

Ground Plin,-AA, "Siege" or Floor of Furnace BB, Piltars, which support the Crow u. C', Gruces. D, Furnace Loor. LE, Position of lincibles.
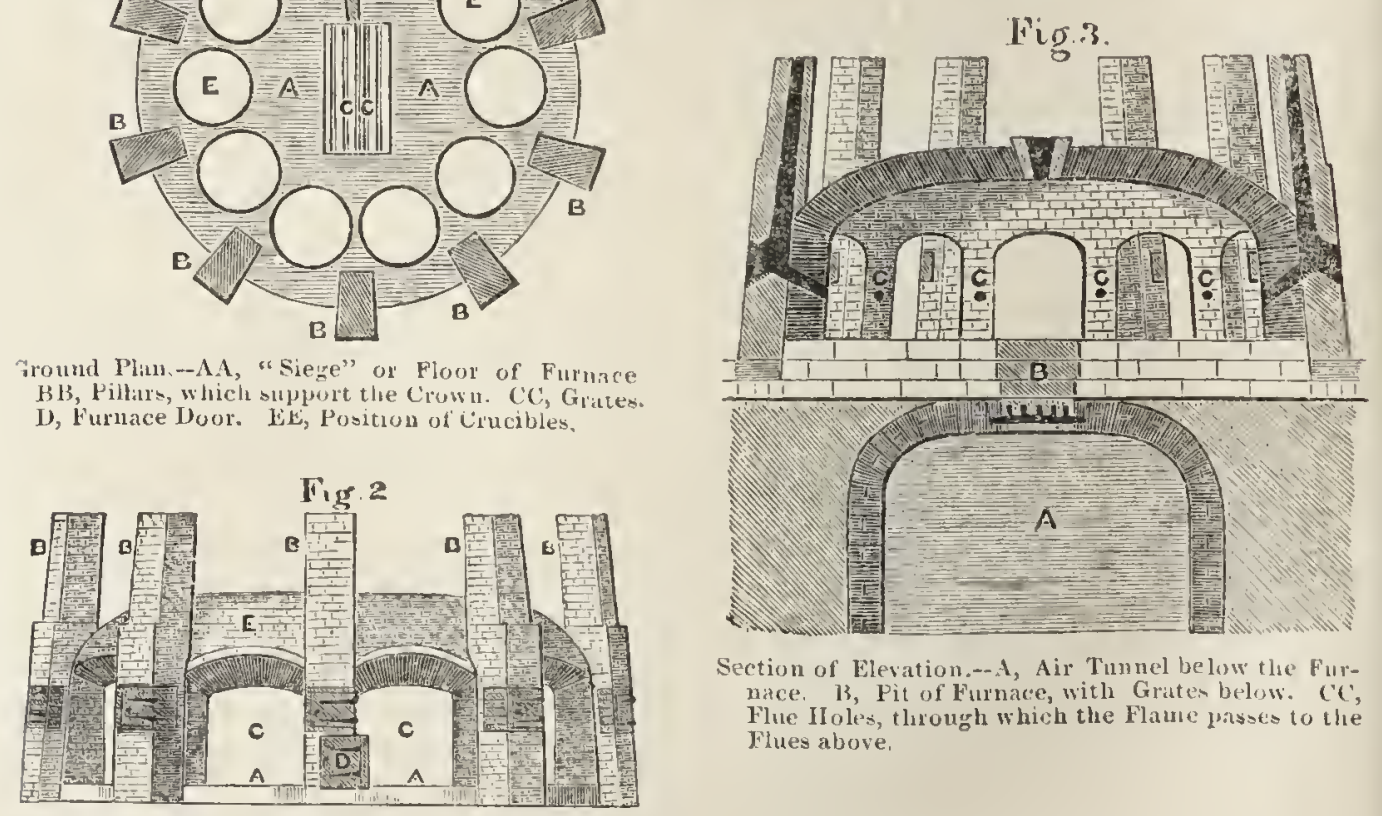

Section of Elevation - t, Air. Tumnel belux the Furuatee, 13, Pit of Furnace, with Graten below. CC, Flue IIoles, though which the Flaure pisses to the Flues above.

Elevation.-. A, klevation of Siege abore the Glasshouse Floor. $\mathrm{HB}$, Plues above the Pillat's. C', Operuings for Crucibles. D, Furuace Doot. $\mathrm{k}_{\text {, }}$ Reverberating Irome. 


\section{THE FALCON GLASS-WORKì}

IN one of the most dingy parts of the banks of the Thames is a great building, whose outside is duskier than the spot where it is to be found. Black bricks are too common in 'town' to act as loadstones, except to men in trade. We should, belike, pass by the dull corner of an out-of-the-way place, with no more to take our eye than a wall that goes round a tall shaft, like the rampart of an old fort to guard the central kicep.

The only sign outside that it is worth while to go in is the board over the door, with the words of gold, 'Apsley Pellate's Works.' We will use this door, and dive into the secrets of the place. At once we meet with bright objects. The path, on, either hand, is hung with clear shining wares, such as might have crossed Aladdin in the cave of the genius of the ring. The ground is strewed with the same sorts of things. Counting-house and counters display samples likewise. Up-stairs we go, lighted with hues of the rainbow, and on and on we pass, fearfull of damage at each step, through 
store-rooms and narrow lanes, till we reach the centre, and start with wonder. A well-lit hall greets our sight. Thick from the roof hang crystal drops, such as may be seen in the great caves of some parts of the world, but which prosy folks would call chandeliers. All round about the walls, the ceiling, and the floor, the most lustrous diamonds cluster, and send out their shoots of light. For a time we can enter into no details from the brilliancy round about. Like the sun which puts out the stars, so the one blaze hides here the sparkling points. Our eyes, getting used to the tremulous scintillations, begin to trace the walls, and look at the rich stores one by one. Join in our wonder, when the very first crystal we touch is the Koh-i-noor! Here it is, covered only with a glass shade, a solid lump of the first water, sending forth lines of fire, yet never burned up. No iron guard keeps a tingling ninger from it as at the Great Exhibition; visitors to this crystal palace are so honest, that the tempting jewel is placed close to the door. We can now boast over our gracious Queen. She (may God ever bless her !) has the precious gem in its fresh cutting, but here we view it, not only thus, but in its pristine ugliness. The little attendants upon the 'Mountain of Light,' like priceless Indian ear-drops, keep faithful service. The Koh-i-noor is itself but a trifle amongst the decorations of the place. Masses of pure carbon many times outvie this noted gem in size, and would make the queenly brow ache from their very weight. 
These, again, are only types of the treasures. Rubies and emeralds are commonplace beside brilliants which a king's crown could not buy. The facets, cut by a cunning hand, are made to cross cach other through the clear medium, so that their sharp edges seem broken, and flash more numerous rays. One eggshaped trophy of the diamond-cutter displays the genius of the artist in design, but, being in regular facets, appears as though bands went round. 'Play of light' is thus lost, which the Mentor whose beck has been our guide points out as a fault. Some such stores as these must Aladdin have had to give to the caliph, his future father-in-law, or to stud the windows of his magic palace. They increase as his did. All the diamond world is here (in copy); the 'Pitt,' the 'Regent,' and the 'Russian.' From this place came also the cases of the same gems in the Museum of Practical Geology. We begin to think that the reign of the genii is not over. Even they could not exceed the beauties above and around. Maybe, after all, it is in truth their palace. Aladdin, who sits at his desk making out bills, could feast a good party if his viands were as bountiful, and splendid, and costly, as the table services at his commaud. On his right are decanters and glasses of every fashion, to please the most fastidious, taste. Coloured glasses, so giving flavour to some wines that the connoisseur could not endure plain glass again; long-leg negus and punch glasses with a mimic bowl at the top; and others so high and nar- 
row that they seem nothing but spindle-shanks. Salts of ' prism cut,' so that the rays of light, in lieu of going through, may break upon the surface, and dart a myriad little fiery arrows like the diamond itself from every point of view; and spangling ornaments for the mantel-shelf. Some of the crystal wares are engraved, some are covered with a network of mazy line, some have curious, close spirals of two or three colours running up their legs; such would make London boys caper with joy to twist upon their palm, like a gimlet eating its way through their flesh.

Porcelain, too, tries to excel the crystal in lightness and beauty. Tureens and dishes; dinner and breakfast services; china of the finest clay, and most exquisitely painted, are piled on the long shelves and platforms, and on the counters that cross the room, and form graceful stalagmites, rising to kiss the lustres overhead. We pass up and down amongst the fragile elegancies, every moment stopping to admire a trimmph of fictile art. Plates, whose rims are the frames of artistic landscapes such as leave the studios of Sèvres; vases and urns, whose classic shapes might have been cut by the first Itruscan tools, and whose fine reliefs of satyrs and fauns vie with old camecs.

The glory of the tables is a grand cut épergne. If it were not 'very like a bull,' and, what is worse, 'a bull in a china shop,' we should call this heavy mass a light and airy vase. 
Some time ago, owing;, doubtless, to 'internal heat,' a fire broke out, and burned up everything. Time has not yet been able to restore copies of much that was lost, though good promise is given for it by-and-by. Relics of the ruin, and of the effect of fire upon some of the goods, are kept under a glass shade. So curiously are a 'salt' and a huge crystal twisted and twined, that we don't know at a glance whether fancy or chance designed them. We learn, also, that we must dive down deeper into the mysteries of the earth, before we can reach her workshop, and see her journeymen. For the porcelain, indeed, we should have to travel further than time admits. None of that is made here. It comes from the potteries of counties well known in England.

Several years ago, certain parties in London thought that the potteries might be added to our already huge trade there, and a company was formed to do so. But Staffordshire cried 'No!' and with parties who heard their doom in the project, resolved that not a pound's worth of clay should leave their district in a raw state. 'For,' said they, 'the first porcelain manufactory in London would ring our knell.' So the scheme fell to the ground. To make up for what might appear to the world an undue wish to keep close to what they had, the old potteries gave London men full leave to buy as much clay as ever they pleased after it was moulded, and baked, and made up. So the matter now stands. 
Every piece of porcelain looking so picture-like, has come by some means or another from a distance.

Prepare for descent to nether realms. We must not expect to find the scene as light and beautiful as the place we leave. But we have been so captivated with what we have seen, that we are ready to undergo anything in the desire to know how the crystal wares are produced.

Down, down, till we reach an underground passage, arched over, and black as night, with a footpath of cinders which crunch under every step. To traverse the darkness is an adventure to make one quake. We clutch our conductor's hand, and beg him to go first, for fear of pitfalls. Stooping, and taking very short steps, though the roof is not low nor the path uneven, and with the way beguiled by encouraging words, we in a minute or two notice a red glare before us, getting brighter and brighter as we near it. Our road would have served Milton for a path to Pandemonium, or Bunyan for his ' Valley,' and the fiery hue at the end would be a good aid. As we pace along, we half expect to meet some unearthly goblin, and just as we reach the fire, there are two bright staring eyes shining upon us like the ghost of a basilisk. We are sure they belong to an elf. It is satisfactory to find that they belong to a stoker. Let us rest awhile, now we have reached the central heat, and collect our wits. The passage we have come along is only one of several that reach to the outer world for the supply of air to the fire. 
The fire is above our heads, on a grating of straight bars of iron, which move apart so that the 'clinkers' can be poked through into the ash-pit, or taken out when burned through by the heat, so that new ones may go in their place.

The ash-pit would hold half a dozen loads of ashes, and were it not cleared out pretty often, it would soon be full. The red cinders pour down day and night, for weeks, and months, and years, a heavy rain of fire. The fierce heat keeps up currents of air along the passages so free and regular, that the furnace roars as a hot blast.

Thus around us we have representatives of the old elements, earth, air, fire, and we may fairly add water, for our guide is an old salt, whose life has been chiefly spent in the service of Neptune. He pleasantly weaves in with his discourse tales of his shipwreck, and how he lost all on board, and how he had a berth kindly offered him under Vulcan, for surely in his realms are we now.

We are at the very foundation of the great chimney to be seen outside. Distance made us deem it a chimney; close to we feel, from the magnitude of the fire, that we are at the base of a volcano, a Stromboli rather than a Vesuvius, for it is always burning.

One of the passages leads to a volcano now extinct, but whose last eruption continued for five years. Vulcan finds such fires to damage his forges, as truly they might, and has only one in play at a time. 
That now a-light will keep so almost long enougin to generate a salamander, the only animal (as old books tell us) that can live in fire, and whose birth comes from one kept up for seven years. The other is meanwhile repairing, and will set for years before use again.

You have been kept long enough in underground darkness. We will ascend towards the crater, taking, however, a winding path round, in lieu of passing up through the fire. Our guide takes us through a room on the route, where we find a man hard at work with his shovel, stirring and mixing a troughful of powdered matter, in which a red colour predominates. He calls it 'new glass.' It has been' put into the trough in layers of beautiful fine white sand, alkali, and oxide of lead (which gives the bright, red tinge), nitre, and sometimes arsenic. It is to the presence of the oxide of lead that the Pellatts attribute the clear bright crystal lustre for which their wares are famous. Without it, they could never produce the models of precious gems that sparkle in their show-rooms, and in the cabinets of the curious. No one is even second to them in this branch of art. Indeed, the spangling drops forming their chandeliers are brilliants of the first water.

The lead itself is prepared with the very greatest care. In German glass, of which great quantities are used in this country, there is seldom or never any lead, For some purposes it is not fit thero 
should be. Many chemical experiments could not be done with lead in the substance of the retort. Apparatus of this kind is of German glass, or made a special manufacture. Great care is required and much practical knowledge in the proportions of the ingredients used. The sand must be even and small in grain, or it would take too much alkali and fuel to melt it; and yet not too small, or it would form into a lump, and stay in the glass as white specks. Only pure potash is used for flint glass-two-thirds of carbonate to one-third of nitrate. If the first is in excess, it gires a light-green tint; if the last, the glass verges to a purple, and if the cheaper substance, soda, is used, it imparts a dull gray.

The usual formula for flint glass is one part, by weight, of alkali, two of lead, and three of sand. Upon the care in the mixing depends the homogeneity of the melted glass. In the case of liquids of different specific gravities being mixed, and resuming their state of rest, it will be found that each liquid is arranged according to its gravity, and while this is taking place, it-will present the appearance of cloudiness. This is precisely what takes place in glass, the difference in specific gravity of the materials being very considerable. The cloudiness, or want of homogeneity, is termed strix.

Another cause also exists to produce cloudiness. The back of the crucible in the glass furnace is exposed to a greater degree of heat than the front and sides; consequently a current of the fused matters is 
constantly passing from back to front, keeping up a partial movement of the mass.

Equal care is required with the other substances. Were too much alkali employed, the glass would sweat, as the technical term is; that is, it would exude moisture; the deliquescence of the alkali seeming to be retained even after it has left the furnace.

The sand is brought from Aylesbury in Buckinghamshire, and Alum Bay in the Isle of Wight. Visitors to the last-named retreat will remember the peculiar sand rocks of Alum Bay, streaked with various bright and gay colours, mementoes of which they have doubtless brought away, prettily arranged in a glass phial, or glued into a 'sand landscape.' Before being used, it is well washed and dried in an oven, care being taken that it absorbs no carbon in the process.

Every one knows that the essential components of glass are simply silica and alkali. The first is the constituent of flint, from which the name of flint glass. Chemistry has shown the advantage of introducing the minor ingredients. Flint stone would be rather stubborn in the melting-pots by itself. Even with the company of an alkali, it would take a fiercer heat than coals give out to dissolve it. It is therefore necessary to pulverise it first. The sea kindly takes the hard work of grinding flint stones pretty well out of our hands. Seea-sand is flint already ground to powder. The incessant action of 
the waves upon the shingle of the shore has elaborated for our purposes an inexhaustible. supply. Flint is nevertheless crushed and pounded by artificial means, but more especially in the porcelain manufacture. If flints are heated to redness, and then immersed in water suddenly, the calcined masses will crumble into innumerable fragments, which are afterwards with comparative ease ground as fine as you please.

We call our good pioneer's attention to a tub full of old broken bottles, and bits of glass in lumps, bottoms of decanters, stopples, and a little multitude of different things.

'Oh,' he cries, 'I forgot to say that we mix up with the new glass a good deal of that sort of stuff.'

We step outside of the door at his hint, and find a long, open-air passage pretty well stopped up with tubs and boxes of these odd fragments. At one end also two old women are at work, washing and sorting them.

'We buy a great deal of old glass,' the man says; ' and we can't get enough of it.'

'Does it improve the metal?' we inquired, using' his own terms quite knowingly.

' Oh no,' he answered; 'but it is much cheaper. Glass is never so good the second time of melting, but if we used nothing but the new glass you saw in the trough, it would make everything very dear.'

It is to supply this demand that we see the bills and boards of the marine store-dealers in the back 
streets of London, announcing the 'best price for old bottles and broken glass.' For the very best glass, virgin materials only are used. All the substances we have named, well mixed together, form what we are taught to call a batch. All of them are opaque bodies, yet by their transfusion become crystalline and clear.

During the melting the glass assumes different appearances. After ten or twelve hours, it is a very white and perfectly opaque honeycomb. In a few hours more it becomes transparent, but filled with thousands of air bubbles; white gives place to a light purple, arising from a small quantity of the oxide of manganese, which is also added to the batch, that, by parting slowly with its oxygen, it may in the end take all trace of colour out of the glass. This purple vanishes in turn. As the melting goes on, the air bubbles get fewer and larger, and at length quite disappear. The glass is now a molten mass, fined, as the workman has it, and ready for his manipulations.

We will go to the laboratory, and see what sort of a place it is. Having reached the higher story, for which we were bound, we discover ourselves in a dimly-lighted; lofty-roofed area, filled with busy functionaries. Twenty or thirty demon-like beings, with ruby red faces, are puffing away at long iron pipes, or 'blowing irons,' with fiery molten matter at the end. Surely they are Vulcan's forgers, for here is one blowing out hollow bomb-shells as large 
as a man's head. We know they will be filled with combustible matter as soon as they form the globes of gas lamps. Another is making cannon-balls or thunderbolts of a size that would do for cricket, if that be a game in vogue amongrit the gods. The huge furnace is in the middle, glaring from a dozen holes, and the flames roaring with the smoke up a dozen fines. Streams of fiery air issuing from each hole diverge as from a policeman's bull's eye, and make effects of light and shade that would have rejoiced Rembrandt to see. The workmen have a slab of iron to roll and work their melted metal upon, and an imp in waiting to vanish with each product of their skill.

Changes take place like magic in the process. What was a moment before hanging from the workman's blowing iron, an opaque, semi-fluid, reddened lump, without form, grows lucent, colourless, solid, and symmetrical. The conjuror sits easily in his ' chair,' turning the metal in the simplest of all lathes, welding one piece to another by mere contact: at red heat, cutting it with scissors as easily as cloth, or breaks it in straight and even fractures with the simple touch of cold iron. A diamond could not give a cut so clean. At a higher temperature it is more ductile than any other metal, and may be spun to the finest hair, or blown to an almost impalpable film. It is beyond description what beautiful shapes are formed with tools as rude as a battledore, and. pincers and shears. 
Darting in and out of the fiery rays, the imps and their demon masters have, as is only quite proper, a most unearthly look. Next to the fabricators of the missiles of death, we come to the making of, what sly wits will say is akin, doctors' bottles, and sample phials for the spirit merchant.

These bottles are all cast. A small thick bulb of the metal is dipped out from the port-hole by means of the long iron tube, and then dipped in an iron mould of the shape and size of the bottle. The man blows through the tube, and spreads the soft metal as he would a somp bubble, till it fills the mould with a thin inner film. He then lifts it out and presents it to the imp, who stands ready with another iron rod, into the hollow end of which the new-made bottle fits. The man pokes the bottle into this hole, and severs his connection with it by one gentle tap. He rums off for more metal from the melting-pots, while his imp has further to do with the bottle. The place of 'severance is where the neck comes. 'Casting' has made the glass cool and hard. It is therefore held to a small hole till it is red again, when it is removed, and by means of rolling and clever use of tools the neck soon comes. Glass when heated, as everybody knows, is very sensitive to cold. If taken into the outer air, it would break into a thousand bits. The strange network of some of the wares which ere now we stopped to look at in the showroom, was produced by dipping the vessels into water, when they were first made. The sudden con- 
traction of the surface caused it to crack in all directions, before the inner surface was affected, making crevices for dust and dirt, which must vex the maid.

Would you not like to view the interior of the furnace? Step inside with us. We have the word of Munchausen that he leaped down the crater of old Etna, and saw what was going on below. We, always sceptical of that story, despite the baron's threats to unbelievers, defer a walk amongst the lurid melting-pots. The extinct fire which we have spoken of must have had a like place to kindle in. To it we hie. Like mice under a mountain base, we can at leisure examine the details of its construction. We stand upon the siége or floor, in the middle of which is a new iron grating, true assurance that the fire long thought to be dead may one day again become active, when through the apertures all round we may see the troubled lava seething with an atmosphere as heated and angry as itself. Our guide says, 'there is no danger of its being in action for several years.' Through the grating come the breezes from the subterranean lanes we traversed. Rushing upwards in a wild blast, they would, were the fire a-light, send the flames blazing round us, over our head, curling around the domed roof above us, down the sides again a little way, and rushing up the flues which take turn with the openings. We can see this going on in the other furnace; here we can probe for the cause. There is no cirect con- 
nection with the large shaft overhead. That would be a waste of much heat. An arched roof serves to hold the fire, as it were, in a box, and makes the furnace many times hotter than it would otherwise be. In the burning furnace a little way off, meltingpots are ranged all round, with their mouths gaping wide at the regular apertures, and displaying down their wide open throats nearly a ton each of liquid fire: a faint cloudy circle distinguishes the glass from the pot. In the dilapidated furnace we can best understand the position of the pots. Even with the wall, they look like so many Egyptian sphinxes with their heads cut clean off; fat examples, albeit their growth has been breadthwise at the expense of length. Nine of them form a ring, with a little one in near the teasing hole. Workmen have the oddest ways of calling things. You would not guess, at first, that teasing the furnace means feeding it with coals. The man who does it is called a teaser. The teasing-hole takes up part of the room, and prevents a larger pot being placed there. Advantage is taken of this, to put a small pot holding only six hundredweight of blue metal. The object to be looked after in a glass furnace is, the greatest amount of heat at the least cost for fuel. It must be of the smallest area, yet so large that the cold air from the grates cannot strike upon the crucibles. It would not suit to use the common method of getting a draught of air, for which reason the tumnel passes below. The force of the current always flowing in deponds upon 
the height and bulk of the chimney, and upon the good luting up of all the cracks round the furnace.

Stepping out of this strange abode, we survey the exterior. We find that the flue bends over and. forms a quadrant to the shaft. The shaft itself is midway between the two furnaces. How struck the world would be, we think, with an eruption, the blended fury of both fires! But here, again, we are told that this is not likely. One fire is never lighted till the other is put out.

The arts and ingenuity of man have penetrated even these queer regions, for close by us is a ladder quite like a New Road manufacture. We will mount it for a few minutes, and enter the warm chamber above. There we find a collection of melting-pots, newly made, and waiting their turn to be used. The date is on them, by which we find that they need much nursing before they are fit for use. One of them has been kept warm for a year and a half, so the inscription of the workman informs us, while lus skill in spelling and writing more surely convinces us that these pots were first meant for sphinxes, and that we are reading off hieroglyphics.

The pots are made on a floor above, and brought down into this room to dry. After a long drying, they go into an adjoining room, which we find, upon going there also, to be much cooler; 'no flues,' so says the man, "passing under the floor as they do in the other room.' Great care has to be taken, in making the pots, to drive out all air bubbles, for 
these would expand in the furnace, and burst the crucibles. They are subjected to severe tests before being applied to their final use, being raised, by degrees, to the temperature of the furnace heat. Even then they sometimes fly, to the complete waste and loss of their valuable contents. The searching fire finds out the least flaw.

Owing to the build of the furnace, the result of Westminster wisdom, it is not possible to carry on the melting of coloured glass and plain glass at the same time. The two kinds demand different degrees of heat. The colouring ingredients of some varieties are very valuable; gold being employed to produce ruby glass, silver and copper for other colours, though Bontemps has shown that all the colours may be produced by any one of the metals. It is necessary, therefore, to wait for an accumulation of orders in coloured glasses, that it may pay to regulate the furnace expressly for them.

'If a customer comes in,' so the manager remarks to us, 'and says he wants some article in coloured metal in a hurry, we are obliged to tell him that we can't do it. He at once says, "Why not?" for he thinks we make everything; and so we do, for the matter of that, but we can't make everything just when we like.'

Blue glass is an exception. There is usually blue glass in the pot near the teasing-hole. This colour bears heat. In the earthenware manufacture, we have a good proof of this fact. For a long time, 
blue was the only colour found to be manageable at the potteries. Even now, the popularity of the 'willow pattern plate,' that eminent trimph of English taste, shows how much it is still liked.

The manager shows us the design of a gorgeous chandelier which he is about to produce. It makes, as a design, a picture worth framing, and we doubt not that it must look princely in a house of equal grandeur. It is to be composed of many thousand drops of bright and valuable hues. Several such have been made already. One was shown in Hyde Park in 1851. It took the eye of the representative of the Pacha of Egypt, who wanted to send to his sublime master a memorial of the Great Exhibition. None but that identical one would serve his purpose, which, according to the rules laid down by the Commissioners, could not be removed till the Exhibition closed. His highness could not wait. Another should be made exactly like it. 'No, that wouldn't be a memorial of the Exhibition.' He had therefore to go without, and Pellatt without a customer.

'Why don't you have smaller furnaces, and more of them?' we inquire.

'For the same reason that many other great trades can't adopt good modern methods!' says the manager. 'Thousands of pounds have been sunk in our place as it is. That would be all lost, if we were to make radical changes. One thinks that all this ought to have been foreseen from the first. So, truly, it was, and in our day it is hard to explain 
why such difficulties were chosen, and how they have been borne. The reason is, that even in this dark out-of-the-way nook the blessings of law have come. Not many years ago, before the excise got into disrepute, we should have found about the place, not merely the operatives, but a tribe of officers whose duty it was (to put it in plain English) to see that government was not cheated. Dues were put upon every pound of glass. These dues varied in different reigns, and were at last so cleverly adjustel, that the trade was nearly driven out of the country. Gentlemen at Westminster are first-rate hands at law-making; they express themselves concisely, speak excellent grammar, and generally, are so good as to make an "Act of Explanation" for the use of the judges. Yet we must own, that when they bccome manufacturers also, they step out of their domain, and look rather foolish. One of their deep schemes was measuring the new glass so, that any misadventure in the furnace might fall upon the maker, and not upon them. The articles made, the remnant of metal in the pot, and the broken spoiled glass, were compared, to certify that nothing had been added while melting. The makers might well laugh in their sleeve. Besides the impossibility of successful cheating where so many men must have been in the secret, the maker's' eyes were too wide open to cheat themselves. If they put in anything, no matter what, while the glass was nelting, it would yrodnce strice and air bubbles, and spoil the glass.' 
We must not be too hard upon our Commons. If the manufacturers' interest could not be secn, they discovered when their own was failing. Heavy fiscal restriction had not only pressed down the trade, but had kept back improvement. Experiments were too costly with repeated dues, and too annoying with the interference of officers. Dr. Faraday and other gentlemen were appointed, at last, as a commission to investigate the rights of government, and the wants and claims of the trade. A long course of experiments at Apsley Pellatt's, at an expense of 3000l., of which 500l. went to reimburse the proprietor of the works, clearly proved the injury done to the trade by fiscal interference. The duties were obliged to go. Cheap glass is one of the many obligations we owe to Professor Faraday. The furnace at which he worked is now also extinct, and the room is used by the packers, and for old stores. With the continuance of the duties, the number of manufacturers would, by this time, have been reduced to zero; the noble erection in Hyde Park, and its still nobler offspring at Sydenham, would have been abortions. As it is, we see our cities and towns bedecked with the luxury of plate-glass which every year adorns more and more even our private houses. Untaxed plateglass is less costly than the common crown-glass of yore. It is so beautiful a luxury, that we may well pray Parliament never to lay hands upon it again.

In the course of this tirade against the excise, we almost forget that our duty is to describe just what 
we see before us. Some one has been asking us, how the pots get into the furnace at the first, and how they are filled from time to time. Just listen to our hearty guide, who is anxious that you shall be deep in the subject. He says, if we come on Friday morning, we shall find the melting-pots in the course of feeding. They have a fiery appetite. The sides of the fumace are opened, and the compound which by-and-by changes into glass, is poured down by shovelfuls into the stomachs of sphinxes without heads. Why their heads are chopped off is now clear; for their throats are more capacious, and their belly is nearer to the spoon. When all hare been well filled, the holes in the furnace are closed, and they are left in a goodly heat to digest thoir meal. Like the inhabitants of the moon (according to the ipse dixit of MInchausen), these melting-pots have but one meal a week. It takes from Friday to Monday to melt the glass. Jack-tar knows it, now and then, to take much longer, so that, when the workmen come on Monday, they are required to take an extra holiday. Generally speaking, they are not hard to persuade. The temptation to supply waste of moisture, great in their warm work, is yielded to. pretty easily. We hope we to them injustice, though we speak not without knowledge. After all, it is a charge that may be only too truly laid to the score of working men. Glass-blowers do not go much beyond their mates of leather or of beaver. They 'drink like fish,' we are told, which would mean, 
strictly, that they only drink as much as nature needs.

We are curious to know whether the fire has any bad effect upon the sight. The workmen deny it, though the 'industrial pathologists' have of late been crying sympathy for them. One genial, large fellow, with dewlap rolls of fat like a Christmas ox, and whose appearance shows how quickly he makes up for evaporation, says 'he has worked a good many years in the trade, and can see as well as ever.' Nor can he remember an instance of his fellow-workmen going blind. While talking to this sensible and polite fellow, we are interrupted by a man, whose remark runs counter to what we have just been told. He wanted to 'wet his eye' with a drop of beer. Evidently the fire affected him injuriously. His eye, to us, seemed to have been moistened already too many times. We helped him to a pint, yet thought that 'a drop of beer, yer honour!' was a very degrading salutation from an English workman, who could earn, we were told, sometimes $3 l$. or $4 l$. a week.

We are over and over again hearing of the tyranny and monopoly of capital, and the hard usage of labour. There is a wide-spread fancy, that masters only care to get everything they can out of their men; a dogma which, if ever true, grows less and less so every year.

It is seldom thought that working men may themselves become tyrants. It is only masters who feel 
that. Yet what are trades' unions frequently, but the incubus of ignorance upon all improvement! What are strikes often, but the effort of obstinacy and igmorance to gain an unjust share of influence and profit! It is only a gigantic capital that can successfully cope with the injustice of labour. Granting that our present system of manufacture is an enormous mistake, we assert that the rights which labour contends for are but a pigmy to the evil which all the claims of working men's ignorance would inflict upon our country. It is not that union is wrong. It is only lamentable that intelligence does not always guide union. Men continually 'bite their nose off, to spite their face.' To show a false and foolish independence, they will throw themselves out of work, or 'get the sack'. from those they wish to rule over.

'We are slack of hands just now,' said our cicerone; 'you don't see us at our busy time.'

'How is that?' we rejoin.

'Oh,' he answers, 'our Mr. Pellatt has been obliged to send some of the hands about their business. Why, they wanted things too much their own way. They wanted to be master, instead of our Mr. Pellatt, and of course he wouldn't have that. They belonged to the "union," and wanted to be paid so extravagantly, that it would never do.'

'Have you any union men now?'

'No, sir, not one.'

So here, in the largest glass-works in London, 
men have cut themselves off from good work and wages, rather than advance with the improving spirit of the age. Thus, too, have men shut themselves out of the 'Times' newspaper office, Her Majesty's Printers' office, and other large establishments, whose work is so well-paying, constant, and sure, that many a man would now gladly give up his society for an engagement in them.

When glass-ware leaves the blower's liands, it has to undergo annealing or cooling, a process almost as gradual as the melting. The articles are put upon iron trays, which traverse on wheels a long, arched oven, with open fires on each side of the entrance, which heat at the same time the flues under the floor, where we saw the crucibles. A chimney at the other end causes a strong draught, which draws the fire down the arch. An array of glass-ware as far as the eye can reach, presents a curious sight. 'There is a forest, of all altitudes and girths-a cylinder, tall as a palm-tree, with a big-bellied apothecary's window bottle; chimmeys for gas-lights; glasses of all kinds, for chemists, for victuallers, and for domestic use.

We are now led round to a room which the glass reaches by a shorter road, too warm for us to encounter. By a turn-handle, the trays travel on a railroad to this room. When the journey is over, they are quite cool. Annealing takes up a good many hours. Every article should be annealed as soon as it is made. This is a very sure safeguard to 
the owner of glass-works against dishonesty of any one employed by him. It limits temptation very much indeed. No manufactured article could be removed without annealing, so as to be of service. No after-annealing would effect the end desired. The object of cooling by slow degrees is to prevent fracture from any sudden reduction of temperature. Glass is a very bad conductor, and chills, contracts, and grows solid on the surface, while the inside is half fluid. Annealing makes the strain or pressure equal. The men receive the produce of the annealing furnace. Every piece is then looked at in turn; a small defect condemns any one of them. The perfect articles are put into large, light wickerbaskets for the time being; the condemned ones are put into a heap for re-melting. There is every reason why a workman should be careful; it is a rule of his shop that he should pay for defects. His work is weighed only after the bad work has been thrown aside. A careless man may often have to work many hours to no purpose.

The bull of the work has now gone through its last ordeal. It has but to be stored away, or displayed in the show-room, or sent off to order.

Some part stays for a few last touches. Our saltwater guide takes us along passages, up and down stairs, in and out of the open air. At last he lands us upon an up-stair workroom, the scene again of many busy operations.

Whools, and drums, and tubs, all dirty, moving, 
and splashing, are what first take our notice. Reaching the whole length of the room, a drum-like cylinder is rolling round and round: on each side of it are grinding wheels and busy men, inverted wooden pysamids of sand and water trickling down over the wheels and into the tubs beneath. Leather bands connect the wheels and the cylinder, and all are in motion together. We have come to the glasscutters. The foreman readily lets us pry into his art; he takes up a tumbler. 'Now,' says he, 'you observe that this is at present quite plain, it hasn't had any cutting whatever.' With two minutes' application to the first wheel, which is made of cast iron, he has produced three facets or cuts, as is seen at the base. Passing it onwards to another man, he begs him to continue the process. The facets are now applied to a wheel made of Yorkshire stone. Of a texture much softer than cast iron, it requires the aid of sand and water to act upon the glass. The effect is, that, instead of the rough, coarse, surface left by the cast iron, the glass exhibits a dull polish. One facet is left for comparison, still rough.

We pass the glass forward again to a third wheel, made of wood. A minute brings the half-polished facet up to its pristine lustre. Thus iron wheels, and sand, and soft stone, and wood, cut, and smooth, and polish. Similar rules respecting damaged articles exist amongst the glass-cutters, as anongst the glass-blowers. A splendid, cut decanter is 
shown to us, the defect in which neither we nor our guide can detect; but, as he remarks, 'the wheel has gone through one of these deep cuttings, or it would not have been turned on one side.' Two or three hours expended upon that decanter were lost time to the operative. We wonder if the next decanter will be cut through? A turn of the room brings us to other workmen, who are grinding the interior of the necks of bottles, or grinding the stoppers. To insure a good fit, the one is, last of all, ground into the other, so that they become quite airtight. We cannot describe other occupations of the people here. In the department of the glass-cutters and engravers, are many slkilful artisans, or more properly artists. Not only is wonderful skill displayed in the mere cutting of the glass, but powers of design are possessed by many of them. We must only add that these men are at profitable labour, though, from their earnings, it is the custom to charge them a daily rent for the apparatus they use.

We retrace our way through all the maze of the building. Passing the furnaces once more, we think of Pliny's tale of glass being discovered by the shipwrecked mariners, who made a fire of sea-weed on the sands; and feeling the glowing heat upon us, we doubt the fact. We doubt the power of such a fire to vitrify the sand, even if the discovering of glass articles at Nineveh had not already made us doubt Pliny's chronology of the invention. 
Our eyes sparkle still with the splendour we have seen. They are the lenses through which the sens:tive surface of our brain has been impressed with a photograph. The development of it we present to our readers. Though we have not taken one of the largest places in London for our camera, wo have, unless spoiled in the process, one of the most curious, elegant, and beautiful. 



\section{RAILWAY COLONIES-LOCOVILLE.}

A TRIP to Australia is no feat now-a-days, nor does a tour over half a dozen colonies dub one a tion when he comes home. It is very shameful this; for, with our quick means of transit, we long for a voyage, and yet, if we take it, we are robbed of the glory. Our feeling heart has been made aware of these things ; and it is from pure beneficence we tell the world at large, that colonies may be seen at home, as primitive, as interesting, and as instructive, as any in the realms of the Queen. A few hours will take us to any one of them. Railways knit, net, crochet, and embroider the land at such a rate, that we have but to start from any terminus, and we shall be amongst modern inland settlements, corresponding to the roses and leaves of the ladies' fancy work, which cannot exist without their netted base, any more than these colonies without the iron track to which they owe their being.

One such colony is located about fifty miles from London. As the 'express' flies past one station after another, the distinction is so trifling in their aspect, and still less in the cry of the guard-who 
farrours you with the last syllable only, and that not clear-that no thought is given, in the excitement and enjoyment of rapid motion, to the towns on either side, or of the busy hands in them.

The point we want to reach is got at only after a good extent of one of the 'midlands' has been ploughed up by the engine. North of tlie county, you are hailed with the cry of 'Locoville,' 'Coville," or, nearer still, 'Ville; wait here for ten minutes." We are inclined to heed the guard's advice, and eren. to multiply the ten minutes allotted to us. Is not Locoville famous for the 'beauties' of its refreshment-rooms? 'Stay, traveller, stay,' and answer for yourself; and though you may think some of the items of the highest, say, is it dear at any price to be helped to soup or tea by the blooming beauties at the urn? Assuredly the iron age of railways has not driven all the 'gude folk' out of the land. 'Once upon a time' (that eventful epoch upon which was affiliated all our early marvels), fairies lived in leafy dells-maybe amongst the beech-trees that are said to have stood sponsors for the county. The old sprites and hobgoblins died out long, long ago. Let us not moan about it, for the race remains, albeit they have taken to science and philosophy. Deeds are done in this year of grace, as well worth a note as anything told of in fairy rolls.

The pork-eating Saxons must have cherished the bech-tree, for the mast would fatten the pig they 
loved. Saxon and pig; the merry greentrood and the beech nuts; the shady alleys and the "liut thatched with straw;' the bridle-paths and the roadside inn-are things of a past date. Modern genii have visited the site. With the tap of a wand more potent than in old tales, the rude beans, and rafters, and walls, and doors, which have solaced poor clodpole, as well as the pedlar, when a 'pack' bore the trophies of commercial spirit, are now changed into grained woods, and crystal panels, and sylphs behind the counter, in eyeing whom, mind, sir, you don't lose your heart-or the train. There's the bell ringing. 'Take your seats, please.'

The bulk of the travellers have gone on, or, if you like, gone off. The curious, however, will 'squat' with us in the settlement. Leaving the hotel, which in itself deserves a whole article to describe its arrangements, economical and moral, we march along the rails for a hundred yards or more, and reach spacious covered caravansera-looking buildings on either side. Electing one to push inquiries at, we learn that 'the men leave off work on Saturday afternoons at two o'clock.' Our watch shows us it is four. We may imagine the factories, and go back to town, or stay till the next week. Had we chosen the first, we should have lost a most pleasing spectacle. As it is, our readers are plagued with a long report.

From the workshop, let us turn to the colony itself. Locoville has come into being since you and 
we were born. The settlers were led to make it their habitat from certain advantages it possessed as a birthplace for new engines, and as a halting-place for infirm ones, or sickly carriages, which could not class as A 1 at the Lloyd's of railway concerns, Euston Square.

One of the first duties of a young colony is to provide shelter. The leaders of this enterprise did not neglect the duty. Our eyes are looking down streets as straight as arrows, and composed of tiny red tenements, alike in size, in shape, and in colour. Some hundreds of these brick huts form the town. They do not have a nice look, nor produce a pleasant impression, for, though we admire the saving of space in bee-hive or ant-hill, we don't much like the same principle carried out as far in human dwellings. Here they are huddled close, like cells, with only make-believe yards; and we are ready to cry shame on the stint of a company whose, revenues are 50,0007 . a week. The population is wholly of working people; and, if you want one, you will find him at No. 695 , or 847, for the town is numbered, not the streets. Having passed through a number of these streets, whose only difference is, that they are all alike, we come to the high road, dignified with a pretty church on the left, and a handsome pile of Elizabethan buildings on the right.

The credit which the company had got for their religious and educational efforts in all their settlements, has been the great inducement to oux visit 
We had heard of their reading-rooms and evening classes, their day-schools and Sunday-schools, thcir church and their worthy pastor. The handsome building detached from the town houses attracts us at once. Well might such a place be built, we think, as we make our way through throngs of boys and girls, from babyhood to sweethearts, who crowd every space, romping gleefully on the half-holiday.

The schools, like the. workshops, are closed. Very few are found in the newspaper rooms. A weekly jubilee is Saturday.

The central part of the scholastic range is used by the director of the educational works. We find him ready to show and to tell us everything in his own department, and to be courier to every other part of the colony. We have reason to thank bim exceedingly, for, besides finding in him a gentleman highly talented and unusually intelligent, we found him not less hospitable at his own bright and happy fireside. We don't know if it be his fashion to treat all visitors as he did us; or, if it be, we advise them to go to him instead of to the refreshment saloons.

Under his leadership, we have pointed out to us true liberality in the management of this branch of railway affairs. The schools for boys, girls, and infants, provide an excellent education for the teeming progeny of the young, hearty, vigorous community, amongst whom an old man is not yet to be counted. Every modern appliance in the art of teaching is adopted that deserves a trial; and 
teachers are encouraged to their duty by liberal stipends. Money never fails when anything useful is proposed. Comfortable rooms are provided for lectures and reading, the company supplying gas and coals, and keeping the place in good condition, the members providing their reading, and managing their own concerus.

These"things duly shown, we march again into the town. Under the guidance of one to whom the history of the place is known, our first prejudices are one by one removed. Although the houses are confessedly huddled too close, it is an error that is made up in many ways. Water is laid on in every house, and gas too; but, with true British independence, the many will not avail themselves of the last comfort, which puts them to the cost of fittings. There is also a choice of tenements between $1 s .6 d$. and $4 s$. a week, although to our eye there is not much difference in the red rows of bricks. A new settlement like this, where a population of a thousand men, besides women and children, came at once to live, was necessarily built upon a plan rather uniform, leaving the denizens little power to exercise their taste in the choice of homes. One street is constructed irpon the model of Prince Albert's Lodging-houses. Some of the houses are the depôts of provisions and merchandise, and are dignified with the announcement of 'Co-operative Stores.'

A curious trait of the people here, is their disposition to combine for trading purposes, and for 
mutual advantages of other kinds. Groceries and necessaries of life are bought wholesale, and retailed to the subscribers at cost price, or else securing to them a dividend (when the neighbourhood generally is allowed to buy) of, in some instances, as much as fifteen per cent. Our friend tells us, that the principle of co-operation acts well, and tends to economise the outlay of every family, although some mishaps have occurred in getting the plan into good work.

To confess the truth, we think the aspect of the place more curious than beautiful, and make a remark to that effect. Our friend qualifies our impression by observing, that this town exhibits the first attempts at lodgments, and that we shall see something more deserving admiration soon. Twelve hundred 'hands' at the factory have made all the neighbouring villages populous, as well as overflowed the new town. Even then there has not been room enough, and a new village is pointed out to nis at the distance of a mile or two. On the way to it, we pass fields allotted out in gardens, and studded with busy engineers, and smiths, and others, all dressing up seed-beds for the spring. It is a most gratifying sight. The relief from the week's factory life is heartily enjoyed. Every one is intently occupied in spade husbandry, digging his beds or cutting his paths, while his youngsters are swarming about, making heaps and bonfires of the weeds, which blaze and smoke away here, there, and everywhere. Not a doubt is on our mind that the workers are as happy 
as sunshine. Health and pleasant work make them so. Gardening is a profitable pastime, as well as a complete variation in their daily employment. So happy is the whole scene, that we are as ready to give the surveyors credit for foresight, whom we were as ready to scold, a few minutes before, for their disregard of garden appendages to the houses. An advantage is gained by the gardens being out of the town, and tempting the men out likewise. The habits of men in the workshop cling to the strong young gardeners. The neat, burnished parts of engine-work are finished with so much care, that eyes accustomed to their fabrication could never bear a ragged, untidy plot of ground. 'The beds are laid out with a degree of finish rarely witnessed; the edges and corners are of mathematical nicety. Indeed, we are told, there is no small amount of real scientific gardening amongst them, displayed more in the production of dinner vegetables than of floral beauties.

Tramtown, which we at last reach, is decidedly nicer-better built, and laid out more tastefully. All the dwellings are of white brick, in lieu of red, and a light and genteel appearance takes the place of the poverty look of the original Locoville. They are also more varied in size. Some of them, by the taste and cleanliness of the 'mistress,' are made to appear quite of a superior order. As the men earn" good wages (none less than 30s. a week), they can afford a little style. Perambulating the stony streets 
of Tramtown, we see, for the first time in our life, an itinerant butcher's shop. This trade was a failure as a 'co-operative.' Building is still going on rapidly, yet not rapidly enough. For miles round about, the railway works have put life into the builders. There is something truly English in the jolly, easy independence of the natives. The innate essentials of their nationality display themselves strongly in various ways, even while adapting to a new position. Grimy, black, oily with a week's engineering, still health is the feature of every one we pass.

Evening now approaches, and the happy gardeners can either enjoy the twilight, and spring breezes, and their pipe, on their own little estates, or return to town with us, to be begruiled with the notes of their town band. Nothing but the best of their kind will suit these real English well-paid workmen. 'Sax-horns' is the order of the day. The old brass instruments have been discarded ever since a 'Sax' was once introduced. The company encourage their workmen in their schemes for rational amusement as much as for self-improvement. In the case of the new horns, for example, a request was made to the managers to buy the lot at once; the owners afterwards having a weekly deduction from their wages made, to repay the outlay. This is the usual plan adopted when anything is wanted, which is equivalent to-must be had.

Thus passes Saturday; secluded from the great world, but far from unprofitably. Some few of the 
young men find amusement in the reading-rooms; but, generally, it is a holiday. Profuse indulgence is the usual rule where workers have plenty and little care; and from what we see around us, we are led to doubt whether savings-banks find much favour here. Genial, good-natured, and lavish, we judge the people to be, who would do no wilful wickedness or injury to any one, yet who trouble themselves with very few grave reflections of the past, present, or future.

Sunday also we pass with the community. All are dressed in their best, and appear with wives and sweethearts abroad, pictures of health and happiness.

Not one dirty being shows his face. Scarcely can we believe that the grimy jackets of yesterday are before us. Broadcloth has taken the place of canvas for the day; and though in some instances the brawny son of labour is still to be detected at the first glance, yet many hare taste in dress, which would serve them to promenade liegents Street or Kensingion.

It. is 'Fig Sunday,' and a day of feasting-as what day is not? Great heaps of figs have disappeared from the shops, and though now distributed throughout the town, we have only to look at the myriad youngsters, and take credit for a power that will, ere long, make another and final disappearance of the fruit. Where they learned the custom of figeating, or what in London we call 'Palm Sunday,' we wot not. Two or three hundred of the children 
are congregated in the various spacious rooms of the building in which we have taken up our quarters, engaged in,their Sabbath exercises. It augurs well, we think, of a great company, when they evince a desire to do more than get large dividends. All we have yet seen has been a direct outlay from their revenue, and involves a yearly expense. All could have been left undone without incurring censure. Such voluntary efforts for moral good, now distinguishing not only companies, but capitalists generally are the bright spots in the present history of our country, which, like the radiations on the sun's disk, spread over incalculable extent.

The pretty church, a step or two into the fields, next engages us. It is well filled. Any law of church-going would meet with sturdy rebellion; the company has shown judgment in using persuasion rather than force. We listen for two hours to most impressive reacing and preaching. Never did we hear the church service more devoutly gone through. The people, we thought, enjoyed it, there was so much heartiness in the share they had to take. A handsome church, a fine organ, well played, music of a cheerful kind, hymns and chants so well known that all could join in, and so frequent, that the length of the service was beguiled; these were the charms to bring the people again. And the minister: to our mind he was the model of what the church should furnish. Simple, but deeply earnest, he knew his flock, and spared it not. His patrician 
face, and chaste and pure utterance, proved him in the highest sense a gentleman and a scholar; while the deep feeling with which he read, proved that the words were to him not a ' form, ' but really ' prayer.' To every part of his exposition, there was a pointed home application, more chaste, but similar in style to Rowland Hill, a divine with whom, we are told, he spent much of his early life. We could not help attributing the seemliness of this pleasant Sabbath-day, to the liberal regulations of the railway with respect to the rest of the week. Where men are jaded with long hours in towns, we know too well that church is not the place to find them on Sundays. Here they cease work at four or five every day, and at two on Saturdays, and change the close, hot atmosphere of the factory for the invigorating work of their gardens. No one with these opportunities would want any Sunday morning gardening, like Spitalfields' weavers; or other London operatives.

After this sojourn at Locoville, we are certainly not satisfied without a peep into the factory itself, and are constrained to stay another day. Morning arouses us with a 'ring-ding,' 'a linked sweetness long drawn out,' to tell the men that rest is over, and work again begins. The sound travels a mile or two, and brings forth from Tramtown and other neighbourhoods a legion of workers, and from the hives of Locoville troops of bees. Along the different roads they come, converging to one centre, and intent upon business. 'They must get to the 
gate by the second bell, or a quarter of the day is docked. Bright white canvas is the uniform of them all again. Whether by common or by statute law, Monday morning demands clean washed jackets. Doff we our sleep with the hum in the hive, and don our inquisitive eye. We are off to the factory too. Once before, in the course of the night, we have been roused by the bell. Daylight assures us it is not now a false alarm. After rouling the household, who are too used to the clang of hammers and ding of alarums to heed them, we find out that the first bell was to call up the 'breakdown gang,' who are always prepared at any moment in the night, to start for the repair of misadventures on the line.

Now on the way, and the clang incessant tells us to expect a scene of industry. Inside, and we feel, without a hint, that we have to do with railways on an uncommon scale. First, we enter a covered way of magnificent dimensions, and capable of forming a terminus of itself. In fact, it does so in some degree, for an array of engines on each side becomes an avenue long enough, one would fancy, to supply the world with locomotives. We are in the asylum of valetudinarian engines. On each hand we count above a score, some of them the mightiest that the world can boast. Our friend pleasantly remarks, that we may see here engines in all stages of composition, decomposition, and recomposition. One we see flayed, and a pigmy man is renewing its epidermis. Had we time and endurance, we could learn 
much of the treatment of the faculty, in every phase of physiological derangement of the monsters. The central part of the area is taken up with a railway and movable stage, to which is affixed a small but sprightly locomotive, engaged now and through the day in passing to and fro, drawing after it loads that require removal. At the moment, it seems a means disproportionate to the results aimed it, for a load is put on the stage about as much as a man could comfortably carry in his arms. But men won't carry things on their arms that they need not carry at all. To give a semblance of utility to what the engine is doing, we ourselves jump on the platform, and save our legss.

Presto, the picture changes. We have an equally large area opening upon us, but devoted to forges and smiths. Everything is black but the glance of the fires; yet we see at once that skill has devised the mapping out of the space, and neatness and elegance are paramount in all the fittings. Even so crude a thing as a smith's forge is made to possess symmetry of form, and the whole of the appurtenances are placed geometrically over the ground. The centre is adorned with two liuge shafts, like trunks of the Baobab. These, we are led to observe, belong to the hot-blast furnaces, in which the metal to be forged is exposed only to the flames, and is not suffered to come in contact with the fuel. The girths of the chimneys are much larger than they would be naturally, but that they serve also as 
heaters to an exterior case of water-the boilers of. a steam-engine. 'Thus, without the expenditure of' an extra atom of fuel, the water is boiled that works a steam-hammer. This hammer, weighing two tons, was made by Nasmyth, and works night and day without intermission, shaking the neighbourhood by its force. Such particular work as engines require, so much depending upon 'quality' of material, must all be forged. Even the iron wheels of the carriages are made under the hammer. The spokes being separate at first, are made with heavy masses at the end, and these, when at a white heat, are welded to form the box of the wheel. Wonderful as is all this in reality, yet it is so easy to the sight, that we are not ready to appreciate it. The scintillations from the hammer and the brawny workers attract more admiration than the gigantic work they are really accomplishing. Our eyes suffer us hardly to believe that the mass moving up and down, like the 'devil' of a pile-driving machine, can really be iron; rather must it be pith. Iron enough to fit a dozen blacksmiths with anvils, rises and falls so easily, that it is by the tremendous shaking of the ground at each descent, that we receive the testimony of our senses of what steam is achieving. Then, again, it is a fiery sight that of fitting the tires to the wheels. The red-hot hoop, slung from the furnace; is suspended over the middle part of the wheel, and is gradually dropped down into its place. Being then deluged with water, the contraction causes it to bind 
so fast, that there is scarcely a possibility of its ever after slipping.

Another department reveals men at boiler-making; riveting or bolting the sheets of metal together, and explaining in the process the clang of hammers we heard before entering.

Amongst the masses of metal lying about, we are called to look at one piece, dull, heavy, huge, and long, which moves soberly round a fulcrum. Inspecfion opens up the mystery of its half-intelligent motion. It is not, as we might be pardoned for thinking, an antediluvian beast brought to life, but a punching machine. Just under the end of the short arm of the lever is fixed a well-tempered punch or die. Under the end of the long arm works a concentric heart-shaped wheel, fixed upon a shaft: Clearly as the elongated part of the heart comes uppermost, it raises the long arm, and at so great a distance from the centre as to multiply the power of the lever many times. The short arm of course descends correspondingly, and gives us as many proofs as we please to stay for of its porrer. A man comes at our friend's bidding to astonish the novice. He takes a plate of iron more than half an inch thick, and places it to intercept the die as it comes down. We fancy that must be his object, for we are not prepared to see the die go through thick cold iron with scarcely the hesitation of a second. While we can count slowly one, two, three, a row of large holes have been punched; and this is how the rivet- 
holes you may see in every stcam-boiler are made. Incredulity besets us while we look on. Such 'punching' would frighten the pets of the prizering.

'Are you quite sure that is a sheet of iron?' we ask old Clem's votary.

'There's no mistake about that,' says he, as he puts the thick, heary, cold piece agrainst our shrinking fingers. 'There's no mistake about it,' he repeats; and, like a wag as he is, adds, 'but it would be all the same if it were wood, the punch would go through, I expect.'

The next space we enter has the air of a printing establishment, for, down as far as we can see, there are ranged machines on each side, with a multiplicity of wheels and movements. It is whispered to us that we witness a sight unequalled in England. The products of genius are here. Machines are playing with iron as though it were an easy-yielding thing. Resistance to the tool no more is thought of, than would it be were the substance gutta percha. Common working men would open their eyes wide again. They have heard of shears to cut cold iron plate, and of siws and other tools which make men carpenters of iron, but it is remarkable how 'little description is realised, without the aid of the thing itself.

:- One huge automaton, weighing many hundredweights, moves its arm playfully backwards and forwards over a "Joc-table" of iron. The monster's 
strength is shown at each alternate journey. As easily as we could scrape the rind from an old Cheshire, the gentle mammoth scrapes off a ribbon of iron with its thumb-nail. 'Work' is its motto, not 'noise.' To and fro it travels, turning the face of the 'bit' at each journey of its own accord, till the iron surface is planed smooth and bright as the artisan would make his malogany.

Another machine is devoted to 'sliding and screws.' We will explain its action in the words of young 'six-foot,' who has it in charge :-

'It is sliding now, not cutting a screw,' he observes. 'I have to get this piece of iron true, and then after I shall shave it off clean.'

'But how do you get it true?'

"Oh, you see, I lift this "dummy," and then I turn this wheel, and that gets it true.'

While the youth is performing these cabalistic arts, the 'centre-bit' is eating its way into one end of the bar that is to cut into a screw, and gradually works out a socket in 'true position.'

Similar in its operation is the next engine, except that an immense tube, large enough for a water main, is peeling itself against the sharp tool. The mass of metal pushes forward to its fate, as insensately as everything else, and the tool adjusts itself as if it had a mind of its own.

A railway carriage-wheel is submitted to the tool next in order. The well-tempered steel moves up and down through the hole of the axle-box, gently 
touching one side only at each descent. An iron shaving is left below. These shavings accumulate to a heap. The chisel has cut a deep square groove through the whole length of the axle-box. This we are told is 'slotting.'

The numberless variety of labour-saving machines strikes us with amazement; but the marvels are far from ended at this point. We have but to turn round one wall, and we see a repetition of the engines as numerous and complete as in the other department. The whirr of wheels is louder than the noise of the tools. Noise, in fact, seems to be in the inverse ratio of the work done. Several circular saws are revolving with a rapidity inappreciable by the eye. A little mistiness in their neighbourhood alone indicates their presence. We must except now and then when a fizz, and a whizz, and a scattering of sparks, make us jump out of the way, for Vulcan has sawn a bolt of iron in two, not unlike the way in which a pork butcher would carve a sausage. And sawing it of a proper length is not all he has done. A moment before it was but a square piece of metal. It would have taken a smith some considerable time to have rounded the shank, and have formed the head. Here there does not seem such a thing as hard work. Everything is done for the workers. A compact assortment of steam hammers, of curved as well as flat faces, is contained in a strong framework. Curious enough they look when all in motion, for, being of a more reasonable size 
than the 'Nasmyth,' many of them are moving in a small space. Under each of them is a little anvil to correspond, and it is upon one of these with a grooved surface that the workman puts his heated bolt. By simple turning he forges and rounds itthe hammering is all done for him. It remains to form the head, the only part of the process that looks like work at all.

All the machines round about this spot are worked by a hissing stationary locomotive, if the term be permitted. An engine that has served its time on the road is still made useful as a stationary motivepower. The fly-wheel, instead of biting the rails, has a strap banded round it, and works merrily in its old age. We have not time to think; we can only see. So many steam-boilers sputtering, and engines sawing, punching, planing, slotting, sliding, hammering, drilling, turning, would make us nervous in another place; but here they seem appropriate, and danger is the last thought in our mind.

Speaking of 'turning,' the lathe demands a recognition. Before it is revolving a fly-wheel several yards in diameter, which some day will be traversing between London and the North. Can the tire be real iron? we again ask ourselves; and well we might, for with each revolution of the wheel the circumference grows nearer the centre by a quarter of an inch. Stop, and think now what that means. A strip of iron is simply scraped off as the wherl turns round. Get an iron wheel and a sharp gouge, and 
take off a like strip, a quarter of an inch deep, equally all round the tire. That will tell you what this lathe does.

There are other departments in this thoroughly English workshop; but they are similar in their arrangements, only differing in the fineness of the work. We have seen the huge and grand operations; and although the rest are equally interesting and wonderful in their investigation, their principle being the same, they do not strike the beholder with the same sudden surprise which the first induce. The 'fitting-shop,' for example, has engines small only in comparison, and of most delicate and perfect construction. Here the bright parts of the engine are burnished and beautified, and the whole is examined, tried, and fitted. It is cleaner and more elegant work than the rest, and engages some of the best hands.

Our prying eyes are only satisfied just as the bell announces breakfast. The army of workers are on the alert at the sound, for, be it known, none there are averse to eating and drinking. Some of them have anticipated the joyous moment, by putting their tins of tea upon pieces of red-hot metal, so that they may 'peg away' without loss of time. Those who live in Locoville troop out a little army, to attack the stores at home. Clean and white were they at six o'clock, but grimy enough now. Their jolly wives are used to the sight, or would scarcely know them again. He would never do for an 
English workman, who did not show his industry by the state of his clothes, much less would he do for a railway shop. Oiling the machinery, no doubt, is a dirty office, but, if it were not, smiths would find means of getting black. There is not the excuse of using oil with the tools, for that appears to be discarded for soap and water. Every operation that we have seen beguiled with oil in other places, is here performed as easily with water, and far more economically.

As good English hearts are covered by those white (now piebald) canvas jackets as breathe anywhere. There is true worth amongst them, and loyal feeling. They sent 125l. to the Patriotic Fund, every man giving up a day's pay: this, too, direct from the factory, and exclusive of profits on concerts, and other schemes, which have added much to their donation. Then, too, the example of the chiefs tells well upon the young fellows. The head manager has achieved success by his own exertions. From a poor boy in a Manchester factory, he has, by study, and diligence, and force of character, gained one of the most responsible posts in the company's service. And as a medium between a thousand men on the one hand, and a board of directors on the other, we should think his office as irksome sometimes as it is responsible. Others under him have taken a like up-hill course, and have reached good elevations. It is in the power of the young workmen equally to rise, They know it, too, by esta 
blishing an engineering class, and working with zeal in it.

Another bell calls us from these reflections: it is the intimation of our train coming. With hearty thanks to our hospitable friend for his singular kindness, we start back to town. Sure are we, that the guard's cry of 'Coville,' 'Ville,' will never sound in our ears again, without inducing us to spend an hour in this newly-discovered colony. We indulge the hope, also, that our readers, if they ever pass, will be led to think that something real is going on near them, to insure the comfort of a railway ride. 



\section{9}

\section{GLIMPSES OF LIFE AMONG THE SPITALFIELDS WEAVERS.}

PART I.-SPITAUFIELDS, ANCEENT AND MODHRN.

IIODERN London may be not inaptly characterised as a vast congeries of towns, drawn into juxtaposition by the consolidating force of civilization, and the centralising necessities of the age. But, whilst thus confederated into one stupendous unity, they are not so far merged as to lose altogether their separate individuality. Each district still retains, to an extent that is obrious to the most superficial observer, those peculiarities in its population and its trading pursuits which the locality may be more especially adapted to generate and foster, or which, in a modified form, have been transmitted with all the force of hereditary habits and associations through successive decades and centuries. The justness of this remark may be readily verified by glancing over a map of the metropolis, and drawing an inky belt around those sites where certain handicrafts or vocations are found to be chiefly localised, and where the working bees belonging to these respective hives of industry gregariously swarm. Though brought by 
the constraints of commerce into close contiguity, there yet yawns too often a moral and social gulf between the classes thus massed within the limits of this populous region, that is almost impassable. The environs of London, embracing a glorious circuit of twenty or thirty miles, are adorned with palatial abodes, and peopled with the graduated aristocracies of birth, title, and wealth. A wide strip, extending on either side of the Thames, is inhabited by, or dependent upon, a unique, unassimilative race of seafaring men. The old city focalises within its boundaries the chief treasures of national wealth, vast store-streets teeming with the most precious merchandise, and the exchanges that daily witness the transactions of a world-wide commerce. In like manner, other quarters are inhabited by a preponderance of persons pursuing their several arts, grouped in distinct labour-tribes. Thus we have 'the potters of Lambeth-the hatters of Southwark-the tanners of Bermondsey-the coachmakers of Long Acre-the watchmakers of Clerkenwell-the marine storedealers of Saffron Hill-and the old clothesmen of Holywell Street and Rosemary Lane.' But by far the most notable and perfect exemplification of this propensity, in the followers of particular trades to herd together, is seen in the case of the metropolitan silk-weavers. They are exclusively confined to that extensive realm commonly known as SpItaLFIELD,

This term properly applies only to the parish so 
LIFE ATONG THE SPITALFIELDS WEAVERS. 221

designated, but it is popularly used, in an enlarged acceptation, to denote that large district in the northeast of London, bounded by the Hackney Road, the Regent's Canal, Mile-end and Whitechapel Roads, Aldgate, Houndsditeh, and Bishopsgate Street. Within this irregularly-shaped region, nearly the entire body of the silk-weavers reside. Considerable sections of Stepney, Bethnal Green, Shoreditch, Whitechapel, and Mile-end New Town, are embraced within these factitious boundaries. Until within comparatively modern times, the larger portion of the site now so compactly built upon, and prematurely wearing such an air of dilapidated antiquity, consisted of open fields covered with grassy sward. Contiguous to the suburban fields, a large hospital was founded, in the year 1197, by Walter Brune, a citizen of London, and Rosia his wife. It was from this circumstance that the adjoining meadows were called Hospital Fields-subsequently abbreviated to 'Spital-fields. Although this institution was monastic in its character, being designed for the poor brethren of the order of St. Austin, yet it appears, from the writings of our early chroniclers, that hospitable entertainment was afforded to poor travellers, and relief extended to persons in sickness and distress. Munificent donations from opulent citizens ever and anon enriched its charitable coffers ; so that, in 1534, when the Spital was pillaged and dissolved by Henry VIII., ' beside ornaments of the church, and other, goods pertaining to the hospital, 
there were found standing 180 beds, well furnished, for the receipts of the poor of charity; for it was an hospital of great relief.'

Stow makes the following allusion to the state of these fields in the reign of Elizabeth:-' On the east side of this (i.e., the Spital) churchyard lieth a field, of old time called Lolesworth, now Spittlefield, which, abont the year 1576, was broken up for clay to make brick.' A century later, it still retained its name, but had undergone considerable alterations, as may be seen by consulting the 'Map of London in the time of the Great Fire.' It is represented as being then a square field, bounded on the west by the Artillery Ground, and nearly surrounded by houses. At that period fairs were frequently held upon the spot, abounding with astrologers, conjurors, and mountebanks. Passing over the interval of one or two generations more, we find the new streets that had thus gradualiy sprung up inhabited by a new tribe of settlers-the progenitors of the present race of weavers.

At the junction of Bishopsgate Within and Without, is a small street leading eastward into Spital Square-the heart of the silk district in London-its old, sober-looking brick houses being occupied almost entively by the austere lords of the loom. This square is supposed to be identical with 'Spital Yard.' Bolingbroke once lived in this square. Two centuries ago, this was an open plot of ground, having a pulpit placed in the north-east comer, nearly fiac- 
ing the spot now occupied by Sir G. Wheeler's Chapel, together with a house near it for the accommodation of the Lord Mayor, the Corporation, their ladies, and other persons of distinction, during the preaching of the famous Spital sermons. On thess occasions, a curious display of official magnificence of attire was wont to take place. The city magistrates wore violet robes on the Good Friday and. Wednesday, and scarlet at the other services. The boys of Christ's Hospital were accustomed to attend the Spital sermons, until the period when the pulpit was destroyed during the civil wars. From the Restoration to 1797, they were delivered at St. Bride's. Church, and since that time at Christ's Church, Newgate Street.

- The modern silk-weaving district wears an aspect unique and peculiar to itself. There is a singularity and a general structural uniformity about the buildings quite characteristic of the region. The passing stranger, in traversing its crowded, dingy, and sinuous streets will be struck with the appearance of the wide lattice-like windows that run across almost the entire frontage of the upper stories of the houses. These ' lights' serve to distinguish them as the domestic factories in which the monotonous operations of the Spitalfields weavers are carried on, and which are absolutely necessary in order to throw a strong light upon every part of the looms, that are usually ranged directly under them. Many of the roofs of the houses, also, exhibit a variety of odd and ingenious 
contrivances, scarcely to be discovered in any other part of London. These consist sometimes of a singular species of bird-trap, and at others, of a curious specimen of mechanism, resembling a pigeonhouse, and which appears to be used as a large cage. These strange architectural excrescences, however, are rapidly disappearing - the weavers having now no leisure for any such superfluous recreative occupations. Not many years ago, they had the reputation of being the most famous bird-catchers within the limits of the metropolis. They were wont, in a great measure, to supply the home market with such British song-birds as linnets, woodlarks, goldfinches, chaffinches, and greenfinches. Many dwellings may even now be seen in some of the more secluded streets that have been converted into aviaries, all alive with the flutterings and chirpings of multitudes of these caged creatures. The birdsnaring operations used to be extensively carried on in the fields encompassing the northern suburbs, and principally in the months of March and October, by means of an apparatus totally unknown elsewhere. 'Call-birds' have been trained by them with great skill, and the whole of their proceedings have been conducted with great originality. There is even now a remarkable rivalry existing between some of the weavers, manifested by the heavy wagers they will frequently lay, as to which of their 'call-birds' will sing or jerk the longest-an exploit that is regarded as the test of superiority. The mode of 
testing the claims of the feathered competitors consists in placing them opposite to each other beside an inch of candle, and the bird that jerks the oftenest before the candle is consumed is deemed entitled to the wager. Birds have sometimes given 170.jerks in a quarter of an hour; and a linnet, during such a trial, has been known to persevere in its emulation till it swooned from the perch.

The abodes of the Spitalfields weavers will be observed to be chiefly of three classes-such classes only exhibiting different gradations in wretchedness. The domiciles tenanted by the better kind of operatives consist of three rooms, two on the basement and one long apartment above, which is entirely filled with looms, and appropriated to work, and, with the view of economising space, is generally entered by a trap-door in the floor. Where such dwellings are occupied by only one family, the decencies and comforts of domestic life may be to some extent cultivated and enjoyed; but they are too generally shared by two or more families. A second description of house consists of a narrow building, with three or four stories, all reached by one door and one dark winding staircase-each story com. prising only one room the entire width of the building, and each room constituting the miserable haunt of a separate household, sometimes with lodgers in addition, in which cooking, eating, working, sleeping, washing and arying of linen, and every other function of domestic life, are of necessity performed. The 
remaining class of hovels are of the very meanest character, and possess only one room; but these, happily, are not numerous. 'With very f'ew exceptions,' says Dr. Gavin, in his 'Sanitary Ramblings,' 'the dwellings of the poor weavers are destitute of most of those structural conveniences common to the better classes of houses. There are never any places set aside for receiving coals; dust-bins to hold the refuse of the houses are exceedingly rare, and cupboards or closets are nearly altogether unknown. There are never any sinks, and the fireplaces are constructed without the slightest regard to the convenience or comfort of the inmates.' The terrible sum of domestic wretchedness, and life-and-healthdestroying influences, sheltered in this 'bricken wilderness,' may be guessed from a view of the unparalleled denseness with which the conscripts of indoor toil are packed together. The inhabitants bear a proportion of rather more than six individuals to each house, with nearly seventeen houses to each acre. 'The average number of individuals per house throughout London is $7 \cdot 4$, and the average number of houses per acre is 5.5 ; so that, though each particular house contains one person less, still each acre of ground has twelve houses more built upon it than is usual throughout London.' It is an inevitable inference from these facts, that the majority of tenements in this part of the metropolis must be mean, comparatively low-rented, and incommodious. So far is this their almost universal character, that, according 
to the returns of the parochial officers in 1839 , the number of houses rated under $20 l$. was about 11,200 out of 11,782 .

There is considerable difficulty in arriving at an accurate estimate of the population comprised within the boundaries assigned to the Spitalfields district, and the proportion that the weavers bear to the aggregate number. A recent authority gives the total at 80,000. A reference to the population returns of 1851, however, exhibits the inhabitants of Bethnal Green alone at 90,193. Now, as this vast parish is principally embraced in the indefinable region denominated Spitalfields, and is peopled to a great extent by the silk operatives, we think the estimate of 80,000 is rather minimised than exaggerated. This view is further corroborated by the evidence taken before a Committee of the House of Commons on the silk trade in 1831-32, when it was affirmed that the population of the district in which the weavers resided, comprising Spitalfields, Mile-end New Town, and Bethnal Green, could not at that time be less than 100,000, of whom it was supposed that 50,000 at least were entirely dependent on the silk manufacture, and the remaining moiety more or less indirectly so. At the period just referred to, since which time the weaving fraternity have witnessed the most desolating changes in their trade - and social condition, the number of looms varied from about 14,000 to 17,000 , and of these, about 4000 or 5000 were generally unemployed in times 
of depression, which, unhappily, were of frequent occurrence. As there were, on an average, children included, about thrice as many operatives as there were looms, it is clear that during the staǵnations of trade, there were as many as ten or fifteen thousand persons reduced to a state of non-employment and privation.

Coming down to a later date (1838), it appears, according to the census of the silk operatives taken at the time of the Governmental Inquiry-and in the substantial correctness of which, the weavers with whom we have spoken acquiesce-that the number of looms was ascertained to be 10,196, of which 9302 were at work, whilst the residue, 894, were idle. Every two looms, it is estimated, employ five hands, including those engaged in warping and winding, as well as weaving; so that the total number of weavers actually employed, taking adults and children, would amount to more than 20,000. In the year 1836, Mr. M'Culloch, as the result of very extended and elaborate researches, estimated the aggregate number of silk-weavers in the country to be 200,000 ; the amount of wages paid 3,700,000l.; the interest in wear, tear, profits, \&c., 2,600,000l.; and the total annual value of the silk manufactures of Great Britain, 10,480,000l. Now, accepting 20,000 as the number of operatives actually employed in that year in Spitalfields, this. would show one-tenth of the silk goods manufactured during that period, amounting to a value of more than one million 
sterling, to have been their production, for which they received about $370,000 l$. in the shape of wages, being an average of $18 l$. 10s. per annum, or just over $7 \mathrm{~s}$. a week per head. 'Now, from inquiries made among the operatives,' says a correspondent of the 'Morning Chronicle,' who entered into the subject some years ago, 'I find that there has been a depreciation in the value of their labour from from 15 to 20 per cent. since the year 1839; so that the total amount of wages now paid to the weavers is $60,000 l$. less than what it was ten years back. It may, therefore, be safely asscrted, that the operative silk-weavers, as a body, obtain 50,000l. worth less of food, clothing, and comfort per anmm now than in the year 1839.'

PART II.-HISTORY OF THE SPITALFIELDS SILKWEAVING.

It was some time during the thirteenth century that a large quantity of silk fabrics was first introduced into this country. The novelty, richness, and splendour of the article speedily secured the patronage of the opulent and noble. The first documentary evidence we possess, however, of the naturalisation of the manufacture in England, is found in an act of Parliament passed in 1363, in which 'women' employed in the weaving of 'silk' are expressly excepted from some restrictions then imposed ripon certain specified avocations. From this period there appears to have been a class of females designated 
'silk women,' employed in the production of ribbons, and so forth, for the protection of whose occupation a prohibitory law was promulgated, preventing the importation of all similar articles from abroad. There are no records to show that these early English mothers of the beautiful art of weaving inhabited Spitalfields and Bethnal Green; spots which were, indeed, at that era, completely in the country, and almost free from human dwellings.

During the latter half of the fifteenth and the early part of the sixteenth centuries, there is evidence to show that the silk goods manufactured in England were confined to small and inferior articles; for while, by a statute of 1502 , it was declared illegal to import 'silk ribands, laces, girdles, corses, and corses of tissues or points, under pain of forfeiture of the same,' persons were permitted freely to introduce silks in other forms, whether raw or manufactured. The manufacture of 'broad-silks' (lustrings, satins, velvets, \&c.) dates its origin a full century afterwards. James I., after having unsuccessfully attempted to introduce silkworms into this country, turned his attention to the advancement of the manufacture in its higher styles and wealthier fabrics; and by affording encouragement to Mr. Burlamach, a London merchant, he attracted some silk-throwsters, silkdyers, and broad-silk weavers to the metropolis. From this auspicious commencement, the operatives multiplied so rapidly, that by 1629 the former class constituted a body of sufficient importance to be 
LIFE AMONG THE SPITALFIELDS WEAVERS. 231

incorporated. By the year 1661, they are said to have employed about 40,000 men, women, and children; a statement, however, that has been deemed by some persons to be an exaggeration. The growing importance of the broad-sillk weavers at that time is apparent from the fact that in 1638 the Weavers' Company-one of the oldest of the City companies, established when the woollen manufacture formed the staple of English industry-were empowered to admit a certain number of them into their honourable body, provided they were 'conformable to the laws of the realm, and to the constitution of the Church of England!'

But a new and surprising impetus was soon after given to the silk manufactures of England, by an event replete with tragic and terrible interest to all European people. We refer to the massacre of the Huguenots -a name by which a host of unfortunate victims to Popish perfidy and sanguinary despotism have been immortalized on the monuments of history. A law, known as the Edict of Nantes, promulgated by Henry IV. in 1598, for the tolerance and protection of the French Protestants, was revoked by Louis XIV. in 1685 ; the revocation being initiated by a simultaneous and fearful slaughter, and followed by the sudden expatriation of a vast number of that cruel monarch's best subjects, a number that has been varibusly estimated at from 300,000 to $1,000,000$. A considerable portion of these came to England, many of them making London their city of refuge. 
Alluding to these poor exiles, Stow has the following excellent remarks:- 'The north-west parts of this parish (Stepney), Spittlefields, and parts adjacent, of later times became a great harbour for poor Protestant strangers, Walloons and French; who, as in former days so of late, have been found to become exiles from their own country for their religion, and for the avoiding cruel persecution. Here they have found quiet and security, and settled themselves in their several trades and occupations; wEAvers especially; whereby God's blessing is surely not only brought upon the parish, by receiving poor strangers, but also a great advantage hath accrued to the whole nation, by the rich manufacture of weaving silks, and stuffs, and camlets, which art they brought along with them. And this benefit also to the neighbourhood, that these strangers may serve for patterns of thrift, honesty, industry, and sobriety.' In 1687, no fewer than 13,500 of these refugees were sheltered and relieved in the metropolis alone, all of whom, excepting 500 families, possessing a higher social status, were artisans and husbandmen. In one single year $40,000 l$. was collected for them ; and four years subsequently a royal order was issued, providing for them a free admission and hospitable welcome at any of our ports, and granting every facility for their naturalisation as British subjects. For a long period the French language was universally spoken by the population of Spitalfields; and even within the 
LIFE AMIONG THE SPITALFLLDS WEAVERS, 233

memory of persons now living, their religious rites were performed in French, in chapels erected for that purpose.

The beneficial consequences of this large influx of skilled operatives were soon visible in the prosperity of the silk manufactures, as well as in other industrial departments. The refugees introduced the weaving of the various silk fabrics known by the names of lustrings, alamodes, brocades, satins, black and coloured mantuas, black padua-soys, ducapes, tabbies, and black velvets, thus rendering us less dependent on foreign supplies. Once settled and rooted here, however, the adopted strangers, like their predecessors, clamoured for protection, which they succeeded in obtaining, in the shape of a legislative act, prohibiting the importation of foreign lustrings and alamodes. Their object, however, was speedily defeated by a change of fashion, which drove these privileged articles out of the markets.

Another important change was effected in the silk trade in 1718, through the labours of Sir Thomas Lombe, who introduced from Italy the process of organzining (or preparing for the weaver) raw silk by the aid of machinery, and for which commercial benefit Parliament awarded him a recompense of 14,000l. The rapid advancement of the manufacture in Spitalfields, owing to the crown and the legislature, is disclosed in a petition presented by the Weavers' Company in 1713, wherein they stated, that the silk weaving at that time was twenty times 
greater in amount than in the year 1664 ; that their productions were fully equal to French fabrics; and that black silk, for hoods and scarfs, which 25 years before was all imported, was now made by them to the annual value of $300,000 \%$. The invention of Lombe's machine was hailed as a great triumph and boon for England; and it was then supposed that every part of the process of manufacture might be accomplished by our domestic skill, being dependent upon foreign lands for nothing but the raw material. It was soon found, however, that Italian organzined silk could not be dispensed with, for the warp (with which the cross threads or shoot* are interlaced) in the weaving process, owing to some superiority in the quality of the Italian production, arising from the influence of the climate, in combi-

* 'In employing the terms warp and shoot, or web and weft, we may explain, that in weaving silk these are made of different kinds of threads, the warp being formed of threads called organzine, and the shoot from other threads called tram. The raw silk imported from Italy, India, China, \&c., in the form of skeins, must pass through the hands of the "throwster" before the weaver can use it. The throwster, by means of a machine, twists the silk into a slight kind of thread known as "singles," and these singles are combined to form tram, or organzine. Tram is formed of two or three threads of silk lightly twisted together; but organzine is the result of a larger series of operations . . the whole of which operations are included in the general term "silk-throwing," and are entirely distinct from the weaving. Nearly all the Spitalfields population engaged in the silk manufacture are weavers; the throwsters being spread over various parts of the country, and working in large silk factories.'Knight s London. 
nation with other causes. This preference exists to a great extent even at the present day, notwithstanding the achievements of English ingenuity; and it is owing to this fact that, despite a high prohibitory duty, foreign thrown silk has always met with a certain, although limited demand, from English silkweavers.

Notwithstanding the great increase and success of the Spitalfields weavers during the reigns of Anne, George I., and George II., French goods still found. their way into England, either by smuggling or by honourable trade, according to the state of the import laws. This induced them to clamour for 'double duties' on foreign fabrics; and, on their request being refused, they became more importunate and menacing, and went to the House of Commons, on January 10, 1764, with 'drums beating and banners flying,' to demand the total prohibition of the obnoxious goods. Although the legislature refused to succumb to this intimidation, acts were passed lowering the import duty on raw silk, and prohibiting certain articles. In the following year, fresh concessions were demanded, and partially granted, to avert threatened outrage.

These unseemly collisions and disputes between the silk operatives and the legislature, soon extended to the masters. Emboldened by the concessions they had wrung from their rulers, they next resorted to summary measures to coerce their employers into an advance of wages; destroying the looms and the 
houses of such as declined compliance with their arbitrary demands. To settle these altercations, an act was passed in 1773, empowering the aldermen of London and the magistrates of Middlesex to regulate at quarter-sessions the wages of journeymen weavers, penalties being inflicted upon either party who should violate these authoritative regulations. In 1792; this act was made to extend its beneficent wings to, those who worked upon mixed materials; and in 1811 the female weavers were brought under the same regulation. These three enactments constituted the 'Spitalfields Acts,' and which were repealed in 1824. These impolitic acts have entailed infinite mischiefs upon this suffering branch of British industry. One of the most conspicuous evils to which they gave birth was the inordinate spirit of competition. Many of the employers, galled by the restrictions imposed upon their enterprise in the metropolis, took their looms into the provinces, set on a large number of weavers at reduced wages, became formidable rivals in the markets, and thereby accelerated the ruin of the entire body of operatives.

The introduction of the Jacquard loom about this time, by which figured silks can be made with much greater facility than heretofore, exercised also a marked influence upon the destinies of the trade, regarding the precise nature of which, however, there are very conflicting opinions abroad. Still, by the aid of this improved machine, more complicated 
and elaborate articles may be fabricated than by the old method. We have seen it stated that there are 60,000 Jacquard looms in Manchester and its neighbourhood; while in the lingdom it is supposed that there are no fewer than 150,000 in use.

The prospects of the trade at the present time are gloomy enough, nor do we perceive a streak of brightness in the clouded sky. The power-loom, that has effected such mighty revolutions in other departments of manufacture, and entirely displaced whole branches of manual dexterity, seems incapable of more than partial application to the manufacture of silk. Except for the most inferior goods it does not possess any decided advantages over the handloom, owing to the exceeding delicacy of the material to be worked, and the close attention that must be given to the process of the weft, which render it so frequently necessary to stop the machine, to avert or repair injuries. In reference to hand-loom weaving, Mr. Hickson says, that 'it is not only incapable of improvement, but of remaining in its present state. The best friends of the weavers are those who would advise and assist him to transfer his labour to other channels of industry. If he cling to the hand-loom, his condition will become worse from day, to day. A few of the more skilled class of weavers may indeed maintain their position, but the fate of many (unless their intelligence and foresight avert it by change of occupation) is, decreasing employment, dwindling wages, and ultimate destitution.' 



\title{
HISTORY OF THE CHEAP PRESS.
}

\author{
THE DAILY TELEGRAPH.
}

IT is scarcely thirty years since a periodical was issued from the press, which at the time of its appearance, and long afterwards, was accounted one of the marvels of cheap literature. That periodical, as will at once be divined, was the 'Penny Magazine.' In one sense it was not original, being in fact more or less an imitation of a popular publication brought out a little time before in Paris, by M. Emile de Girardin, under the title of Le Journal des Comnaissances Utiles. But it was new to the English public, and very speedily obtained a wide-spread reputation and very general support. People marvelled that such a work could be issued at such a price. True, the Magazine was published under the auspices of the Society for the Diffision of Useful Knowledge, and was conducted by an editor, Mr. Charles Knight, whose valuable knowledge and experience were wholly at the service of the enterprise. And still it seemed incredible that eight large pages of printed matter, well written and well arranged, adomed too with woodcuts by no 
means deficient in merit, could be sold to the public at one penny, without entailing a ruinous loss upon the proprietors. Great was the astonishment accordingly, and great the satisfaction among the friends of popular progress, at the continued success of the new periodical. The more reflective saw that a new era was dawning, and that the printing-press was entering upon a fresh stage of its development, in which results were to be produced, such as in olden times could scarcely have entered into the most hopeful anticipations of Koster, of Faust, of Guttenberg, of Schoeffer, or of Caxton.

And they were right. The 'Penny Magazine' may fairly be said to have been the pioneer of the cheap press, clearing the way for the long line of popular periodicals which followed it. But what great advances have been made since Mr. Knight's useful and meritorious publication first saw the day! The literary marvel of 1832 was the 'Penny Magazine.' In 1861 it is the penny daily newspaper. If the one caused astonishment and admiration in its time, what are the feelings which must be excited when we contemplate the other ! - the latest result of the great invention, which is silently effecting mightier changes than were ever accomplished by any other human agency.

It is no figure of speech to say that the penny daily newspaper of to-day is one of the most remarkable products of our modern civilization. Glance at its well-filled columns and its massive 
pages. You find there telegraphic intelligence from all quarters of the globe, transmitted with a rapidity that rivals the wonders of Eastern romance; you find correspondence from the chief cities of the Continent, from America, from Asia, from Africa, from Australia, from every spot in which events are passing that afford interest to English readers: you find a complete record of domestic events, the proceedings in parliament and in the law and police tribunals, the movements of the royal family and of the court, the exploits of the army and the navy, the progress and development of the Volunteer corps, the speeclies delivered at public meetings, at dinners, and at provincial gatherings, criticisms upon the latest productions of art and literature, besides daily comments upon home and foreign politics, and the social topics which claim the attention of the public writer. Nothing is wanting to place the penny paper on the same level with its high-priced contemporaries, which but a few years ago enjoyed the exclusive monopoly of public support. Not only does it contain intelligence of every kind quite as complete and quite as early as its rivals; but the remarks it ofiers mon that intelligence are distinguished by equal. knowledğe, equal ability, equal force of expression, and by a loyal, temperate tone, against which even Conservatism can bring no accusation.

The idea, indeed, that a penny paper must necessarily be an incendiary paper has long since passed away. In the days of Pitt and Castlereagh it might 
have been entertained perhaps with some show of reason, but in the days of Palmerston and Gladstone it is utterly out of date. The cheap newspaper is universally supported without being either a torch of revolution or a firebrand of discontent. It makes no appeal to vulgar political passions, does not in any way pander to popular prejúdice, or base its claim to favour upon ignorance and credulity. There are no fierce invectives in its columns against the sovereign, no vindictive tirades against the aristocracy, the clergy, or the wealthier classes, no misleading interpretations of the rights of capital and labour, no houndings on of the employed against the employer; in a word, the views it puts forward, though expressed in bold, vigorous, and outspoken language, are in accordance with the advanced state of public opinion, and are such as meet with endorsement by the great majority of liberal thinkers. As in religious inquiry the day has passed for the scurrility and profaneness of Tom Paine to find favour, so in political discussion all sympathy with the eloquence of Orator Hunt, or the coarse abuse of Cobbett, has completely died away.

The advantages to the great mass of the community of a cheap daily paper, thus conducted, it would loe difficult to overestimate.

Almost every man who can read is enabled to do so in the present day, and learn thus something of what is occurring in other districts besides those in which he chances to pass his days. And this is no mean advantage either to individuals or to the state. It 
may be quite true that the information so obtained is superficial and imperfect; and if we were to accept the popular dictum, that a little knowledge is a dangerous thing, we might consider this a case in which its truth would be fully illustrated. But there is something far more perilous than knowledge, however small, however superficial, however imperfect, and that is-ignorance. The working man who reads his penny paper every morning may not have the most enlightened views upon political or social topics; but his opinions are at all events likely to be far better than those of his comrade who never opens a journal at all, and who lives on from week to week in the narrow circle of manual labour and uninspirative domestic intercourse.

Let a time of national trouble and commotion arise-provoled it may be by war, by a bad harvest, by insufinciency of employment-which of the two men is likely to prove more dangerous? The one will be guided by his mere instincts or passions, and will be ready to listen to any declaimer who promises to ameliorate his condition. The other will have obtained some knowledge of the causes of his misfortunes, and will be slow to adopt any remedies which do not to some extent meet with the sanction. of his better sense.

We do not wish to push this comparison too far. It is honest Sancho, we think, who says that, 'a hungry belly is an evil counsellor ;' and there can be no doubt that many well-instructed men, under the 
pressure of a personal calamity, are apt to attribute that calamity to wrong causes. But such men are at all events more accessible to reason and argument than those whose minds are utterly uncultivated.

It would not be difficult, we think, to show that the penny paper is effecting among working men, and a portion of the middle classes, what no other form of popular literature could effect. It brings them, if we may say so, face to face with the rest of the community. In reading day by day his penny journal, the operative or the small tradesman feels that he is admitted, as it were, into the confidence of contemporary history. Nothing is a secret to him. $\mathrm{He}$ feels that he is no longer standing outside the barriers raised by wealth and exclusiveness. He, too, knows what is passing in Parliament, what is taking place abroad, what is occurring at home. $\mathrm{He}$ feels that no measure will be adopted by the legislature, in the discussion of which he has not to some extent a voice; that no public event can happen in which he does not, as it were, play a part.

And let no one think it is a slight thing to have accomplished such a result as this. When all classes of a great community are brought into relation with each other, when the highest and the lowest alike feel that they have a stake in the nation's welfare, one great cause of disaffection is removed, and the very foundations of patriotism are strengthened. But we need not dwell upon this theme. In the 
publicity given to every event by the press lies the very essence of our national freedom. The penny daily, paper has extended that publicity as it never was extended before, and is exerting thus an influence which, vast as it already is, may be considered as yet only in the infancy of its development.

One feature in connection with the penny daily paper, which to some extent accounts for its widespread influence, is the facility with which it can be obtained. In the outskirts of London, at all the railway stations, the very earliest travellers by the morning trains find the news-boy at his post, provided with his budget of journals, until an ever-increasing demand has exhausted the supply. It is the same at the omnibus stations. It is the same at the metropolitan railway termini. Nay more, if we go away from the capital to any part of the country, the penny paper is just as accessible. In Manchester, in Liverpool, in Nottingham, in Birmingham, in all our provincial towns, it is to be obtained without difficulty, and within a comparatively few hours after publication. Ere its weary editor and sub-editor have left their beds you will meet with it at Bristol, at Devon, at Lincoln, even at Exeter in the distant west, or at York in the far-off north.

Wherever sold too, it is still a penny paper, no charge being added whatever the distance it may have travelled after leaving its publishing office in Fleet Street or the Strand. In the good old daysand not very distant days either-people had to 
wait for the slow action of the post ere receiving their London journal. When it arrived, too, it came saddled with an additional penny, the charge for transmission.

This system is already almost a thing of the past. Private enterprise has gone far ahead of state regulation. The real post-office for newspapers is now at 184 Strand, and the directors of that establishment, Messrs. W. H. Smith and Son, although no government officials, have business under their exclusive control, rivalling in extent and importance with that of a department of State.

They are in fact the great newspaper carriers of the country. "They have an establishment in the strand, which, although a palace externally, is one of the busiest of hives within. They have almost an army of employés, clerks, sorters, messengers, $\&$ c., besides an immense number of light carts somewhat similar in size and aspect to those used by St. Martin's-le-Grand. You will not see many such carts in the London streets during the time when those streets are most animated and bustling: But if you are an early riser, a very carly riser be it understood, you will meet with them in every direction, and will form a good idea of the speed at which they can proceed through metropolitan thoroughfares, which a few hours later allow no vehicle to advance except at the pace of the snail.

These carts are laden with the very earliest impressions of the morning newspapers, and are pro- 
ceeding to the various metropolitan termini to catch the first departing trains.

A smart race it is sometimes; for a press of matter, or unusually late debates in the House, may retard the publication of the daily papers, and then if country customers are to be supplied at their usual hour, it must be quick work indeed with the vehicle which has charge of Messrs. Smith and Son's despatches. But it is seldom that there is any failure on the part of the great newspaper carriers. Their carts leave Fleet Street or the Strand at the very last moment, but they reach the North or South Western as the case may be, ere the clock has quite struck the hour of departure, fling their burdens into the carriage appointed to receive them, and have a full half-minute to spare before the train in waiting swiftly glides away from the platform.

It is in this manner that the provincial districts are supplied with the London joumals before even the metropolis itself has obtained its own copies, thanks to the agency of Messrs. W. H. Smith and Son.

Into the details of management adopted by this firm it is of course not our province to enter. We need scarcely do more than point out that their transactions must necessarily be on the largest scale to allow them to undertake the carriage of newspapers to all parts of the country free of charge to the public. Some idea of the magnitude of their business, and of the rate at which it has increased, 
may be formed when we state that at the commencement of the year 1858, the number of copies of The Daily Telegraph taken by this house amounted to about 8,000 a day. In December, 1860, the number taken daily of the same paper had increased, we believe, to nearly 25,000 copies.

A more striking illustration of the extraordinary development of the cheap press could not be found, pernaps, than in these figures.

In connection with the transmission of newspapers to all parts of the country, we must not overlook one of the sights of 'the City,' which cannot fail to strike a stranger with amazement-we mean, of course, the General Post Office about 6 P.Mr., especially on a Friday evening, when, in addition to the ordinary business, as one may say, the weekly papers are being posted. Enter we St. Martin's; time, 5.50 p.M., Bradshaw style.

Here come the porters from the various newsvendors. Puffing, panting, straining under huge sacks of papers, they chase one another up the stone steps of the portico. Troops upon troops jostle up, and it is as much as beadle and police can do to keep the way clear. Thicker and thicker they come. The usual slit for papers won't serve now. A whole casement is torn away to admit the news, by the sackful. Baskets large as a crockery crate fill every minute, and vanish, while empty ones come forth in turn. The porter inside seizes the sacks, and pours their load out. 


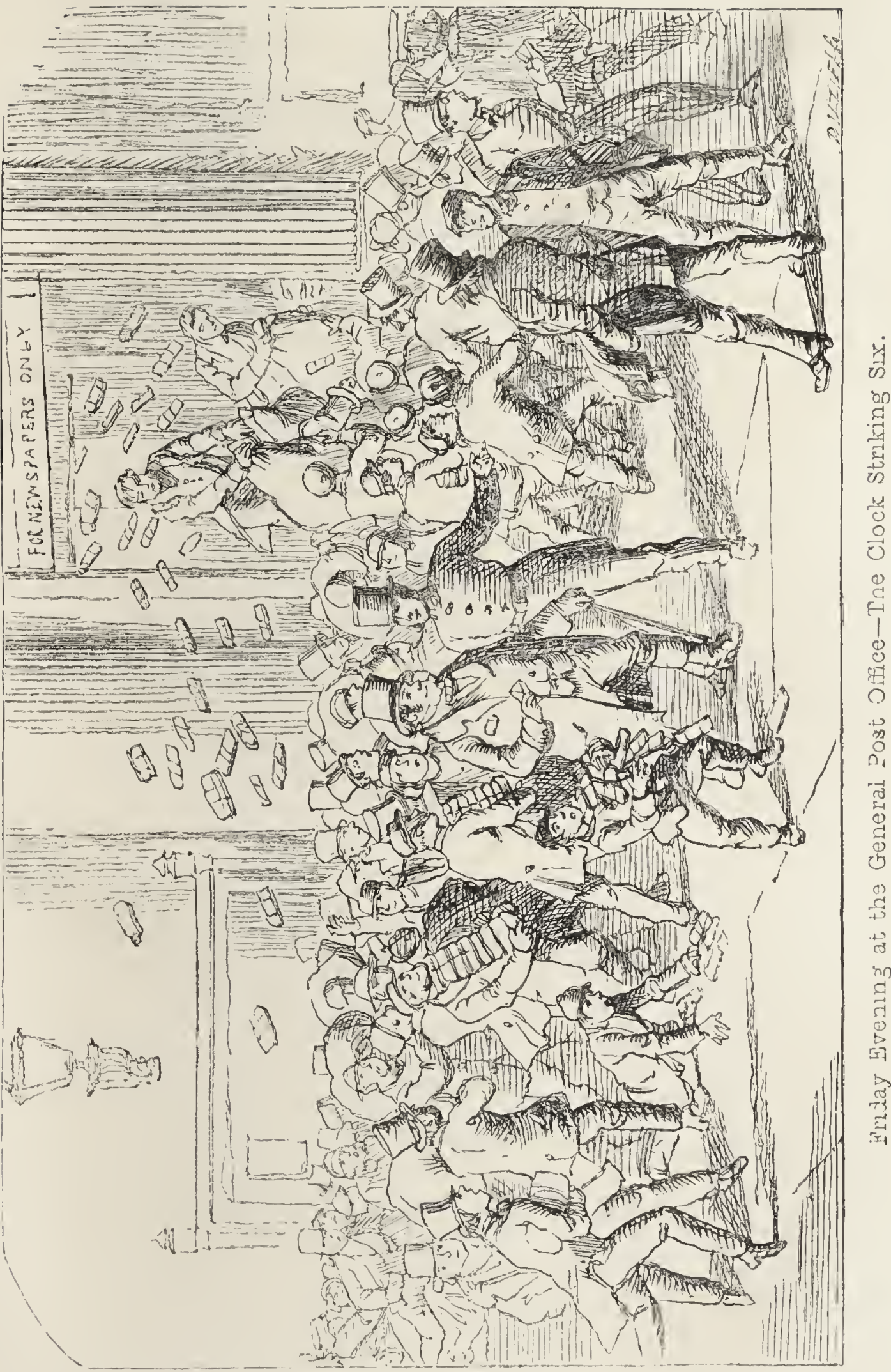



'Mind your eye,' cries Pat, as he bangs his bag right in, and himself almost with it.

'Look out, old fellow,' another cries, who, having only one paper well bound up, can take excellent aim at the man inside.

A roar of rough laughter succeeds the lucky stroke. Commend us to the pillory rather than to that unlucky wight's post.

'One !' goes the clock.

'Quick, quick, you're too late,' sing out a mob of lungs ; and the stream of cords, fustians, canvas, and shirt-sleeves, runs apace.

'Two !' goes the clock.

Sackful after sackful pours in.

'Gallop for your life.'

'Run along, little one.'

'Three!'

'Four!'

More and more furious still.

'Five!'

A last rush is made, and a score of sacks go in together.

'Six!'

The stroke of doom. The casement flies to. So nicely timed have been the movements of the rogues, that the chase ceased exactly as the clock struck.

'No; a solitary, wet, red-hot face gets to the spot one tick too late. Poor fellow, he deserved to win, for he has galloped hard. He throws down his freight, and falls back breathless against one of the 
stone pillars of the hall. Used up quite is he, and so mortified as fain to let tears roll down his moist cheeks.

Listen to the urchin marching up and down, and mocking his distress :

'Yesterday's Times half-price! Yesterday's Times, half-price!'

Having alluded to The Daily Telegraph, we cannot do better, perhaps, than give something like a sketch of the rise and progress of that remarkable joumal, which, as the first of the penny daily paper's, may claim the proud distinction of having inaugurated a new era in the history of the English press.

There is an additional reason, too, for selecting this journal, inasmuch as it has firmly established itself in public favour, and, triumphantly proved that the principle upon which it is based has all the elements in it of stability and success. The Daity Telegraph, it cannot be denied, is a power in the State, and one the influence of which pervades all classes. For it should never be forgotten that although the penny daily paper has created, and will go on creating, a new class of readers, it has obtained at the same time a strong hold upon those who formerly were led by the high-priced journals: Only a short time since, a conservative organ of some pretensions, complaining of the influence exerted by the organ to which we have just referred, admitted that if it could only afford better paper it might 
seriously damage The Times itself. It has already done so. It was a fatal blow indeed to the antthorities in Printing-House Square when they discovered that a paper could be issued at a penny in all respects save one-the quality of the texture upon which it was printed-as good as the 'leading journal.' Previously it had been the boast of The Times that it stood alone among its contemporaries.

'Look at them,' it used continually to say, in exulting tones; 'they cost as much as we cost, and yet see how far they are below our standard. We have the earliest news, the fullest news, the most reliable news; we spare no expense to render our journal absolutely perfect; we have correspondents of education and ability in every part of the globe. Telegraphic despatches are sent to us every hour, and are published as soon as they arrive. Then, too, we are absolutely free from the domination of party, faction, or clique. We care not one straw, personally, whether Lord Palmerston or Lord Derby is at the head of affairs; we are only for the general weal, le bien pubtic. Measures, not men, is our motto. Whatever may arise, we shall watch over the national interests, and guard them from all attacks. Let all who have a complaint to make, a suggestion to offer, or a difficulty to solve, come to us. As we are above all party consideration, so are we above all pecuniary temptation. Public support is what we rely upon, and to retain that support we 
have only one policy open to us-the policy of honesty and independence.'

Such was the tone continually maintained by The Times; and for many years it seems to have been justified by the fact that no other paper laid claim to the position the 'leading organ' undoubtedly occulpied in public estimation.

But the case is different now.

Another paper has arisen which may fairly take credit to itself for the qualities of which The Times once had the monopoly. The Daily Telegraph can say, and justly say, "We have a correspondent of ability and education in every part of the globe. Our telegraphic despatches are as good as those of The Times, for they are the same, word for word, and reach us through the same agency. We, too, are under the skirts of no party, and disdain to make ourselves the hired mouthpiece of a faction. We think only of the national welfare, and would as gladly welcome a Tory as a Whig, or a Radical to the head of affairs, if his measures were conceived in a liberal and patriotic spirit. We, too, invite all who have wrongs they wish to redress,proposals they wish to offer, or sentiments they wish to express-to come to our columns, where they are sure of an impartial hearing, and of attentive regard.'

Such, we say, might fairly be the programme of The Daily Telegraph, and such, indeed, it is. But the new journal has an advantage over the old, 
which it may well leave to the last, as its crowning recommendation to favour.

It can say, "We offer to our readers all that you offer, in everything that is primary and essential; and we do this at just one fourth of the price you charge. The Times is sold for fourpence. The Daily Telegraph costs only a penny.'

We have quoted the views of a conservative periodical as to the injury which The Daily Telegraph, if printed upon better paper, might inflict upon The Times. Into possibilities and speculations it is not our intention now to enter. We would merely advert to a fact which we believe is not yet very widely known, that The Daily Telegraph has, indirectly, if not directly, been the means of diminishing the circulation of The Times in the country. Immediately it became evident that London could support a penny daily newspaper-the large provincial centres felt that they could support one also. Accordingly, in all those busy places, local Telegraphs have been started, and although some have failed, a large number still remain, and may be regarded as permanently established. Where fifty and sixty copies of The Times used formerly to be taken, only five or six are now received by certain agents.

So-much for the influence of The Daily Telegraph.

Yet the paper at its commencement had to encounter difficulties and obstacles which most people thought must prove insurmountable. To begin with, the majority of established journals looked 
with absolute disfavour upon the new comer. The first copy of The Daily Telegraph and Courier appeared on Friday, June 29, 1855, during the heat of the Crimean War. Its price then was twopence; and for this sum it did not give very full or very recent news. Four pages were all it contained, and there was but little in them which had not previously appeared elsewhere. People shook their heads, and referred to the unsuccessful attempt of The Daity News years before to break up the monopoly of high-priced journalism. This second essay they said would be as unsuccessful as the first. And it might have been, had not the authors of it modified their plans. Taking advantage of the abolition of the impressed nervspaper stamp, they had started a daily journal at a price which they imagined would be sufficiently low to insure them success. But they soon found they had made a miscalculation. Twopence was at once too much and too little for the commodity offered. New readers were not created by it, and the old were not allured away from journals already established; 'accordingly, after a very short trial, The Daily Telegraph reduced its price to one penny. This was on Monday, September 17, 1855.

The step was a bold one, but it was the only one likely to lead to success. At once the paper increased in circulation and in influence. It was still very far from equalling the established high-priced journals. Its news was necessarily somewhat bald; its reports a little behind time; it had no foreign 
correspondents, and but a limited London staff. Still, from the day on which its price was reduced. to a penny, a fresh element of vitality had been introduced into its organization, and it could scarcely do otherwise than go on improving.

Slowly, but surely, as it made its way amongst enemies and rivals, it strove to render itself worthy of the most extended support. Writers of distinguished talent were engaged to write its leading articles; a good staff of parliamentary reporters was secured; foreign correspondents of eminence were engaged. Day by day the public noted the change, and began to talk more and more about the new organ. Even those who had disdained at first to notice it now found themselves compelled to accord it some little attention.

Success carried with it of course its usual penalties. Other London penny papers arose directly it was seen that the first was becoming an established journal. There was thus the competition of old and new rivals to stand against. But The Daily Telegraph still kept steadily advancing on its way.

From the first The Times had indirectly shown itself bitterly hostile to the cheap press. Among the many country imitations of The Telegraph which speedily arose, it was natural that some should prove failures. Whenever one of these unlucky speculations came to an untimely end, the 'Leading Journal' ostentatiously chronicled the fact, never omitting to mention that it was a penny paper which had suc- 
cumbed. The inference to be drawn was of course that none but fourpenny papers could stand their ground.

A large portion of the public, however, declined to accept that verdict, and continued to support the new organs.

Soon came another era in the history of low-priced journalism. From the first The Daity Telegraph and its imitators had contained only four pages, and it was not thought possible, even with a knowledge of the American press to guide opinion, that this size could be enlarged without a corresponding increase in price; but a London morning newspaper, inventing a new system by means' of which it appeared with some slight modification under two titles, and at two different rates, suddenly astonished the metropolis by giving a double sheet on exactly the same terms as the single sheet of The Telegraph. The Standard at one penny contained in fact exactly the same news as The Morning Herald at fourpence, both being owned by one proprietor, and both being printed with the same types. The leading articles and the texture of the paper alone were different.

It was not to be supposed that The Daily Telegraph should allow itself to be outdone by a younger rival. Accordingly, although it had no such appliances at its disposal as those to which we have just referred, it almost immediately followed the lead of The Standard, and on Monday, March 28, 1858, appeared for the first time as a journal of the same size as The 
Daily News, The Post, and the other morning papers.

By this step many people said it had sealed its own ruin. There was no chance of its maintaining existence. Persons who should have known better were the loudest in prophesying evil. The writer of this paper was at a public meeting on the evening of the day when The Daily Telegraph doubled its size, and was so placed that he could not but overhear the conversation of 'the gentlemen of the press' close at hand. They were nearly unanimous in adopting this tone:

'Did you see The Telegraph this morning?' said one.

'Yes, indeed,' replied the person addressed, seeming to indicate by gestures that the sight had filled him with acute suffering.

'Did you notice the advertisements?' inquired another of the party, with a look of deep compassion.

'Shovelled in,' was the pitying rejoinder.

'I give it three months,' said a fresh speaker. And more remarks of this kind would doubtless have been uttered but for the observation of a gentleman who had hitherto remained silent, and who now announced that he had the honour of representing The Daily Telegraph, and that he felt bound to intimate this fact to the speakers before they continued their conversation.

The Daily Telegraph doubled its size as we have said in the spring of 1858 , and to judge by its pre- 
sent appearance, in the winter of 1860 , it has not had cause to regret the change. We will not enter into any dry details or statistics to indicate its existing position; we will merely take the reader with us to the premises in which the paper is published, and let him draw his own conclusions from what he sees there.

We are in a clean and cheerful-looking countinghouse in Fleet Street, and stand in the presence of some five or six clerks busily engaged with their account books. This is the advertisement office of The Daily Telegraph, we are told, and if we had not been told we should have divined the fact from the transactions taking place at the counter in front of us, and the clink of precious metal which accompanies them. We sce a calculating gentleman adding up a long list of figures, and we know that the total represents the day's receipts in the department we have entered. Lest we grow splenetic let us depart at once, and declare that we envy no man his prosperity while we can do so with a good heart.

We pass by a side door into Peterborough Court, along which the premises connected with the paper extend for many yards. We proceed onward and then re-enter by another door, and find ourselves in a very different part of the building. On our left is a porter's lodge, a little like the loge of a Paris concierge, but a good deal more like the stage doorkeeper's abiding-place at a theatre. Unless we are provided with good credentials it will be in vain for us to attempt to pass beyond. The Cerberus on duty is not 
surly, he is merely suspicious. Six feet in his stockings, and with strong muscular development in the arms and legs, he is evidently not a man to be trifled with. $\mathrm{He}$ is tormented by so many visitors who want to see the 'editor,' who must see the editor, who never do see the editor, and who yet will not be persuaded that the editor is invisible, that he looks askance upon a stranger, and is already preparing to repeat to us his usual formula, 'you must write what you have to."say, and it will be sent up.' Fortunately our eye falls at this moment upon one of the principal proprietors of the journal, by whose courtesy we have received permission to visit the establishment, and upon a sign from this gentleman we are permitted to pass onwards.

We descend a staircase, the walls of which have no other adornment than is conferred by whitewash painted upon rough brick, and after a very few steps find ourselves in a cellar redolent with the damp and. unsatisfactory odour which even the best-ventilated cellars are only too prone to accumulate within their cavernous walls. A turning to the right takes us into an inner cellar stocked with piles upon piles of paper, extending from floor to ceiling. We are about to hazard some pleasant remark upon the large number of reams we see before us, and to express our opinion that they are sufficient for many months; but we altogether think better of it when we learn that we are looking mpon little more than a couple of days' supply. 
Of the accuracy of this information, indeed, we are soon enabled to form some idea. For in the 'wettingroom,' where the paper is being damped, quire after quire is being passed by hand rapidly in and out of a cistern of water, and huge as the pile is which has already accumulated, it is only a small portion, we are told, of what will be required on the morrow.

And now we are in the printing-room itself, and stand in presence of the beautiful 'ten-feeder' machine, invented by Colonel Richard M. Hoe, of New York, and sent from that city to London expressly for The Daity Telegraph. The description of the machine, published by the journal, is so complete that we cannot do better perhaps than introduce it here.

'It is, as its name (The Ten Cylinder Type Revolving Machine) indicates, on the rotary principle; that is, the form of type is placed on the surface of a horizontal revolving cylinder of about four feet and a half in diameter. The form occupies a segment of only about one-fourth of the surface of the cylinder, and the remainder is used as an ink-distributing surface. Around this main cylinder, and parallel with it, are placed ten smaller impression cylinders. The large cylinder being put in motion, the form of types thereon is carried successively to all of the impression cylinders, at each of which a sheet is introduced and receives the impression of the type as the form passes. Thus as many sheets are printed at each revolution of the main cylinder as there are 


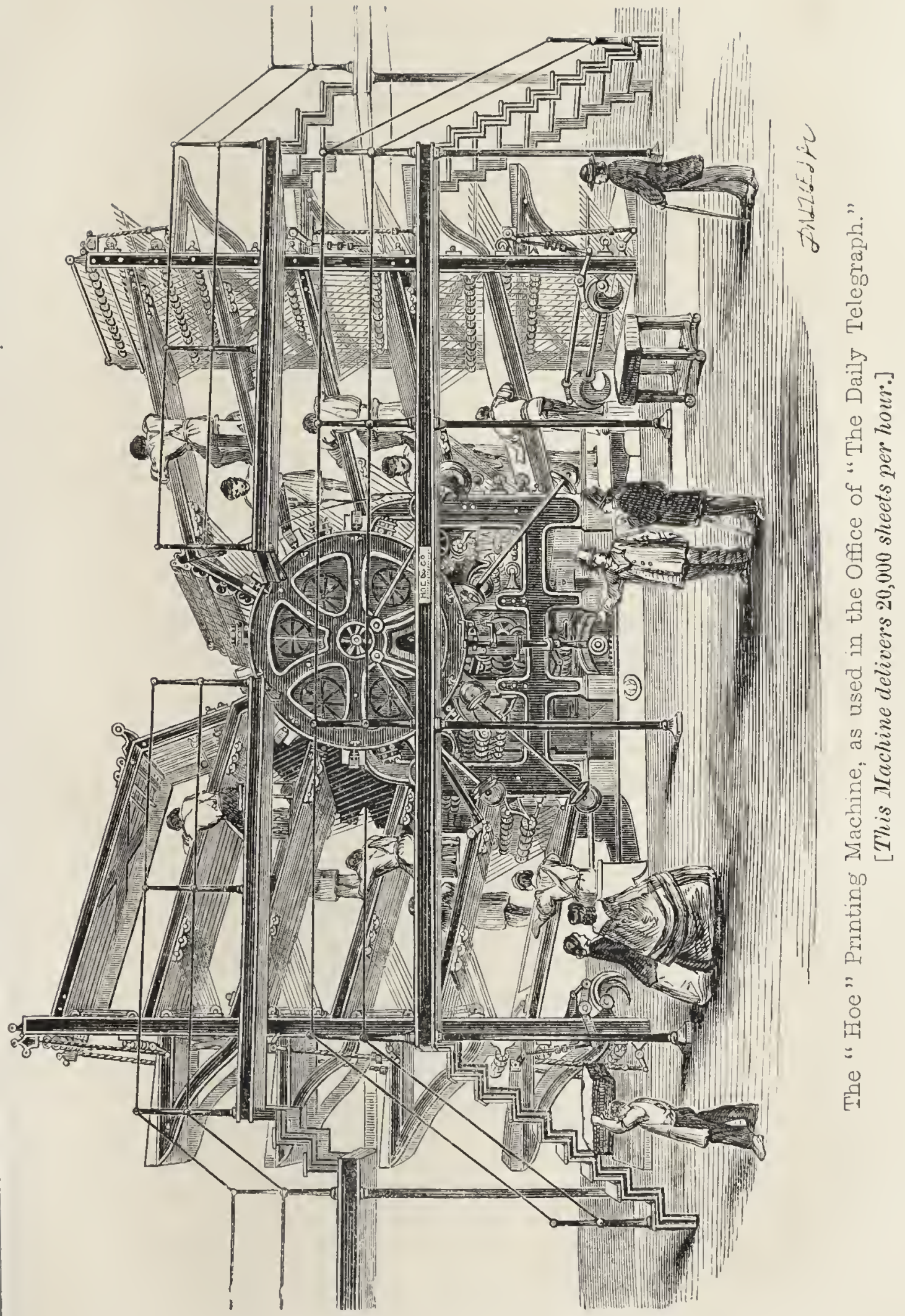



mpression cylinders around it. One person is required at each impression cylinder to supply the sheets of paper, which are taken at the proper moment by fingers or grippers, and after being printed are conveyed out by tapes; and laid in heaps by means of self-acting flyers, thereby dispensing with the hands required in ordinary machines to receive and pile the sheets. The grippers hold the sheet securely, so that the thinnest newspapers may be printed without waste. The ink is contained in a fountain placed beneath the main cylinder, and is conveyed by means of distributing rollers to the distributing surface on the main cylinder. This surface being lower, or less in diameter, than the form of types, passes by the impression cylinder without touching. For each impression cylinder there are two inking rollers, which receive their supply of ink from the distributing surface of the main cylinder, and ink the form as it passes under them, after which they again advance to the distributing surface. Each page of the paper is locked up on a detached segment of the large cylinder, which constitutes its bed and chase. The column-rules run parallel with the shaft of the cylinder, and are consequently straight, while the head, advertising, and dash rules, are in the form of segments of a circle. The column-rules are in the form of a wedge, with the thin part directed towards the axis of tho cylinder, so as to bind the type securely. These wedge-shaped column-rules are held down to the bed 
by tongues, projecting at intervals along their length, and which slide in rebatted grooves cut crosswise in the face of the bed. The spaces in the grooves between the column-rules are accurately fitted with sliding blocks of metal, even with the surface of the bed, the ends of which blocks are cut away underneath to receive a projection on the side of the tongues of the column-rules. The form of type is locked in the bed by means of screws at the foot and sides, by which the type is held as securely as in the ordinary manner upon a flat bed, if not even more so. The speed of these machines is limited only by the ability of the feeders to supply the sheets. From twenty to twenty-five thousand impressions an hour can be worked by the ten-feeder machine.

'Colonel Richard M. Hoe's invention was the first successful attempt to print, on the rotary principle, with ordinary types made up on a cylindrical form. This system combines the greatest speed in printing, durability of machinery, and economy of labour.

' The Daily Telegraph machine, including flyers, is thirty-five feet long, twelve feet wide, and eighteen feet high; it weighs upwards of thirty tons; and was brought to this country in forty-seven cases.'

There is much in the above account which will not be understood, perhaps, by untechnical readers, but one passage every intelligence will appreciate. The machine prints. from twenty to twenty-five thousand copies an hour! We see, now that it is in motion, why it is called a 'ten-feeder' machine. 
Ten separate sheets of blank paper are received by it simultaneously every moment, and simultaneously do they immediately reappear printed on one side. And to think that it is a penny which feeds those ten gaping mouths, and which supplies this voracious monster with its daily banquets of paper! The thing appears incredible, and it does not seem less so when we learn that this one machine cost, with its appliances, about 8000 .

We throw a hasty glance at the twenty-five horsepower steam-engines in an adjoining room, by which this wondrous machine is worked, and then having gazed again at the revolving wheels, and hurrying straps, and oscillating cranks, and falling sheets, until our eyes begin to swim, we prepare to ascend into another part of the building; for the noise made by this giant labourer is none of the lightest, and is apt to carry suggestions of perpetual deafness even to the dullest ears.

We pass upwards to the compositors' rooms, where some eighty or ninety men are busily at work 'setting up' the morrow's news. For while one portion of the paper is actually being printed, the other is not even yet in type. A good room is the compositors' room; lofty, spacious, and well ventilated; and the men who are at work evidently are skilled hands. The 'reader,' who sits alone at his desk, will, no doubt, have plenty of errors to correct in the 'proofs' handed" over to him during the evening; but if every line were a blunder, need we feel 
any surprise when we see the hideous and unintelligible manuscripts which are passing under his hands for fragmentary distribution on all sides?

Without prying into the literary sanctum of the collaborateurs, or of that awful personage the editorin-chief, we enter one of the editorial rooms, and note what is passing. Three or four gentlemen are seated at a large table, and before them is a mass of mantrscripts and of newspapers. They attack the former with eyes, and the latter with pen. The execution done is rapid and satisfactory. In obedience to the summons of an ever-ringing bell, a printer's boy appears, and supplies upon supplies of matter are sent by this messenger to the compositors. And yet every moment fresh supplies arrive. Here comes a messenger from Reuter's office, fresh continental telegrams in his hand. Anon there appears a porter from the railway with a country parcel. He is succeeded by the office messenger, with reports from the House. Then a small lad brings some 'flimsy,' containing an account of a conflagration which has just taken place at Limehouse. In a minute a gentleman drops in with a musical criticism he has been writing in another room. The dramatic critic has also been doing duty, and he too makes his appearance with more 'copy.' That is the unceasing meaning of all these arrivals. They bring 'more copy,' 'more copy.' The sub-editor rises from his chair. He has three columns more matter than the paper will hold, omitting police and law reports, and 
the India mail is not yet in. We leave him finally at 2 A.M., still in the midst of his sub-editorial cares, The London Gazette coming up the stairs as we descend.

We have described our visit to The Daily Telegraph, and have conveyed some idea we hope of its importance and position. To those who like more direct details, we may state that so rapid has been its growth, that it has accomplished in the face of a paper duty, and in four years, what The New York Herald has taken twenty years to effect in a country where the manufacture of paper is unfettered by excise regulations, and that if it does not enjoy, as its bills declare, the 'largest circulation of any daily paper in the world,' it commands the largest circulation of any daily paper in Europe. Its diurnal issue is now, in fact, from 60,000 to 70,000 - some thousands more than that of The Times-and is still increasing. Its advertisements, too, augment in number day by day, and are in themselves the most satisfactory proof of its wide-spread influence. A more striking illustration of the wonderful development of the cheap press it would be impossible to adduce. 



\section{POPULAR ILLUSTRATED BOOKS. AT 3s. 6d.}

In small crown octavo, cloth extra.

The Illustrations on toned paper.

The Star of Hope and the Staff of Duty: Tales of Womanly Trials and Victories. With 8 Illustratlons by JuLias PORTCH.

Men who have Risen: a Book for Boys. With 8 Illustrations by C. A. DOTLE.

Women of Worth: a Bool for Girls. With 8 Illustrations by DICKEs.

The Pilgrim in the Holy Land; or, Palestine Past and Present. By Rev. Henre S. Osborne, A.M. With 12 lllustrations of various Objects of Interest in the Holy Land.

The Book of Children's Bymns and Rhymes. Collected by the Daughter of a Clergyman. Illustrated.

*** This is a Comprehensive Collection of what may be called the "Children's Favourites."

Todd's Lcctures to Children. A Complete Edition of the First and Second Series, with a Life of the Author, and 11 Illustrations.

The Sea and her Famous Saitors ; a History of Maritime Adventure and Exploration, with Incidents in the Lives of Distinguished Naval Heroes and Adventurers. By Frank B. GoOdrich. With 8 Illustrations.

A HandyBook of Medical Information and Advice. By a Physician. * * In addition to the simpler every-day knowledge, which is useful to all, and particularly to the Head of a Household, this little Volume is specially intended as a safe and ready Guide to those resident in Country Places, and generally under circumstances where Medical advice is not instantly available.

The Vicar of Wakefield. By Oliver Goldsmith. Presenting a clear handsome text, with 12 choice Iliustrations.

The Habits of Good Society; a Handbook of Etiquette for Ladies and Gentlemen. With Thoughts, Hints, and Anecdotes concerning Social Observances, Nice Points of Taste and Good Manners, and the Art of Making Oneself A greeable. The whole interspersed with Humorous Illustrations of Social Predicaments, Remarks on the History and Changes of Fashion, and the Differences of English and Continental Etiquette. With a Frontispiece.

Noble Traits of Kingly Men; or, Pictures and Anecdotes of European History, with a Bird's-eye View of the Grander Movements of their Leaders. With 8 lllustrations by S. A. Groves.

Friendly Hands and Kindly Words: Stories Illustrative of the Law of Kindness, the Potrer of Perseverance, and the Advantages of Little Helps. With 8 Illustrations.

Small Beginnings; or, the Way to Get on. With 8 Illustrations by C. A. DOTLE.

Roses and Thorns; or, Five Tales of the Start in Life. With 8 . Illustrations.

Pictures and Herves, and Lessons from their Lives. With 8 fine Illustrations.

The Popular Preachers of the Ancient Church: their Lives, their Manner, and their Work. By the Rev. Wyr. WILSON, M.A., With 4 Illustrations by HeNry ANELAY.

Favourite Passages in Modern Christian Biography. With a group of Portraits.

The Pilgrim's Progress. By John Bunyan. A Complete Eation, presenting a clear handsome text, with 12 choice Illustrations by C. A. DerLE.

The Angel of the Iceberg; with other Stories and Parables illustrating Great Moral Truths. Designed chiefly for the Young. By Rev. Johs TODD, D.D. With 12 Illustrations by R. W. SHERWIN. 


\section{Nem Ellustratod aboks}

The Book of Drawing-Room Plays and Evening Amuscments : a Comprehensive Manuål of In-door Recreation, including all kinds of Acting Charades - Mute, Comic, Poetic, Fairy, Dramatic, Historic, and Classic ; Proverbs, Burlesques and Extravaganzas; comprising Novel and Original Ideas, numerous Skeleton Plots and Dialogues; Descriptions of Continental Court Tableaux hitherto unnoticed in this Country ; Intellectual, Active, Catch, and Trick Games ; Forfeits, Board Games, Puzzles, and Parlour Magic. The whole interspersed with Practical Directions concerning Costume, and Hints on Management and Accessories. By Henry Dalton. With Scenic Illustrations by CORBOULD and Du MAURrER, and upwards of 120 Diagrams on Wood. Accompanied by a copious Index. 1 vol. $6 s$.

In small crown $8 \mathrm{ro}$, cloth, full gilt, price $5 s$, with Illustrations by ColemaN and PALMER, printed on toned paper,

A Treasury of New Favourite Tales for Young People. Edited and Written by Mary Howitr.

A Treasury of Tales for Young People-The Old Favourites. Edited and written by MARY HowITr. With Illustrations by ZWECKER, printed on toned paper. Small crown 8vo, price 5s., clotll extra.

** The volume contains an original tale, entitled "Rockbourne Hall," introducing the Young Folks' Readings, and their Conversations about Old Favourite Tales. The course of the narrative embraces many stories by various standard authors, given in a carefully revised and sometimes popularized form.

Every Boy's Stories : a Choice Collection of Standard Tales, Rhymes, and Allegories. 1 thick vol. with 12 page Illustrations on toned paper, $5 s$.

The Brave Old English Confessors. With Illustrations by L. Huard, printed on toned paper. Crown \&vo, 5s. cloth, full gilt.

Men who were Earnest: the Springs of their Action and Influence. A Series of Biographical Studies. With 8 Illustrations by FrEDERICK Borders, printed on toned paper. Crown $8 \mathrm{vo}, 5 s$. cloth, full gilt.

The Art of Doing Our Best, as seen in the Lives and Stories of some Thorough Workers. By HALWIN CALDWELL. With 8 Illustrations by JoIIN ArsoloN, H. K. Browne, and the Brothers Dalziel, on toned paper. Fcp. 8 vo. cloth, full gilt, price 5 s.

Fit to be a Duchess; with other Stories of Courage and Frirciple. By Mrs. Grlefspie Smitr, Author of "Selwyn," "Life and Times of Olympia Morata," "Probation," "T'ales of the Moors," \&c." With Illustrations by CorBovLd and Ausolon, printed on toned paper. Crown 8vo. 5s. cloth, full gilt.

Studies of Christian Character. By Bitha Fox, Author of "Pictures of Heroes," "The Yews," \&c. With Illustrations by JasIEs GoDwIN, printed on toned paper. Crown 8 vo, 6s, cloth, full gilt.

Third Edition, revised, in two volumes, fcp. $8 \mathrm{ro}$, cloth, full gilt, price 5 s, each.

Mornings with Mama: Scripture Dialogues for Young Persons from T'en to Fifteen years of age. By Mrs. Grulespie Sirtr, Author of "Selwyn," "'The Life of Olympia Morata," "Probation," \&c.

* * Various eminent Clergymen encouraged the preparation of these Favourite Dialogues, and the late Dr. Chalmers (to whom, by permission, the volumes were originally dedicated) made Daily Use of them in his own Family.

The Old Testament Series. Vol. I. Earlier Lives and Narratives. Vol. II. Later History and Biography.

** Each Volume is Illustrated by eight full-page highly-finished Engravings on Wood by DALzIEI, (printed on toned paper), chiefly from choice compositions of the Old Masters. 



